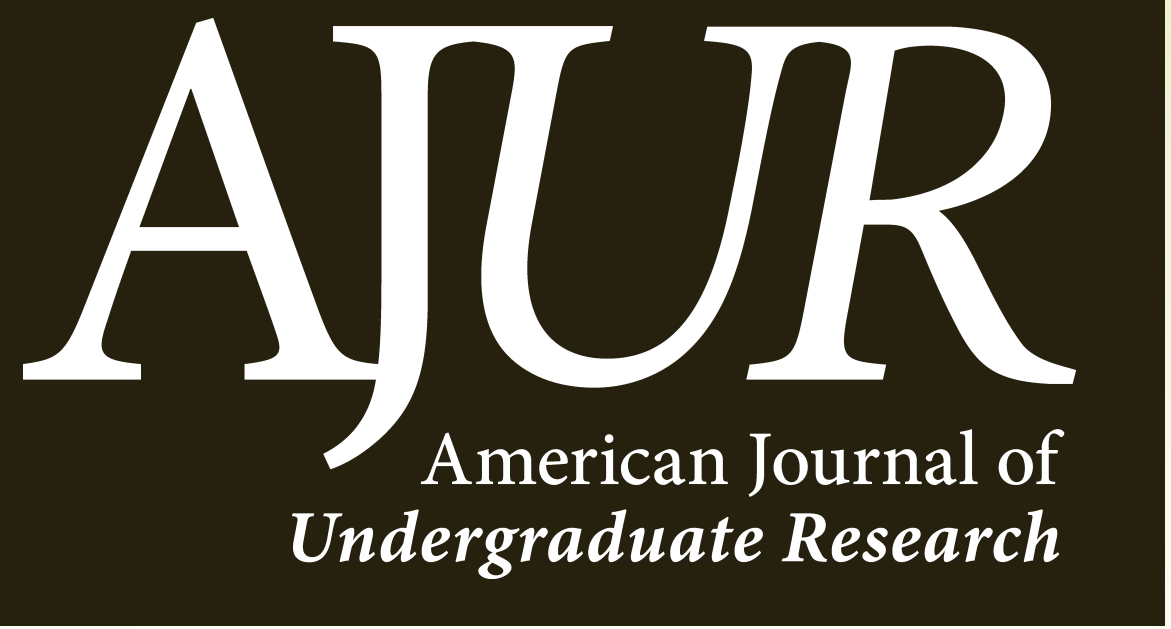

Volume 15 | Issue 3 | December 2018

www.ajuronline.org 


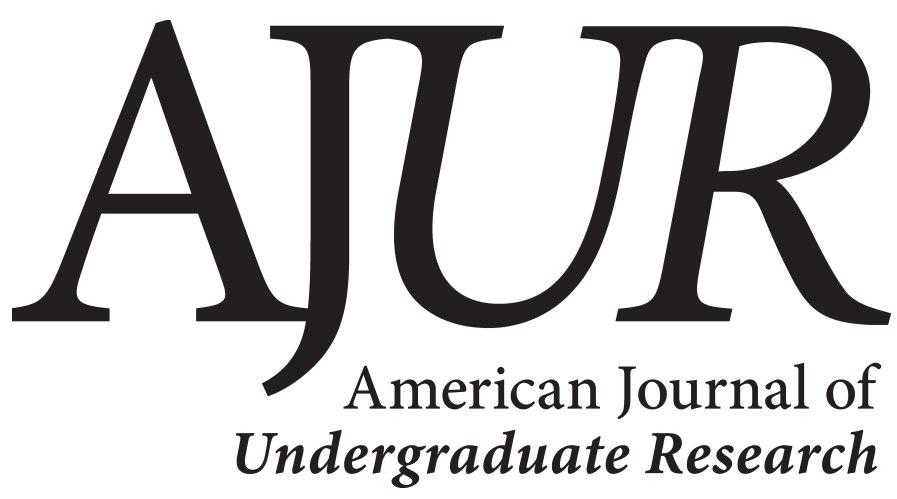

Volume 15 | Issue 3 | December 2018

www.ajuronline.org

AJUR History and Editorial Board

Special Thanks to AJUR's Sponsors

Faunal Remains as an Indicator of Change in Social Stratification at Pecica Şanţul Mare

Brett Meyer

Enhancing Number System Knowledge to Promote Number Sense and Adaptive Expertise: A Case Study of a Second-Grade Mathematics Student

Cami C. Player \& Jessica F. Shumway

Measuring the Mechanical Properties of Laminated Wood Structures Using a Homemade Bending Tester J. Weber \& A. J. Stollenwerk

College Students' Well-Being: Use of Counseling Services Morgan Huenergarde

Underneath it All: Soil Differences May Explain Contrasting Outcomes of Adjacent Prairie Restorations in Madison, Wisconsin Krista Marshall, Nick J. Balster, \& Alex W. Bajcz. from Waste Fluorescent Lamps Phosphor Using Acid Leaching Parul Johar, Vishal Jangir, Yogita Choudhary, \& Sudhanshu Mallick 
American Journal of Undergraduate Research (AJUR) is a national, peer-reviewed, open-source, quarterly, multidisciplinary student research journal. It is indexed internationally by EBSCO and listed via the Library of Congress under ISSNs of 1536-4585 (for print) and 2375-8732 (for web). The journal was established in 2002 and incorporated as a formal non-for profit in 2018.

EDITORIAL TEAM Volume 15 / Issue 3 / December 2018

Dr. Kestutis G. Bendinskas, Executive Editor, editor@ajuronline.org

Dr. Anthony Contento, Copy Editor, Treasurer

Peter Newell, Editor, Secretary

Daniel Laird, Web Master

EDITORIAL BOARD by subject area

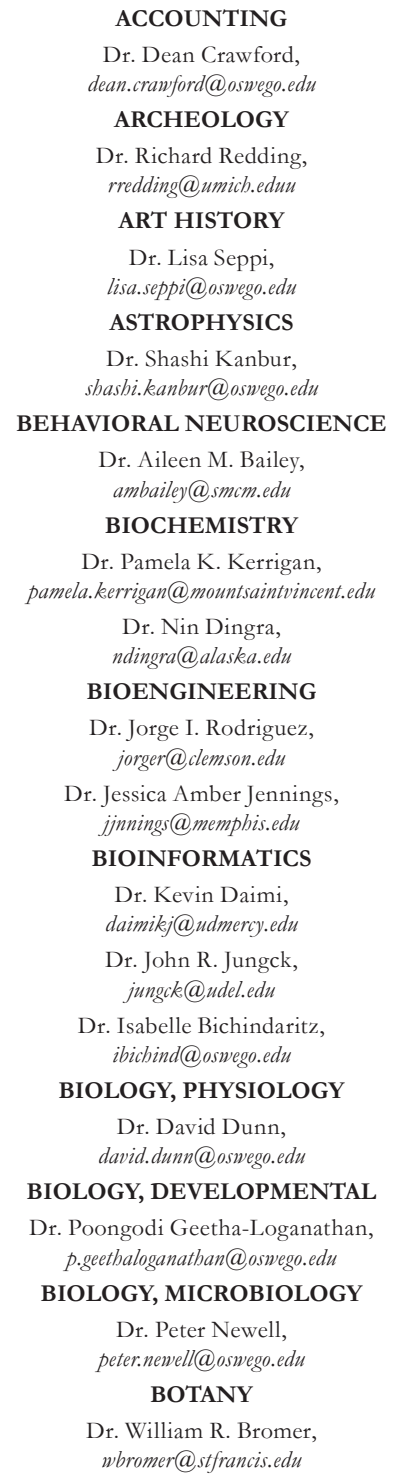

MEDICAL SCIENCES

Dr. Jessica Amber Jennings jjnnings@memphis.edu METEOROLOGY

Dr. Steven Skubis, steven.skubis@oswego.edu MUSIC

Dr. Juliet Forshaw, juliet.forshaw@oswego.edu

NANOSCIENCE AND CHEMISTRY

Dr. Gary Baker, bakergar@missouri.edu

COMMUNICATION DISORDERS AND SCIENCES Dr. Kim Tillery, Kim.Tillery@fredonia.edu COMPUTER SCIENCES

Dr. Dele Oluwade, deleoluwade@yahoo.com

Dr. Kevin Daimi, daimikj@udmercy.edu

Dr. Levent Ertaul, levent.ertaul@csueastbay.edu Dr. Mais W Nijim,

Mais.Nijim@tamuk.edu

COMPUTATIONAL CHEMISTRY

Dr. Alexander Soudackov alexander.soudackov@yale.edu ECOLOGY

Dr. William R. Bromer, wbromer@stfrancis.edu ECONOMICS

Dr. Elizabeth Schmitt, elizabeth.schmitt@oswego.edu EDUCATION Dr. Marcia Burrell, marcia.burrell@oswego.edu EDUCATION, PHYSICS Dr. Andrew D. Gavrin, agavrin@iupui.edu ENGINEERING, ELECTRICAL Dr. Michael Omidiora, michael.omidiora@nyu.edu
NEUROSCIENCE

Dr. Pamela E. Scott-Johnson, pscottj@calstatela.edu PHYSICS

Dr. Mohammad Islam, mohammad.islam@oswego.edu POLITICAL SCIENCE

Dr. Katia Levintova, PSYCHOLOGY

Dr. Joseph DW Stephens, jdstephe@ncat.edu

Dr. Melanie Dyan Hetzel-Riggin, mdh33@psu.edu

Dr. Pamela E. Scott-Johnson, pscottj@calstatela.edu SOCIAL SCIENCES

Dr. Rena Zito, rzito@elon.edu STATISTICS Dr. Mark Ecker, mark.ecker@uni.edu Dr. Mark Baker, mark.baker@oswego.edu

TECHNOLOGY, ENGINEERING Dr. Recayi Pecen, regpecen@na.edu levintoe@uwgb.edu 


\section{SPECIAL THA N K S}

AJUR is made possible through the volunteer efforts of our editorial team and assistance of our sponsors.

Support for this issue has been provided by the Office of the Provost at the State University of New York at Oswego. Thank you!

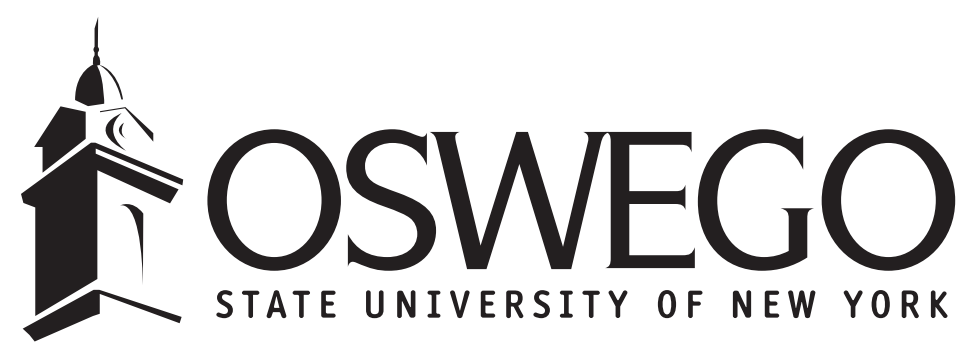

Please support undergraduate research

Request sponsorship information fromeditor@ajuronline.org 


\title{
Faunal Remains as an Indicator of Change in Social Stratification at Pecica Şanțul Mare
}

\author{
Brett Meyer \\ Department of Archaeology and Anthropology, University of Wisconsin-La Crosse, La Crosse, WI \\ Student: brettmeyer04@gmail.com \\ Mentor:anicodemus@uwlax.edu
}

\begin{abstract}
The Bronze Age tell settlement of Pecica "Şanțul Mare" in Romania is regarded as a regional center of the Mureș culture due to the flourishing of higher-status activity experienced during the Florescent Period (1820-1680 B.C.). Recent excavations at the site began to examine whether this higher-status activity was present during the Initial Period (1950-1900 B.C.), the earliest period, or if it grew out of the transition between these periods. This analysis compared faunal remains from the Initial Period and the Florescent Period to examine changing inequality over time. Species utilization, cull patterns, and body part representation were used to infer social organization during these periods. The combination of secondary product utilization, low quantity of horse, and presence of low quality meat during the Initial Period suggests that social inequality intensified over time and reached its pinnacle during the Florescent Period. These results can also be used to examine the development of social stratification in the Bronze Age as a whole.
\end{abstract}

\section{KEYWORDS}

Pecica; Zooarchaeology; Social organization; Power and Wealth; Bronze Age; Elite Activity; Horse Breeding; Tell Settlement

\section{INTRODUCTION}

Social and economic inequalities, political hierarchies, and other forms of social stratification are almost ubiquitous throughout the world today. Since very few societies today are egalitarian, the concept of everyone being equal can be difficult for people to grasp. However, for most of human history, societies have been organized in relatively egalitarian forms. The process of transitioning to a more socially stratified society is an important focal point to study as it reveals how power structures develop. By looking at this transition, it is possible to understand how humans acquire and consolidate power as well as the changes that occur in the everyday lives of the people, such as subsistence strategies, trade, and social relations.

The Bronze Age site of Pecica "Şanțul Mare" in present-day Romania (Figures 1 and 2) provides a compelling case study for the development of social stratification and the emergence of power. According to O'Shea and Nicodemus, ${ }^{1}$ Pecica was an economic center sitting along the Mureş River, which enabled its inhabitants to control trade from the Carpathian Mountains to the confluence of the Tisza and Mureş rivers. Its regional prominence manifested itself through the trade of horses and metal production. Though it started off as a small tell settlement, Pecica quickly grew into one of the largest settlements of the Mureş $\left(\operatorname{Maros}^{\mathbf{A}}\right)$ culture through the aggregation of people from other abandoned settlements. ${ }^{1}$ Pecica thus serves as an excellent case study for examining the emerging social hierarchy of the Mureş culture as well as the Bronze Age more generally.

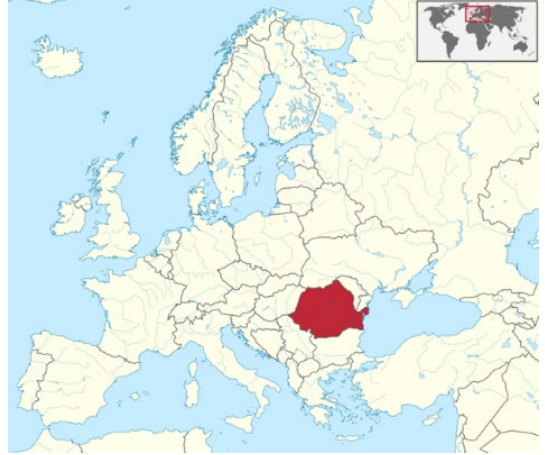

Figure 1. Location of Romania in Eastern Europe.

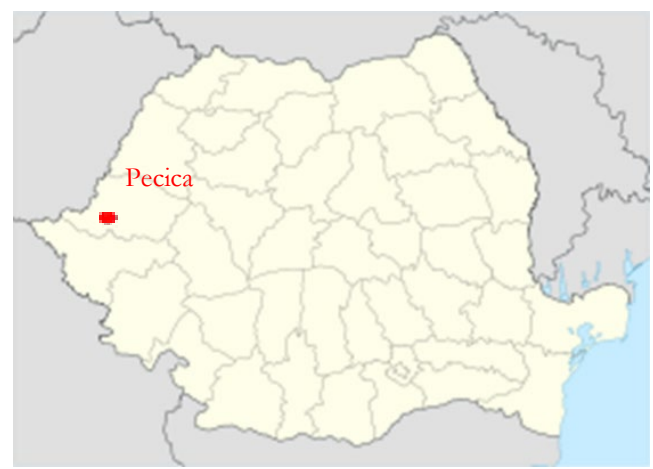

Figure 2. Location of Pecica Şanțul Mare in Romania.

A. Since Pecica is in Romania, the Romanian spelling, Mureş, is used rather than the Hungarian spelling, Maros. 
Recent excavations at the site (2005-2015) have begun to study this development. While these excavations have revealed an abundance of information regarding the later periods of the site, including its peak, the early periods have received little analysis. Understanding the development of social stratification from the early periods to its peak not only benefits the comprehension of the site's transition, but it also allows for better insight into emerging stratification during the Bronze Age on a broader scale. As such, it is imperative to examine the early periods to better understand the characteristics that existed before social stratification developed or when it was in its preliminary stages. This can then be compared to what is already known to add to the larger picture of the development of power during the Bronze Age.

Previous research has focused on metal or other human-made artifacts to examine social stratification during the Bronze Age. However, the excellent preservation of faunal remains at Pecica allows for the analysis of animal usage to provide a lens to study developing stratification. By examining changes in the frequency of certain species, skeletal elements, and age categories, shifts in animal management and preferential consumption of quality meat can be observed. These shifts can be used to examine how those in power are controlling the animal economy and when they solidified their power. At Pecica, changes in the composition of the faunal assemblage between periods permits tracing the shifts in the animal economy over time. Through the comparison of periods, general trends can be established, and the timeline of development can be narrowed.

Social stratification at Pecica was most prominent during the Florescent Period (1820-1680 cal. B.C.) during which horse breeding and metal trade were at their peak. Based on previous research, it is unclear whether social stratification developed during the Formative Period (1900-1820 cal. B.C.), immediately preceding the Florescent Period, or was present in the Initial Period (19501900 cal. B.C.), when the site was first founded. ${ }^{1}$ The faunal data from layers Ea7 and $\mathrm{F}$ was used to examine the degree of social stratification between periods. The data from these two layers will be used to discern what species were exploited, the culling patterns of these species, and what body parts were most common which are used to identify the presence of social distinctions.

The study of the development between the Initial and Florescent periods will not only contribute to the understanding of changes at Pecica, but also other changes in the region and the Bronze Age as well. It can also be used as a proxy for the development of social hierarchies among the Mureş culture in Eastern Europe. Finally, it serves as an example of broader trends taking place throughout Europe during the Bronze Age. Through the examination of the faunal assemblage from the early periods at Pecica, the development of social stratification can be applied to various scales from the site specifically to the Bronze Age as a whole.

\section{BACKGROUND}

\subsection{The Bronze Age}

In Eastern Europe, the Bronze Age lasted from 2800-700 cal. B.C. (Table 1) and was characterized by an increase in metal production and trade, particularly Bronze for which it gets its name. ${ }^{2}$ At the climax, the exchange networks reached across most of Europe. ${ }^{3}$ It was through these networks that horse trading also took place and became the one of the distinguishing attributes of Pecica. At the heart of the trade in the Carpathian Mountains was the Danube River with its branches, including the Tisza and Mureş (Figure 3), also playing a significant role in the trade and development of the regions

\begin{tabular}{|lc|}
\hline Early Bronze Age & $2800 / 2500-2000 / 1800$ B.C. \\
Middle Bronze Age & $2000 / 1800-1400 / 1200$ B.C. \\
Late Bronze Age & $1400 / 1200-700$ B.C. \\
\hline \multicolumn{2}{|c|}{ Table 1. Eastern European Bronze Age chronology. }
\end{tabular}

As a result of the propensity for trade, many settlements were built along the rivers. Settlements in this region existed in two forms: tells and "open" sites. A tell site is a settlement that has been built on the debris of previous habitation making the site located on a mound or hill. Tell sites were typically fortified by surrounding ditches or embankments. Open sites, on the other hand, are sites located off-tell and are unfortified. While residences were mostly off-tell, the tell settlements were typically the location of the social and political hierarchy with the surrounding open sites falling under its control.

An example of a tell settlement system can be seen at Százholombatta, a site similar to Pecica, in Hungary. This fortified tell settlement was divided internally into the acropolis and the village with smaller, outlying settlements also under its power. ${ }^{2}$ This is a good example of the division of power within the site and between the site and surrounding villages. Tell settlements, like Százholombatta, were highly populated but did not reach their zenith until the Middle Bronze Age (2000-1200 cal. B.C.). It is during this time that stratification within societies became clearer. ${ }^{2}$ This period also marks the founding of Pecica and the development toward its eventual stratification.

While the tell may have been the seat of power, it is the surrounding settlements that supported the tell and provided the resources necessary to survive. The outlying villages grew wheat, barley, and millet, as well as raised animals for their own use but 


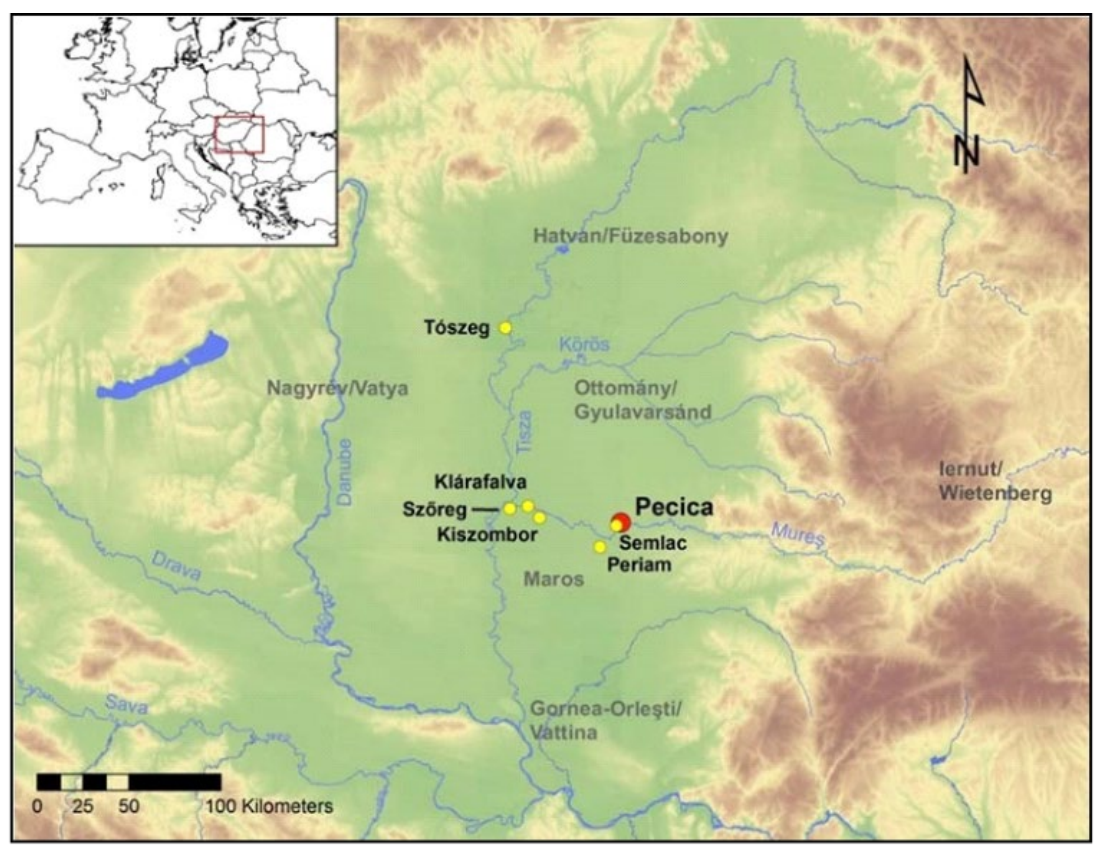

Figure 3. Location of Pecica and other Mureş sites in the Carpathian Basin, except Toszeg. ${ }^{4}$

also to supply the tell. ${ }^{2}$ Sheep and goats (caprines) were the dominant species for consumption followed by cattle and pigs. Horses and dogs were also present but served mostly the purpose of supplying secondary products, such as labor and companionship. ${ }^{2}$ The settlements primarily subsisted on these domesticates but supplemented their diet with wild animals as well. It is through these animals, both wild and domestic, that Pecica will be examined.

\subsection{The Mures Culture}

Pecica is part of the larger cultural group known as the Mureş. However, while Pecica is culturally similar to other Mureş groups, it is politically different. It is the political differences that make Pecica unique. As such, Pecica is referred to as the Middle Mureş, while other groups in the region are referred to as the Lower Mureş. These designations refer to their location on the Mureş River as well as designate their differences.

John O'Shea's book, Villagers of the Maros: A Portrait of an Early Bronze Age Society, ${ }^{5}$ explores this culture group in detail. Inhabiting the marshland regions at the confluence of the Tisza and Mureş Rivers in present-day Hungary, Serbia, and Romania, the (Lower) Mureş culture existed from 2700-1500 cal. B.C. and is known for its highly-structured cemeteries. Based on these cemeteries, status differences could be determined by the presence of certain burial objects. In addition, symbolic treatment like orienting the body north versus south to indicate sex. ${ }^{5}$ However, this only allows for social status to be examined in relation to the cemetery and not specific settlements since several villages are associated with a single cemetery.

Like the other Bronze Age cultures in this region, the Mureş built tell settlements surrounded by satellite communities. According to O'Shea, ${ }^{5}$ these satellite settlements focused on agriculture, which included growing barley and einkorn wheat and exploiting a variety of animals. The economy was based on raising livestock as well as weaving cloth, manufacturing ceramics, and metallurgy. ${ }^{5}$ Pecica exhibits these same characteristics.

As stated earlier, while the cultural characteristics are similar, the political structure of groups on the Lower Mureş and Middle Mureş, including Pecica, differ. The Lower Mureş communities were organized in autonomous villages where each village was self-sufficient and independent from the rest. These groups typically consisted of small hamlets. This is contrasted with Middle Mureş groups, however, which were organized around a two-tiered hierarchy, or simple chiefdom, with the central site being a large fortified tell, such as Pecica., ${ }^{1,5}$ Under this system, Pecica was the center of power and had control over the surrounding villages. As a result, there existed an obligatory flow of materials from the outer villages to Pecica at the center due to the political asymmetry between the two. This typically was exhibited by the smaller villages paying tribute in the form of subsistence goods to the political center. 


\subsection{Pecica}

\subsubsection{History of Excavations}

According to O'Shea et al., ${ }^{6}$ archaeological excavations have been carried out at Pecica as early as the nineteenth century. The earliest known excavations were done by Ladislau Dömötör in 1898 and subsequent excavations were carried out sporadically through the 1960s. However, these excavations only explored the Iron Age deposits at the site. As a result, the Bronze Age deposits were left intact until a project led by John O'Shea, Florin Draşovean, and Peter Hügel aimed to excavate and analyze these layers beginning in $2005 .{ }^{6}$ The preliminary analysis of the Bronze Age deposits concluded that the majority of faunal remains consisted of livestock, which increased in frequency over time compared to wild resources. Pigs (Sus scrofa domesticus) were common in all levels as well as caprines, the latter of which increased in proportion over time. In addition, carp (Cyprinidae) were common. ${ }^{7}$

During the next few excavation seasons, the faunal remains continued the trend of being dominated by domestic livestock. However, the prevalence of fish changed as very few fish were found in these earlier deposits. They were replaced by the influx of an abundance of horse (Equus caballus) remains during the Florescent Period, which would become known as the peak of the site. The importance of horse at the site can be seen through the presence of a row of features in which horse long bones were vertically placed in association with braziers. ${ }^{8}$ This placement probably represents ritual activity, demonstrating the significance of horse during this period.

Following the 2009 season, Nicodemus 9 reported on the preliminary results of all the fauna analyzed up to that point. Overall, the fauna at Pecica has a heavy reliance on animal husbandry. Caprines were most abundant followed by pigs and cattle which were used equally. Caprines were raised for their meat as evidenced by the killing of prime-aged subadults. Pigs, on the other hand, were killed in their first year to control the population size since not many animals are required for breeding. Cattle were used primarily as a meat source, though they were also exploited for dairy as evidenced by sex data. ${ }^{9}$

\subsubsection{Chronology}

Pecica's history is divided into four periods (Table 2). The first period is the Initial Period and lasted from 1950-1900 cal. B.C. This period was characterized by an economy reliant on metal working and other craft production along with long distance trade. ${ }^{1}$

\begin{tabular}{|c|c|c|c|c|c|c|c|}
\hline Era & $\begin{array}{l}\text { Culture } \\
\text { Group }\end{array}$ & $\begin{array}{c}\text { Site } \\
\text { Period }\end{array}$ & $\begin{array}{c}\text { Site } \\
\text { Phase }\end{array}$ & Date (cal. BC) & $\begin{array}{c}\text { Site } \\
\text { Layers }\end{array}$ & Structures & Major Developments \\
\hline Medieval & Árpád & & & AD 1000-1100* & & Str. 9 & \\
\hline Iron Age & Dacian & & & $300-100$ & $\begin{array}{l}\text { (intrusive } \\
\text { pits)** }\end{array}$ & & \\
\hline \multirow{7}{*}{ 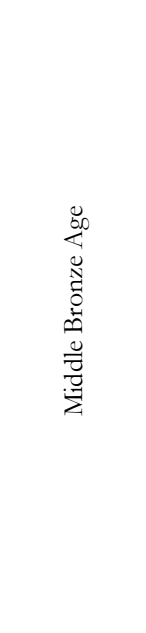 } & \multirow{8}{*}{ 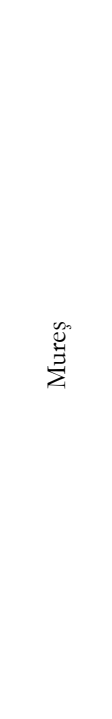 } & \multirow{2}{*}{ 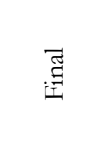 } & 1 & $1615-1545$ & B1-3 & Str. 0 & Final MBA occupation \\
\hline & & & 2 & $1680-1615$ & $\mathrm{C} 1-3$ & Str. 0,1 & $\begin{array}{l}\text { Decline in occupation intensity, settlement } \\
\text { contraction }\end{array}$ \\
\hline & & \multirow{2}{*}{ 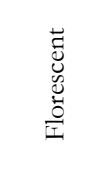 } & 3 & $1765-1680$ & $\begin{array}{l}\text { C4-5/ } \\
\text { D0-2 }\end{array}$ & Str. $2,4,10$ & $\begin{array}{l}\text { Peak metallurgical production, platform construction, } \\
\text { settlement expansion }\end{array}$ \\
\hline & & & 4 & $1820-1765$ & D3, E1 & Str. 3, 4 & Peak horse breeding, feasting deposits \\
\hline & & \multirow{2}{*}{ 总 } & $5 \mathrm{a}$ & $1875-1820$ & $\mathrm{E} 2-3$ & Str. $5-8$ & Final combed ware, initial baroque ceramics \\
\hline & & & $5 b$ & $1900-1875$ & E4-6 & Str. 11,14 & $\begin{array}{l}\text { Construction of 'great ditch,' establishment of central } \\
\text { site plan, construction of central plaza }\end{array}$ \\
\hline & & \multirow{2}{*}{ : } & 6 & $1920-1900$ & E7-F & Str. 15 & First rusticated wares \\
\hline $\begin{array}{l}\text { Early } \\
\text { Bronze Age }\end{array}$ & & & 7 & $1950-1920$ & G-I & Str. 12,18 & Site leveled, erection of ritual structures \\
\hline $\begin{array}{c}\text { Middle } \\
\text { Copper Age }\end{array}$ & $\begin{array}{l}\text { Hunyadi } \\
\text { halom }\end{array}$ & & & $3935-3800$ & $\mathrm{~J}-\mathrm{M}$ & Str. 13,16 & \\
\hline
\end{tabular}

* date from off-tell Medieval Structure 9 (in test unit 3)

**Medieval and Dacian layers and features excavated in block area by Crişan (1978).

Only several deep Dacian pits cutting into Bronze Age deposits left in situ and dated

Table 2. Chronology of Pecica including Copper Age and Iron Age settlements. ${ }^{11}$ 
The subsistence economy during these early periods was focused on raising livestock with an emphasis on secondary products. Activities like hunting, fishing, fowling, and mollusk collecting took secondary roles. ${ }^{10}$

What makes this period unique, aside from the founding of the settlement, was the discovery of pierced pig mandibles in the floor of a house in association with broken and unfinished axes. These were found in a house with a series of objects argued to be legs to an altar, some of which were zoomorphic. ${ }^{1}$ While this suggests ritualistic behavior and possibly the presence of higher-status individuals, not much is known about the social organization during this period. As such, research to this point has been unable to determine the magnitude of the presence of higher-status individuals during this period.

The next period is the Formative Period, which continued until $1820 \mathrm{cal}$. B.C. Metallurgy and craft production continued to abound, however, the subsistence economy changed. It appears that neighboring tells may be subsidiaries of Pecica by providing labor and subsistence goods to those on the tell. Regardless, there is still evidence of the management of livestock on the tell. The Formative Period also experienced an intensification of horse production, which carries over into the following period. ${ }^{1}$

Following the Formative Period, the Florescent Period, which lasted until 1680 cal. B.C., was the pinnacle of Pecica's regional influence. ${ }^{10}$ This period experienced an increase in occupation intensity that was concurrent with a peak in horse production and metallurgy. Horse breeding became the main focus of the higher-status individuals during this period and it appears they engaged in conspicuous consumption of prime reproductive-age mares. In addition, horse trading flourished with age and sex data indicating local stock breeding. This is also the period in which the vertical bone pits were found, representing remains of feasts focused on valuable breeding mares, demonstrating an even further emphasis on horse as a ritualized animal. Horses became symbols of status and prestige and create the basis of this period.

With the pronounced presence of higher-status activity on the tell came changes in the subsistence economy. There was a shift from an emphasis on secondary products to the increase of high-quality meat on the tell, presumably for consumption by higherstatus individuals. In addition, the presence of off-tell settlements became pronounced, though they did not have access to this high-quality meat. ${ }^{1}$ This disparity in meat quality, as well as significant socioeconomic differentiation, exhibits the separation of the two settlement areas with the tell at the center and the off-tell settlement serving a subsidiary role. The Florescent Period is the first instance when intense higher-status activity is definitively seen so far, though more research is required to examine when this stratification emerged since this period is the peak of this activity.

The Final Period at the site saw a quick collapse and abandonment of the tell by 1545 cal. B.C. The intense metalworking, horse production, and manufacturing of high-value crafts all broke down and were replaced once again by a generalized subsistence economy. This site would not be occupied again until the Iron Age when the Dacians built a settlement here. Pecica was not the only settlement to meet its end in this region. Around this time, all remaining Mureş settlements were abandoned as well as most polities across the Carpathian Basin. ${ }^{1}$

It can be seen through this overview of the chronology of the site that the later periods, particularly the Florescent and Final periods, are well understood. However, the analysis of the earlier periods is lacking, and much is yet to be learned. One glaring gap that is the focus of this paper is the insufficient understanding of the social organization preceding the Florescent Period. While it is obvious that this period exhibits the height of control by higher-status individuals and social stratification at the site, the knowledge of the beginning and transition to this consolidation of power is missing.

\subsubsection{Indicators of Status}

The results of this faunal analysis can do more than just demonstrate what the inhabitants of Pecica were eating and using for work. The fauna can also be used to infer social organization, including the presence of inequality. Nicodemus's article "Food, Status, and Power: Animal Production and Consumption Practices during the Carpathian Basin Bronze Age"12 examines the role animals play as markers of status. Food can be manipulated by the higher-status individuals since they prefer meat with higher quality, quantity, and procurement costs because it demonstrates the power and wealth they obtain to be able to afford this more costly meat. Therefore, social differentiation can be exhibited by a shift to high quality products rather than focusing on less costly animals that minimize risk, typical in small scale breeding practices. ${ }^{12}, 13$ It seems that, early on at the site, Pecica's animal economy was focused on a mixed strategy of large quantities of meat and secondary products and was characterized by a low number of horses. However, during the Florescent Period there was an increase in horse remains at the expense of caprines, which was coupled with an increase in the culling of young animals and scheduled off take indicating a control of the economy by higherstatus individuals. ${ }^{14}$

Political centralization and social inequality can also be shown through a tribute system where outlying settlements give goods to the tell settlement, demonstrating that they are under the control of the tell. ${ }^{12}, 15$ Smaller scale societies and those without 
stratification take place in a direct distribution system where goods go directly from the producer to the consumer. ${ }^{14,15}$ For example, in a direct distribution system, the crops and animals that are grown or raised by the producers would be directly exchanged with the people of the village. Larger scale and stratified societies, on the other hand, are usually characterized by indirect distribution systems where the consumer does not receive goods directly from the producer. These systems may include provisioning, which focuses on animals that have achieved maximum body weight, large animals, and favors animals of a particular age and sex to show power over herd reproduction. ${ }^{14,15}$ In this system, the higher-status individuals on the tell receive tribute from the surrounding settlements and then redistribute it to support their agendas and some may be given to the people of their tell, which in turn solidifies their power. However, the redistribution by the higher-status individuals is not an act of generosity. This action serves to create hierarchy, display power, and generate debt relationships. In some cases, the goods may never be redistributed to the people but rather kept by the higher-status individuals to support their own interests. Pecica exhibited only a direct distribution system at the beginning and end of its occupation but displayed some aspects of an indirect distribution system at its peak as well when higher-status individuals were most prevalent.

In addition to these indicators of social stratification, differences in status are also apparent through feasting activities, which are evidenced by collections of high quality parts, large animals not consumed on a daily basis, and animals with a symbolic significance. The vertical horse bone pits mentioned earlier hint at the occurrence of feasting, which is furthered by the evidence that these bones were protruding above the ground surface as a display of conspicuous consumption. Supplementary evidence for feasting at Pecica comes from deposits containing bones of large animals and high-quality meat portions. The use of high-quality meat on-tell contrasts with the low-quality body parts found off-tell. ${ }^{14}$

The presence of horses at Pecica is a unique indicator of social stratification since they were used for more than just transportation. Horses were used in ritual feasting, in the case of the bone pits, as well as prestige items in trade. Pecica was one of the only settlements in the region with horse breeding, giving it a monopoly on horse trading. For this reason, the use of horses in ritual feasting is even more significant since it was a display of power by being able to kill and eat such a valuable animal. ${ }^{14}$

\section{METHODS AND PROCEDURES}

Using basic faunal analysis techniques, faunal remains from two layers and their associated features from the Initial Period were studied to gain a better idea of the role animals played in society at Pecica. Layer Ea7 and Layer F were chosen to answer this question because they had not been analyzed yet, and they would give an insight into what was occurring with the animal economy during the early periods at the site. Much is known about other aspects of the economy during these periods, but there is no faunal data to supplement this.

Layers Ea7 and F date to roughly 1920-1900 cal. B.C. These layers exist outside of the structures and therefore contain generalized refuse debris rather than debris from specific households. The faunal remains from these layers was collected by hand recovery. Flotation was done throughout the site to check for bias against fish in the recovery method. However, most bone found through flotation was unidentifiable mammal with very little fish, most of which was unidentifiable. ${ }^{11}$ As a result, the use hand recovery does not significantly affect the results.

For analysis purposes, these layers are not only examined on their own, but they are also combined with other Initial Period data when appropriate to increase sample size. Initial analysis began with identifying all remains to taxon, element, portion, side, age, and sex when possible. Identification was accomplished through the use of the reference collection at the Mississippi Valley Archaeological Center as well as the Atlas of Animal Bones: For Prehistorians, Archaeologists, and Quaternary Geologists by Schmid. ${ }^{16}$ While a concerted effort was made to identify all remains, many were too fragmented to identify beyond their class size. For those that were identifiable, taxon was narrowed down to species if possible and elements were identified by diagnostic characteristics.

Determining the differences in goat (Capra hircus) and sheep (Ovis aries), which exhibit similar skeletal morphology, was aided through guides by Boessneck, ${ }^{17}$ Zeder and Lapham, ${ }^{18}$ and Zeder and Pilaar. ${ }^{19}$ In many cases, the differences between goat and sheep were unable to be distinguished and were subsequently placed in a general caprine category. Age was recorded based on dental wear stages. Dental wear stages were established according to the stages laid out by Grant. ${ }^{20}$ Age was also examined through epiphyseal fusion, but the sample sizes were too small. There was also a high degree of carnivore destruction, which disproportionately affects bones that fuse later. For these reasons, epiphyseal fusion data was eliminated to prevent skewed results. In addition, basic measurements of the bones were taken in accordance with the standard measurements found in $A$ Guide to the Measurement of Animal Bones from Archaeological Sites by von den Driesch. ${ }^{21}$

With this set of data, the basic quantification methods of NISP (number of identified specimens) and MNI (minimum number of individuals) were calculated. NISP is calculated by counting the number of specimens or the total number of elements. This method generates the maximum number of individuals at the site, however it is limited in that it does not account for associated 
elements and ignores the role of fragmentation. MNI, on the other hand, counts the quantity of the most abundant element from a single side. This produces the minimum number of individuals possible at the site, which means it does not over-estimate taxa and it takes associated elements into account. However, it can over-represent certain taxa that may not actually be abundant and is affected by animals without symmetrical elements. ${ }^{13,22}$ Overall, NISP minimizes the importance of species represented by only a few specimens and exaggerates the importance of those easily recognizable, while MNI over-emphasizes the importance of rare animals, specifically in highly fragmented assemblages. ${ }^{22}$ For this analysis, MNI was calculated separately for each layer because they are stratigraphically distinct and are therefore mutually exclusive.

These two methods were used to not only give a general overview of animal use at the site, but also to begin looking for differences in species exploitation within the Initial Period and across periods at the site. Using these numbers, \%NISP and $\% \mathrm{MNI}$ were calculated to indicate further differences in species exploitation by variations in the percentages of certain species or animal classes. These percentages were calculated by dividing the NISP or MNI of a certain taxa or size class by the total NISP or MNI for each layer.

In addition to basic bone counts, the significance of meat was also studied through meat utility. This examined the quantity of meat for an element since higher-status individuals generally prefer meatier elements with better cuts of meat. ${ }^{23}$ Utility classes were based on Binford ${ }^{24}$ and were divided into very high, high, medium, low, and very low. The different classes and the elements associated with each can be seen in Table 3. Broader classes were examined by combining very high through medium into a higher category and low and very low into a lower category, which was useful when small sample sizes were encountered. These classifications can be used to establish if there was a focus on higher quality body parts during certain periods or in certain areas that could indicate potential status differences.

\begin{tabular}{|c|c|c|c|c|c|}
\hline Utility Class & MGUI & Element & Utility Class & MGUI & Element \\
\hline \multirow[t]{2}{*}{ Very high } & \multirow[t]{2}{*}{$100-80$} & \multirow{2}{*}{$\begin{array}{l}\text { rib } \\
\text { costal cartilage } \\
\text { sternebra } \\
\text { pelvis } \\
\text { sacrum } \\
\text { femur } \\
\text { patella }\end{array}$} & Medium & $30-20$ & $\begin{array}{l}\text { radius } \\
\text { ulna } \\
\text { astragalus } \\
\text { calcaneus } \\
\text { naviculocuboid }\end{array}$ \\
\hline & & & \multirow[t]{2}{*}{ Low } & \multirow[t]{2}{*}{$20-10$} & $\begin{array}{l}\text { cranium } \\
\text { atlas }\end{array}$ \\
\hline \multirow[t]{2}{*}{ High } & \multirow[t]{2}{*}{$55-30$} & \multirow{2}{*}{$\begin{array}{l}\text { mandible (with tongue) } \\
\text { hyoid } \\
\text { cervical vertebra (no } \\
\mathrm{C} 1 / 2 \text { ) } \\
\text { thoracic vertebra } \\
\text { lumbar vertebra } \\
\text { vertebra (gen) } \\
\text { scapula } \\
\text { humerus } \\
\text { tibia } \\
\text { fibula }\end{array}$} & & & $\begin{array}{l}\text { axis } \\
\text { carpals } \\
\text { metacarpals } \\
\text { tarsals } \\
\text { metatarsals } \\
\text { caudal vertebra }\end{array}$ \\
\hline & & & Very low & $<10$ & $\begin{array}{l}1 \text { phalanx } \\
2 \text { phalanx } \\
3 \text { phalanx } \\
\text { sesamoid } \\
\text { horn core } \\
\text { antler }\end{array}$ \\
\hline
\end{tabular}

Table 3. Meat utility classes for artiodactyls. ${ }^{11}$

As explained earlier, dental ages were recorded according to Grant, ${ }^{20}$ which were used to create mortality profiles. These profiles indicate different culling, or killing, patterns. These patterns can inform on the primary use of animals at the site. For example, an economy focused on meat procurement will exhibit a high culling of prime-age animals, while one focused on secondary products will exhibit a high culling of old age animals. ${ }^{22,25}$ A natural mortality profile shows both medium deaths of young as well as old animals with only a few deaths of prime-age individuals. Based on this, deviation from this profile indicates the use of animals by humans, especially in the case of a high culling of young animals, which could be an indicator of preferential access to meat by higher-status individuals. ${ }^{22}$ In addition to being an indicator of animal use, the aging data also assist in narrowing the MNI counts by either eliminating or demonstrating the possibility that two elements belong to the same individual.

A final statistical analysis of the data was done with chi-square tests to examine the variability in the data within the assemblage and across periods at the site. Chi-square tests can test for variability in the NISP and MNI, counts of meat utility categories, and age ranges. These tests allow distinctions to be made as to whether the Initial and Florescent periods are similar or different regarding these variables. It can then be evaluated whether or not high levels of social inequality were already present as early as the Initial Period or if it appeared later during the transition in the Formative Period. 


\section{RESULTS}

The results of this analysis focus on three lines of evidence: species exploitation, culling patterns, and body part representation. The analysis of NISP and MNI can inform on the species that were most important to the economy and the diet of the people at Pecica. The mortality profiles created by the dental ages display the cull patterns that occurred and indicate the preference for animals during the different periods at the site. It is important to note that sex data would be beneficial to better understand these mortality profiles, however there were only three elements that could be reliably sexed. Finally, body part representation is used to show potential differential access to meat, which in turn is used as an indicator of social stratification. In all of these categories, differences observed between the Initial and Florescent periods may be either an indication of a shift in social and political organization resulting in the emergence of stratification or an increase in the social differentiation that was already present at the beginning of the site.

All three categories were analyzed first by comparing layers Ea7 and F to identify any differences and argue for the validity in combining these two layers with each other as one analytical unit. Once determined that the two layers were similar, they were combined with existing data from the Initial Period, and the results were compared to the Florescent Period to examine broader trends over time. The layers were able to be combined with previous Initial Period data since other evidence, such as craft production, was also similar indicating a congruence between the samples.

\subsection{Species Exploitation}

4.1.1NISP

At Pecica, the NISP data (Table 4, Table 5, and Table 6) reveal an economy based on caprines (Capra hircus, Ovis aries, and Caprinae), pigs (Sus scrofa domesticus), and cattle (Bos taurus). Overall, caprines make up the largest proportion of livestock including horses at $71 \%$ for Layer Ea7 and $75.9 \%$ for Layer F for a total of $73.4 \%$ of the total NISP. Pig follows behind with $21.8 \%$ and $15.8 \%$ for Layer Ea7 and F respectively and $18.9 \%$ of the total. While the NISP for cattle consists of approximately 20 specimens per layer, they only equal $6.8 \%$ and $7.5 \%$ of the assemblage for Layers Ea7 and F respectively and 7.5\% of the total. Even though horse (Equus caballus) is also included in the calculations of proportion of livestock, only one horse element was found between the two layers making it $0.2 \%$ of the total assemblage.

\begin{tabular}{|l|c|c|}
\hline \multicolumn{1}{|c|}{ Species } & Ea7 & F \\
\hline Mollusk & 544 & 1364 \\
Sheep/Goat & 180 & 190 \\
Pig & 64 & 44 \\
Cattle & 20 & 23 \\
Sheep & 15 & 17 \\
Goat & 13 & 4 \\
Red Deer & 13 & 2 \\
Domestic Dog & 4 & 4 \\
Roe Deer & 2 & 1 \\
Horse & 1 & 0 \\
Wels Catfish & 0 & 1 \\
\hline
\end{tabular}

Table 4. NISP of all faunal remains for Layer Ea7 and Layer F.

To examine the significance of the variation in abundance of taxa identified to species, chi-square tests were used. It can be determined that the differences in NISP observed between layers Ea7 and F are not significant $(\chi 2=4.544, \mathrm{df}=3$, $\mathrm{p}=.208)$, and they can therefore be combined for comparison as a single unit. These layers also can be combined with the data from previous analysis from the Initial Period, done by Amy Nicodemus in 2005 and 2014-15, and be compared to the Florescent Period.

When combined, the proportions of each livestock taxon are similar between this previous data and the new results. The united data show that caprines comprise $64.9 \%$, pig $22.4 \%$, cattle $12.4 \%$, and horse only $0.3 \%$ of the total assemblage for the Initial Period (Table 6). When compared to the Florescent Period (Figure 4), where the assemblage is distributed with $33.8 \%$ caprines, $27 \%$ pig, $18.8 \%$ cattle, and $20.5 \%$ horse, there is a significant shift in the utilization of livestock animals, as indicated by the NISP $\left(\chi^{2}=410.1, \mathrm{df}=3, \mathrm{p}<.0001\right)$. In particular, there is a far lower use of caprines and a dramatic increase in the number of horses.

\begin{tabular}{|c|c|c|c|}
\hline Class & Ea7 & F & Total \\
\hline Mollusk & $37.0 \%$ & $58.2 \%$ & $50.1 \%$ \\
Mammal & $62.8 \%$ & $41.4 \%$ & $49.6 \%$ \\
Fish & $0.2 \%$ & $0.3 \%$ & $0.3 \%$ \\
\hline
\end{tabular}


While the focus was on domestic animals, they also exploited wild resources. Though small, a total NISP of 15 red deer (Cervus elaphus) and 3 roe deer (Capreolus capreolus) bones were found in layers Ea7 and F. As a result, wild mammals consisted of $3.0 \%$ of the total mammal remains. This contribution is comparable to the wild mammal used throughout the other periods at the site. There was also a small contribution of fish, which comprise $0.3 \%$ of the total assemblage (Table 5). More significantly, mollusks contributed an enormous portion of the assemblage with $50.1 \%$ of total faunal remains (Table 5). This is almost equal to the $\%$ NISP of mammals, but nonetheless does not represent a large quantity of meat.

\begin{tabular}{|c|c|c|c|c|c|c|c|c|c|c|c|c|}
\hline & \multicolumn{4}{|c|}{ Layer Ea7 } & \multicolumn{4}{|c|}{ Layer F } & \multicolumn{4}{|c|}{ Initial Period } \\
\hline Species & & & & & & & & & & & & \\
\hline Caprine & 208 & $71.0 \%$ & 10 & $52.6 \%$ & 211 & $75.9 \%$ & 8 & $61.5 \%$ & 754 & $64.9 \%$ & 31 & $59.6 \%$ \\
\hline Pig & 64 & $21.8 \%$ & 5 & $26.3 \%$ & 44 & $15.8 \%$ & 3 & $23.1 \%$ & 260 & $22.4 \%$ & 8 & $15.4 \%$ \\
\hline Cattle & 20 & $6.8 \%$ & 3 & $15.8 \%$ & 23 & $7.5 \%$ & 2 & $5.3 \%$ & 144 & $12.4 \%$ & 11 & $21.2 \%$ \\
\hline Horse & 1 & $0.3 \%$ & 1 & $5.3 \%$ & 0 & $0.0 \%$ & 0 & $0.0 \%$ & 3 & $0.3 \%$ & 2 & $3.8 \%$ \\
\hline
\end{tabular}

Table 6. NISP and MNI counts of livestock for both layers and the Initial Period as a whole.

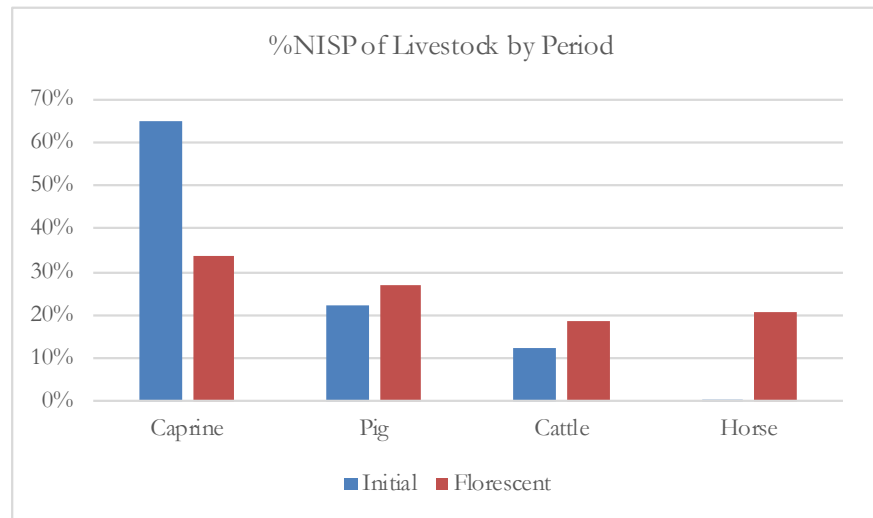

Figure 4. Percent NISP comparison of Initial Period $(\mathrm{n}=1161)$ and Florescent Period $(\mathrm{n}=1970)$.

\subsubsection{MNI}

MNI, as shown in Table 7, was calculated to compare against the results given by NISP data and to estimate a lower limit for the number of individuals present at the site. As was seen with the NISP, caprines were most abundant with pig and cattle following behind. The smallest MNI belongs to horse again with the presence of only a single element between both layers. Based on the MNIs, the distribution of livestock between the layers is similar to those of the NISPs with caprines at $52.6 \%$ for Layer Ea7 and $61.5 \%$ for Layer F, pig at $26.3 \%$ and $23.1 \%$, cattle at $15.8 \%$ and $5.3 \%$, and horse comprising only $5.3 \%$ and $0 \%$. The total distribution of livestock for these two layers includes: $56.3 \%$ caprine, $25 \%$ pig, $15.6 \%$ cattle, and $3.1 \%$ horse. These numbers indicate a similar trend to what was seen with the NISP with an emphasis on caprines and a lack of horse.

\begin{tabular}{|l|c|c|}
\hline \multicolumn{1}{|c|}{ Species } & Ea7 & F \\
\hline Mollusk & 81 & 175 \\
Pig & 5 & 3 \\
Sheep & 4 & 3 \\
Sheep/Goat & 2 & 4 \\
Goat & 4 & 1 \\
Cattle & 3 & 2 \\
Domestic Dog & 1 & 1 \\
Roe Deer & 1 & 1 \\
Red Deer & 1 & 1 \\
Horse & 1 & 0 \\
\hline
\end{tabular}

Table 7. MNI and \%MNI of Layer Ea7 and Layer F.

When these two layers are compared to each other, they also indicate that the differences in MNI between these layers are not significant $\left(\chi^{2}=.826, \mathrm{df}=3, \mathrm{p}=.8431\right)$, and they can thus be combined into a single unit. When added to the preexisting data from Initial Period, the distribution of livestock is $59.6 \%$ caprine, $15.4 \%$ pig, $21.2 \%$ cattle, and 3.8\% horse (Table 6). This compares to the Florescent Period assemblage of 30.1\% caprine, $17.7 \%$ pig, $20 \%$ cattle and 31.5\% (Figures 5). Like the NISP data, there is a significant difference $\left(\chi^{2}=20.12, \mathrm{df}=3, \mathrm{p}=.0002\right)$ between the MNIs of the Initial and Florescent periods. 


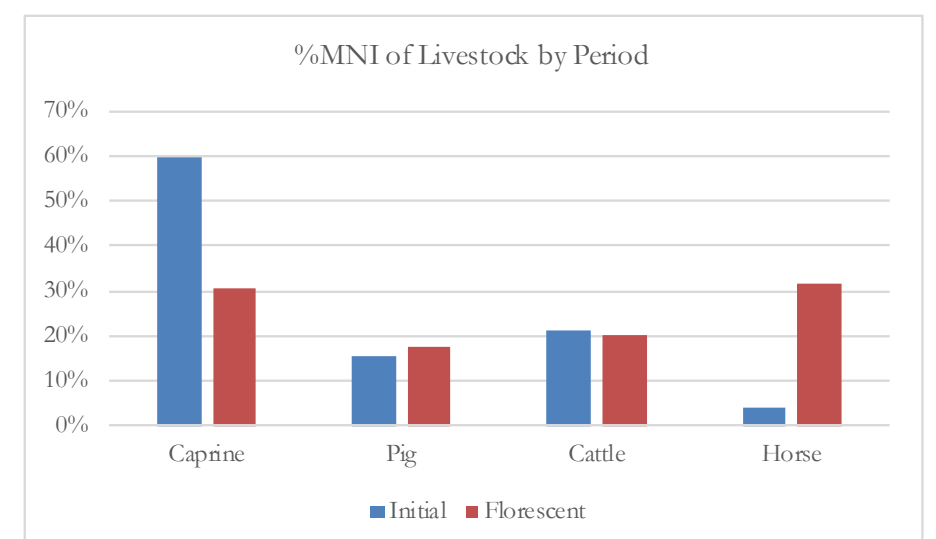

Figure 5. $\%$ MNI comparison of Initial Period $(n=52)$ and Florescent Period $(n=130)$.

As stated earlier, while domestic livestock make up a large portion of the assemblage, the people of Pecica did also utilize wild resources. Though comprising a small percentage of the assemblage, both layers contained a MNI of one red deer and one roe deer. The contribution of these animals was slim with them supplying only $10.5 \%$ of the total mammal remains. However, like the NISP, this contribution is similar to what is observed in the other periods at the site. Fish once again comprise a small portion of the assemblage at 1\% (Table 8). However, mollusks comprise the majority of the assemblage at $83 \%$ compared to only $15.8 \%$ for mammals (Table 8).

\begin{tabular}{|c|c|c|c|}
\hline Class & Ea7 & F & Total \\
\hline Mollusk & $73.2 \%$ & $88.4 \%$ & $83.0 \%$ \\
Mammal & $25.9 \%$ & $10.1 \%$ & $15.8 \%$ \\
Fish & $0.9 \%$ & $1.0 \%$ & $1.0 \%$ \\
\hline
\end{tabular}

Table 8. \%MNI by class for Layer Ea7, Layer F, and total.

\subsection{Mortality and Aging}

\subsubsection{Dental Ages}

Dental ages were first broken down by an age range in months and then converted into the more condensed categories of juvenile (less than 12 months), subadult (12-36 months), and adult (greater than 36 months) to coincide with the categories of young, prime-aged, and old for analyzing the age category preferred during the Initial Period.

\begin{tabular}{|l|ccc|cccc|ccc|}
\hline & \multicolumn{3}{|c|}{ Caprine } & \multicolumn{3}{c|}{ Sus } & \multicolumn{3}{c|}{ Bos } \\
Layer & Juvenile & Subadult & Adult & Juvenile & Subadult & Adult & Juvenile & Subadult & Adult \\
\hline Ea7 & 2 & 9 & 6 & 1.5 & 3.5 & 0 & 0 & 0 & 0 \\
F & 1 & 0 & 1 & 1 & 3 & 1 & 0 & 1 & 1 \\
$\quad$ Period & & & & & & & & & \\
Initial & 7 & 17 & 18 & 4.5 & 17.5 & 1 & 0 & 3 & 5 \\
Florescent & 5.5 & 12.5 & 5 & 20 & 18 & 2 & 6.5 & 12.5 & 7 \\
\hline
\end{tabular}

Table 9. MNIs of each age category for livestock between layers and periods.

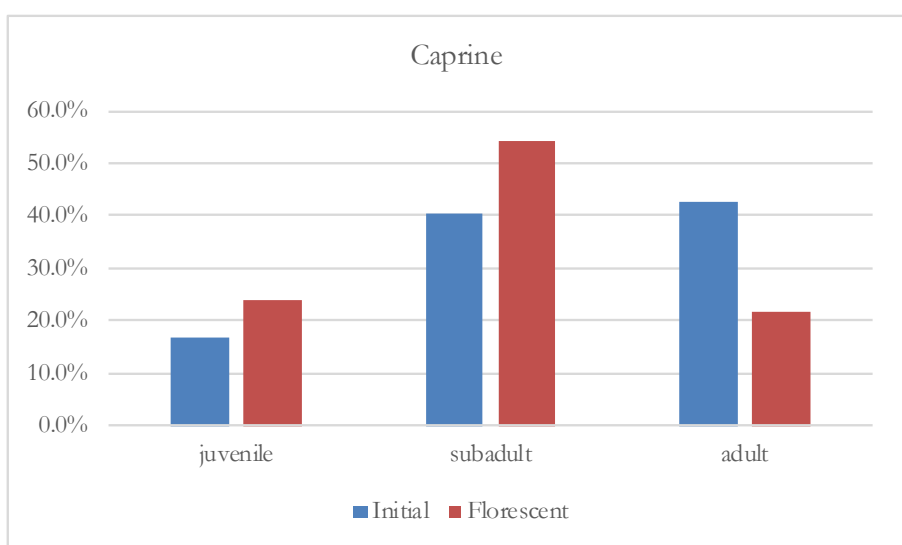

Figure 6. Comparison of age classes for caprines (Initial $n=42$, Florescent $n=23$ ). 


\subsubsection{Caprines}

Among caprines, most individuals fell into the subadult and adult categories in the Initial Period when combined with layers Ea7 and F (Table 9). This indicates a focus on secondary products, like wool and milk, and animals which have reached maximum weight. When the distribution for the Initial Period ${ }^{\mathbf{B}}(16.7 \%$ juvenile, $40.5 \%$ subadult, and $42.9 \%$ adult $)$ is compared the Florescent Period (23.9\% juvenile, 54.3\% subadult, and $21.7 \%$ adult) (Figure 6), the variations in the MNIs of the categories are not significant $(\chi 2=2.909, \mathrm{df}=2, \mathrm{p}=.234)$. However, while not statistically significant, substantial differences are seen in the age classes, which indicates a shift from a focus on secondary products to an emphasis on younger animals and high-quality meat production.

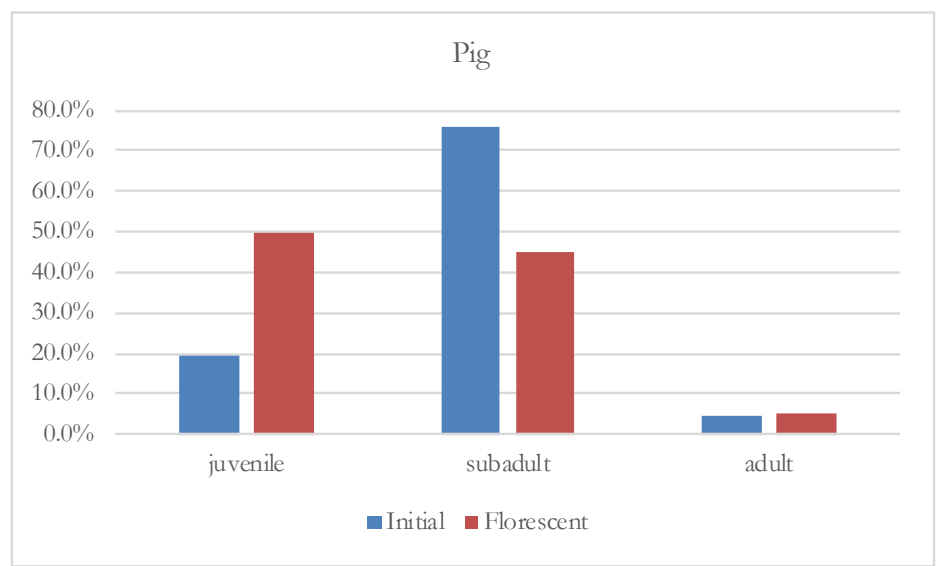

Figure 7. Comparison of age classes for pig (Initial $n=23$, Florescent $n=40)$.

\subsubsection{Pig}

The majority of pigs fell into the subadult category during the Initial Period (Table 9). The Initial Period consisted of 19.6\% juveniles, $76.1 \%$ subadults, and 4.3\% adults, while the Florescent Period broke down into 50\% juveniles, 45\% subadults, and 5\% adults (Figure 7). The differences these proportions reflect in the MNIs are significant $(\chi 2=5.996, \mathrm{df}=2, \mathrm{p}=.0499)$ and indicate a shift to culling younger animals as reflected by the large increase in juveniles between the two periods. Once again, this is a shift from maximizing meat to using costly young animals.

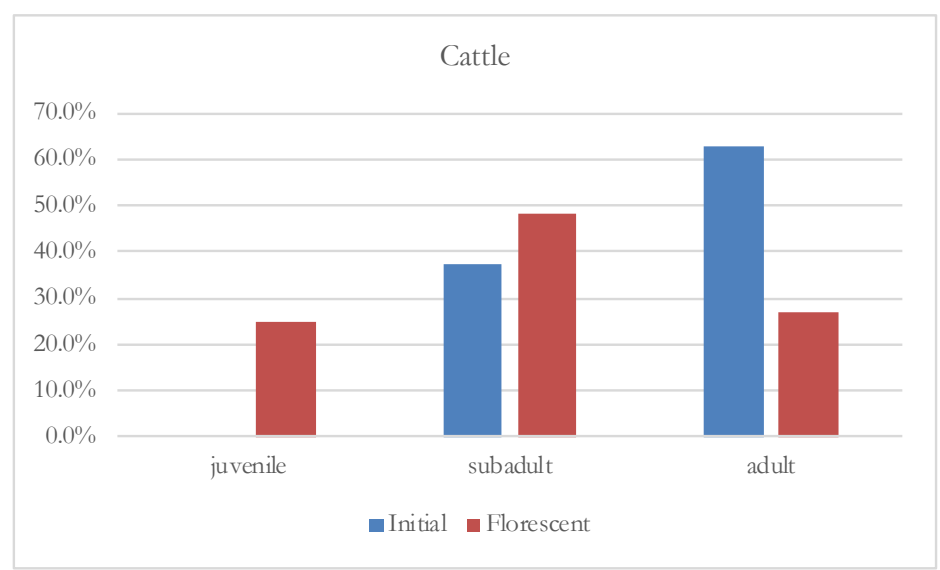

Figure 8. Comparison of age classes for cattle (Initial $n=8$, Florescent $n=26$ ).

\subsubsection{Cattle}

Unlike the other taxa, the Initial Period expresses an absence of juveniles followed by only $37.5 \%$ subadults. As such, adults comprise the largest group at $62.5 \%$ indicating the extended use of an individual for secondary products, like traction and dairy. When viewed in relation to the Florescent Period (Figure 8), which is made up of 25\% juvenile, $48.1 \%$ subadult, and $26.9 \%$ adult, the differences in MNIs are not statistically significant $\left(\chi^{2}=4.344, \mathrm{df}=2, \mathrm{p}=.114\right)$. However, like caprines, the small sample

B. The chi-square tests comparing Layer Ea7 and Layer F showed no statistical differences and were therefore combined with the Initial Period to allow for comparison to the Florescent Period. 
sizes affect this since $\mathrm{n}<5$ for some categories. In reality, the substantial differences in age categories, especially the increase in juveniles, likely indicate a switch from a focus on secondary products to the production of high-quality meat.

\subsubsection{Body Part Representation and Meat Utility}

As stated earlier, body part representation and meat utility can indicate status differences since higher-status individuals prefer higher quality meat, such as elements with a higher amount of better tasting meat, while commoners are resigned to settle for low quality and smaller portions of meat. ${ }^{23}$ Elements, based on MNE, were separated into higher and lower categories to facilitate a more general look at how different quality meat was represented. The higher category consisted of the very high, high, and medium classes based on Binford, ${ }^{24}$ while the lower category was comprised of the low and very low classes.

\begin{tabular}{|lccc|}
\hline \multicolumn{1}{|c}{ Initial } & OC & Pig & Cattle \\
\hline Higher & 284 & 119 & 61 \\
Lower & 122 & 56 & 56 \\
& & & \\
\hline & OC & Pig & Cattle \\
\hline Higher & $70.0 \%$ & $68.0 \%$ & $52.1 \%$ \\
Lower & $30.0 \%$ & $32.0 \%$ & $47.9 \%$ \\
\hline
\end{tabular}

Table 10. Meat utility for the Initial Period.

\subsubsection{Initial Period}

For comparison to the Florescent Period, layers Ea7 and F were combined with previous Initial Period data. This combined data showed the split between higher and lower quality meat favored the higher quality meat (Table 10). Higher quality meat made up $66.8 \%$ of the assemblage with lower quality meat elements at $33.2 \%$. This difference was visible in the meat quality categories of each animal. Caprines displayed a disproportionate amount of high quality meat at 70\% with only 30\% lower quality. Likewise, pigs showed a greater abundance of higher quality elements at $68 \%$ with only $32 \%$ for the lower quality category. Cattle, on the other hand, exhibited a relatively equal distribution of higher and lower quality elements at 52.1\% and $47.9 \%$ respectively. The differences seen between these categories is significant $\left(\chi^{2}=14.782, \mathrm{df}=3, \mathrm{p}=.002\right)$, favoring higher quality meat for caprines and pigs, with virtually no difference for cattle.

\begin{tabular}{|lccc|}
\hline Florescent & OC & Pig & Cattle \\
\hline Higher & 416 & 333 & 160 \\
Lower & 209 & 144 & 174 \\
& & & \\
\hline & OC & Pig & Cattle \\
\hline Higher & $66.6 \%$ & $69.8 \%$ & $47.9 \%$ \\
Lower & $33.4 \%$ & $30.2 \%$ & $52.1 \%$ \\
\hline
\end{tabular}

\subsubsection{Florescent Period}

The Florescent Period also displayed a preference for higher quality meat (Table 11). Overall, $66 \%$ of the elements fall into the higher quality meat category indicating the preference for better quality meat that was also seen in the Initial Period. Both caprines and pig reflect this preference with $66.6 \%$ and $69.8 \%$ of the elements, respectively, being higher quality meat. Cattle once again, showed a nearly equal distribution with $47.9 \%$ higher quality and $52.1 \%$ lower. The differences between the higher and lower categories for each species is significant $(\chi 2=72.364, \mathrm{df}=3, \mathrm{p}<.0001)$, demonstrating the predilection for the better quality meat.

\section{DISCUSSION}

Overall, the data gathered from Layer Ea7 and Layer F followed the same trends that are seen in the previous analysis from other Initial Period layers. This is important in that it ensures the results can be used to compare subsistence economies between the Initial and Florescent periods. Following the same lines of evidence as above, species representation, cull patterns, and body part representation from layers Ea7 and F are discussed in relation to the similarities and differences in comparison to the Florescent Period. For the most part, everything seems to support the hypothesis that the level of social inequality during the Florescent Period was a change from what was present in the Initial Period.

\subsection{Species Representation}

The dominant livestock animal during the Initial Period was caprines, with pigs and cattle taking secondary roles. The consumption of cattle was not a common occurrence. Cattle are large animals carrying a large quantity of meat, more meat than 
can be consumed in a reasonable amount of time. Since there were limited ways to store meat, the animal would need to be eaten relatively quickly once it was butchered. To be able to consume an entire animal, many families would be required to partake in the meal, and cattle were therefore most likely reserved for feasts or other large gatherings where most of the individual would be used. While it could be argued that a market exchange existed to distribute the meat, most of the individuals were old, indicating they were more important for their secondary products than their meat. In addition, raising cattle required a large expenditure of time, food, and labor. To reach maximum body weight, cattle require three to four years of growth. This also points to the use of them for only special events since the time needed to raise a new animal to maximum weight is so lengthy.

Caprines, on the other hand, are small and can be consumed more quickly than cattle. While it would still take several days to consume an entire individual, it is a significantly less amount of meat than cattle. Caprines are also easy to control, require little labor and food, and reach maximum weight in only two to three years. The low cost of raising them combined with quick growth made them perfect for a regular meat supply. So even though cattle and pigs provide more meat to the inhabitants, they most likely did not play as large of a role in the daily life of the people. The main source of day-to-day meat would have come from caprines with cattle and pigs reserved for larger gatherings where a large quantity of meat could be adequately consumed.

The abundance of caprine remains during this period was a substantial difference to the more evenly distributed use of livestock in the Florescent Period. While caprine use decreased in this later period, the preference for pig and cattle increased. This could be attributed to many things including the increase in feasting activities required to consume large animals. ${ }^{12}$ The increase in feasting itself supports heightened higher-status activity, and the increase in large animals suggests more individuals were able to afford the high costs associated with consuming pigs and cattle more often.

However, the change in proportions of livestock is most likely a reflection of the enormous rise in the exploitation of horse (Figure 9). Between Layer Ea7 and Layer F, only a single horse element was recovered. This follows the overall trend of an absence of horse during the Initial Period in which only a total of three horse remains were found making up less than half a percent of the livestock. This is contrasted by the Florescent Period, during which horse outnumbered cattle. This nearly nonexistence of horse during the Initial Period demonstrates that horse breeding and trading had not yet begun and the prestige and wealth that came along with it was not yet present. Trade, at Pecica, initially revolved around metallurgy and the production of high value composite ornaments, which probably resulted in some status distinctions during the Initial Period but not to the extent of those during the apex of horse trading. Once horse trading was established, disparities in social and economic classes likely became more pronounced since Pecica was the only local large-scale horse breeder. These discrepancies were not present earlier when metallurgy was the main trade craft due to the ubiquity of metallurgy in the region.

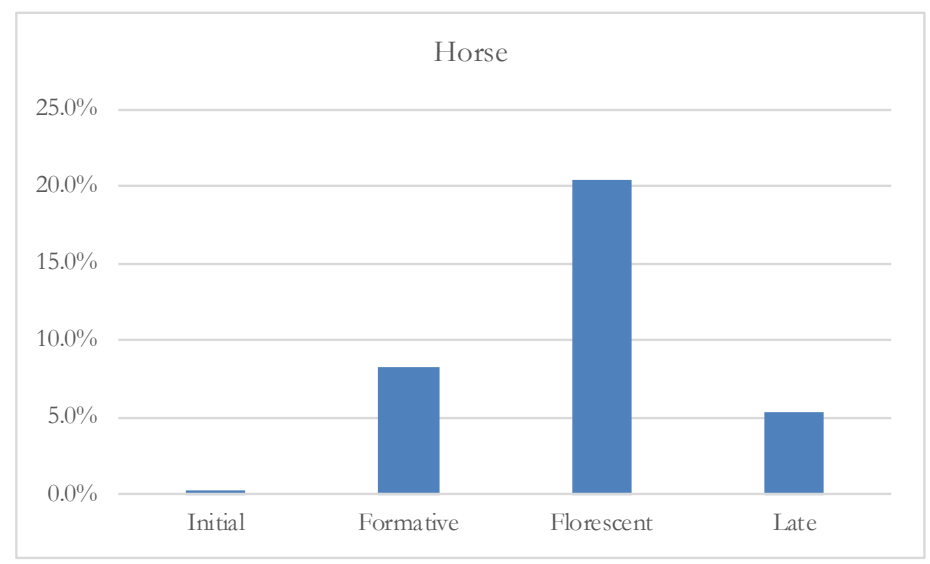

Figure 9. \%NISP of horse across the four periods at the site.

Along with trade, horses were used as symbols of status and prestige. Once horse trading became a higher-status activity, the consumption of horse meat was able to emerge as a display of power and a marker of inclusion in this prestigious trade market. Not only were horse remains more common on the tell during this period because more horses were actually present, but also because they were deliberately being killed for power displays and their bones were being deposited, sometimes ceremoniously. ${ }^{8}$

Due to the large disparity between the two periods, it is evident that the significance of horses emerged somewhere in between. In addition, the virtual absence of horse during the Initial Period points to the emergence of this trade beginning during the Formative Period. Most importantly, this disparity shows that the magnitude of higher-status activity seen during the Florescent Period was not also present in the Initial Period. While there may have been some higher-status activity and the associated social 
hierarchy present as evidenced by the production of high value composite ornaments present in mortuary contexts, it was on a much smaller scale. ${ }^{5}$ It most likely would have manifest itself in the form of small feasts of pig and cattle as found in the study by Zahradka. ${ }^{26}$ Based on species exploitation alone, there appears to be a shift between the Initial and Florescent periods.

\subsection{Mortality and Aging}

The aging data also suggest an intensification of social stratification after the Initial Period. Status differences are exhibited in the increased culling of younger animals. Younger animals are typically viewed as a more prestigious meat source due to the tenderness of their meat and the ability to eliminate an individual from the herd before it reaches reproductive age. Only higherstatus individuals would be capable of butchering these young animals because of the costs involved with losing a reproductive member of the herd as well as losing the secondary products that could be exploited from an individual the longer they live. The increase in the killing of younger animals in general signals the preference for the younger, more costly meat associated with consumption by higher-status individuals.

Caprines display a switch in cull patterns toward younger animals and those who have reached maximum weight. The dental ages show a reliance on caprines for secondary products during the Initial Period with the maintenance of animals well beyond the age of prime meat production. The trend of raising individuals to adulthood changed in the Florescent Period where there was an emphasis on younger animals and prime age animals. Previous research found two distinct culls, one as the animals approached peak body size (16-24 months) and one, much earlier, of animals less than six months old. ${ }^{12}$ Not many individuals survived beyond two years where caprines reach peak weight because it is at this point where diminishing returns are experienced, meaning the continued cost of keeping the animal outweighs the value of the animal.

Pigs also experienced a shift toward younger culling following the Initial Period. Fewer animals reach maximum body weight seen in the decrease in the subadult category from $76.1 \%$ during the Initial Period to $45 \%$ during the Florescent. Unlike caprines, pigs do not provide secondary products other than eating the trash of the settlement. This does not mean that the culling of juvenile pigs had no consequences. The culling of younger animals shows the disregard for body size. Prior analysis has shown most pigs in the Florescent Period were killed before reaching 18 months old and many before six months. ${ }^{12}$ Pigs reach maturity between one and three years of age but are able to continue gaining weight throughout their lives. By slaughtering them before they reached maturity, higher-status individuals sacrificed the maximum meat potential as well as encouraged the mother to have a second farrow, increasing the production of juvenile pigs. It is this sacrifice and preference for juveniles that makes the use of young animals a symbol of wealth and power.

Cattle exhibit a similar change in culling patterns. The Initial Period was completely absent of juveniles with almost two-thirds of the individuals in the adult category. This indicates that secondary products were a priority as well as the use of cattle for meat. If meat maximization was the primary goal, the subadult category would contain the most individuals since it is at this point that the animal is most valuable. However, the majority of individuals fell into the adult category meaning they were kept beyond their peak, presumably to be used as traction and dairy animals. The Florescent Period shows a marked difference from this pattern with nearly a quarter of individuals falling in the juvenile range. Additionally, the percentage of adults declines and subadults increases slightly. This most likely indicated a shift to cattle as a meat source with less value placed on the secondary products. The increase in juveniles is important with cattle since their potential meat contribution is substantial. By culling individuals before they reach maximum weight, an enormous sacrifice was made in the potential food for the settlement.

\subsection{Body Part Representation}

In the presence of higher-status individuals, it is expected that a large portion of the assemblage would be higher quality meat since higher-status individuals prefer this type of meat. Even though both the Initial and Florescent periods show a large proportion of higher quality elements, there was still a considerable amount of lower quality elements present. If the higher-status individuals in the Florescent Period were receiving provisions from outlying settlements, it is expected that the percentage of higher quality elements would be higher due to the most valuable parts of the animal being sent to the tell while the lower quality parts were left in the outlying village. This would not be the case, though, if they were provisioning with whole animals.

It seems that all of the butchering was being done on tell and thus results in the presence of a relatively large amount of lower quality elements. Therefore, the remains may not be just the result of consumption but butchering as well resulting from provisioning of whole animals. As a result, the data show that the Initial Period shows similar trends as the Florescent Period indicating the presence of higher-status individuals. However, during the Florescent Period, people living off-tell only had low quality meat parts from high value animals like cattle and pigs. 


\subsection{Interpretation}

As a result of the differences seen in the data between the periods, it appears that the presence of higher-status individuals and concurrent social stratification during the Initial Period was in the infant stages. Since culling patterns shifted to younger animals after the Initial Period, not during it, and horse remains were lacking compared to later periods, it can be inferred that the presence of higher-status individuals grew after this period. Over time, this system grew and developed into the structure that is represented in the Florescent Period. Due to the Formative Period filling the void between the Initial and Florescent periods, it can be assumed that this period experienced the transition toward the marked social and economic disparity of the Florescent Period. It can be expected that this period would exhibit portions of data representing characteristics from each period. For example, an increase in horse remains and slight increase in the use of juveniles can be expected from this period as well as a shift toward a larger percentage of high quality meat.

\section{CONCLUSIONS}

The social inequality at Pecica may have begun in the Initial Period, but it intensified and expanded over time until it reached its pinnacle during the Florescent Period, when trade and craft production were at their peak. Overall, the data from layers Ea7 and F continue to demonstrate that Pecica experienced a growth of higher-status activity as time progressed and the site grew. Despite the presence of some social inequality during the Initial Period, it does not match the magnitude of what was to come in the Florescent Period. As such, it appears that inequality intensified over time, likely during the Formative Period due to its position between the Initial and Florescent periods.

This research shows how faunal remains are useful indicators of social stratification and organization in addition to the traditional use of metal or other human-made artifacts, as well as clarifies the emergence of Pecica as a regional center. It expands the knowledge of Pecica's history by examining the beginnings of the site, which has not received much attention yet. While there are drawbacks in the data in the form of small sample sizes and carnivore gnawing on the remains, they are informative nonetheless due to the similarity to other data collected from the same period. To improve in the future, larger sample sizes would allow for more detailed analysis and would continue to refine the picture of the social organization at Pecica. Further research into the higher-status activity already present during the Initial Period is also important for the information it would provide on how higher-status activity was displayed. This could then be compared to the displays of power in the Florescent to further define the difference in social stratification between the two periods.

While this research focuses solely on Pecica, it is also useful in examining other sites in the Carpathian Basin during the Bronze Age and the Bronze Age as a whole. It provides an insight into how higher-status individuals are represented in the archaeological record and how their presence changes over time in Mureş cultures. Comparing Pecica to other Mureş sites, it is possible to examine the relationships and connections that existed between the sites as well as understand the role Pecica played in the regional hierarchy.

This research also demonstrates a case study of how power and wealth developed and emerged in the Bronze Age. It looks at the transition towards social hierarchy and the emergence of inequality to better comprehend how large, stratified societies form. Through this study, it is possible to understand how humans acquired power in the form of livestock and trade goods and consolidated that power through displays of wealth such as feasting. Not only does this allow a better understanding of higherstatus individuals, it also gives insight into the changes that took place in the everyday lives of the common people as a result of shifting power.

By examining Pecica, the importance of trade centers and the accumulation of people at sites can be studied for their effect on power dynamics and the development of hierarchical societies. Through the use of faunal remains to study social change, it is possible to better understand how past societies developed and came to leave a lasting impression in history. As a whole, Pecica provides an excellent case study for understanding site, regional, and interregional dynamics as well as examining the development of power and higher-status individuals in Bronze Age society.

\section{ACKNOWLEDGEMENTS}

The author thanks everyone who helped him in the process of writing this thesis. He especially thanks Dr. Amy Nicodemus for giving him this research opportunity by providing the faunal remains as well as offering her advice and expertise along the way. He also thanks Dr. Timothy McAndrews, Dr. Katherine Grillo, Eleanor Waters, and Gemma Zahradka for providing invaluable feedback on his research and helping him develop his ideas. Finally, he thanks the Mississippi Valley Archaeological Center for providing the laboratory space and the reference collection necessary for his research. 


\section{REFERENCES}

1. O'Shea, John M., and Nicodemus, Amy. (Forthcoming) “...the nearest run thing...” The Genesis and Collapse of a Bronze Age Polity in the Maros Valley of Southeastern Europe, in Coming Together: comparative Approaches to Population Aggregation and Early Urbanization (Gyucha, Attilla, Ed.), State University of New York Press, Albany, NY.

2. Earle, T.K., and Kristiansen, K. (2010) Organizing Bronze Age Societies, Cambridge University Press, New York.

3. Kristiansen, Kristian, and Larson, Thomas. (2005) The Rise of Bronze Age Society: Travels, Transmissions, and Transformations, Cambridge University Press, New York.

4. Nicodemus, Amy, and O’Shea, John M. (2015) From Relative to Absolute: The Radiometric Dating of Mureş Culture Ceramics at Pecica-Şanțul Mare. Paper presented at the ArheoVest Symposium Interdisciplinarity in Archaeology and History, Timisora.

5. O'Shea, John M. (1996) Villagers of the Maros: A Portrait of an Early Bronze Age Society, Plenum Press, New York.

6. O'Shea, John M., Barker, Alex W., Sherwood, Sarah, and Szentmiklosi, Alexandru. (2005) New Archaeological Investigations at Pecica Şanțul Mare, Analele Banatulul, S.N. Archeologie-Istorie 13, 81-109.

7. O’Shea, John, Barker, Alex W., Nicodemus, Amy, Sherwood, Sarah, and Szentmiklosi, Alexandru. (2006) Archaeological Investigations at Pecica "Şanţul Mare": The 2006 Campaign, Analele Banatulul, S.N. Archeologie-Istorie 14, 211 -228.

8. O’Shea, John, Barker, Alex, Motta, Laura, and Szentmiklosi, Alexandru. (2011) Archaeological Investigations at Pecica "Şanțul Mare" 2006-2009, Analele Banatulu, S.N. Archeologie-Istorie 19, 67-78.

9. Nicodemus, Amy. (2011) The Bornze Age and Dacian Fauna from New Excavations at Pecica "Şanțul Mare", Analele Banatulu, S.N. Archeologie-Istorie 19, 79-84.

10. Nicodemus, Amy, Motta, Laura, and O’Shea, John M. (2015) Archaeological Investigations at Pecica "Şanțul Mare" 2013-2014, Ziridava Studia Archaeologica 29, 105-118.

11. Nicodemus, Amy. (2014) Bronze Age Economies of the Carpathian Basin: Trade, Craft Production, and Agro-Pastoral Intensification. Unpublished Ph.D. dissertation, Department of Anthropology, University of Michigan, Ann Arbor.

12. Nicodemus, Amy. (Forthcoming a) Food, Status, and Power: Animal Production and Consumption Practices during the Carpathian Basin Bronze Age, in Social Dimensions of Food in the Prehistory of the Eastern Balkins and Neighbouring Areas (Ivanova, M., Stockhammer, P., Athanassov, B., Petrova, V., Takorova, D., Ed.), Oxbow Books, Oxford.

13. Crabtree, Pam J. (1990) Zooarchaeology and Complex Societies: Some Uses of Faunal Analysis for the Study of Trade, Social Status, and Ethnicity, Archaeological Method and Theory 2, 155-205.

14. Nicodemus, Amy. (Forthcoming b) Landscape, Animal Production, and Politicacl Economy: A View from the Maros, in Landscapes of Complexity in Bronze Age Central Europe (Earle, T., Kiss, K., Knlesár, G., and Szerverényi, V., Ed.), Oxbow Books, Oxford.

15. Zeder, Melinda A. (1991) Feeding Cities: Specialized Animal Economy in the Ancient Near East, Smithsonian Institution Press, Washington, D.C.

16. Schmid, Elisabeth. (1972) Atlas of Animal Bones: For Prehistorians, Archaeologists, and Quaternary Geologists, Elsevier Publishing Company, New York.

17. Boessneck, J. (1969) Osteological Differences Between Sheep (Ovis aries Linnê) and Goat (Capra bircus Linné) in Science in Archaeology (Brothwell, Don R., and Higgs, Eric S., Ed.), 331—358, Thames and Hudson, London.

18. Zeder, Melinda A., and Lapham, Heather A. (2010) Accessing the Reliability of Criteria Used to Identify Postcranial Bones in Sheep, Ovis, and Goats, Capra, JAS 37, 2887-2905.

19. Zeder, Milinda A. and Pilaar, Suzanne E. (2010) Accessing the Reliability of Criteria Used to Identify Mandibles and Mandibular Teeth in Sheep, Ovis, and Goats, Capra, JAS 37, 225-242.

20. Grant, Annie. (1982) The Use of Tooth Wear as a Guide to the Age Domestic Ungulates, in Ageing and Sexing Animal Bones from Archaeological Sites (Wilson, Bob, Grigson, Caroline, and Payne, Sebastian, Ed.), 91—108, British Archaeological Reports, Oxford.

21. Von den Driesch, Angela. (1976) A Guide to the Measurement of Animal Bones from Archaeological Sites, Peabody Museum Press, Cambridge, MA.

22. Reitz, Elizabeth J., and Wing, Elizabeth S. (1999) Zooarchaeology, Cambridge University Press, New York.

23. deFrance, Susan D. (2009) Zooarchaeology in Complex Societies: Political Economy, Status, and Ideology, J Archaeol Res $17,105-168$.

24. Binford, Lewis. (1978) Nunamint Ethnoarchaeology, Academic Press, New York.

25. Davis, Simon J.M. (1987) The Archaeology of Animals, Yale University Press, New Haven.

26. Zahradka, Gemma. (2017) Faunal Remains from Structure 15 at the Bronze Age Site of Pecica, Romania. Unpublished B.S. thesis, Department of Archaeology and Anthropology, University of Wisconsin, La Crosse. 


\section{ABOUT THE STUDENT AUTHOR}

Brett Meyer recently graduated from the University of Wisconsin-La Crosse in 2017 with a Bachelor of Science in Archaeological Studies with a minor in Anthropology. He is currently taking two years off to gain experience before returning to complete his $\mathrm{Ph.D}$. in Anthropology. He is originally from Chilton, Wisconsin but currently resides in La Crosse, Wisconsin, where he is a research intern and faunal analyst at the Mississippi Valley Archaeology Center.

\section{PRESS SUMMARY}

The regional center of the Mureş culture, Pecica "Şantul Mare," displayed an abundance of higher-status activity during the Florescent Period (1820-1680 B.C.) Recent research into this Bronze Age tell settlement aim to examine if this activity was present during the Initial Period (1950-1900 B.C.), the earliest period at the site, or if it expanded during the transition between these periods. This research compared faunal remains from the two periods to examine changing inequality over time, as well as cull patterns, species utilization, and body part representation to infer the social organization present during these periods. The results give insight into not only the Mureş culture but can also be used to examine the development of social stratification in the Bronze Age as a whole. 


\title{
Enhancing Number System Knowledge to Promote Number Sense and Adaptive Expertise: A Case Study of a Second-Grade Mathematics Student
}

\author{
Cami C. Player* \& Jessica F. Shumway \\ School of Teacher Education and Leadership, Utah State University, Logan, UT \\ Student: cami.crump9@aggiemail.usu.edu* \\ Mentor:jessica.shumway@usu.edu
}

\begin{abstract}
Instruction for developing students' number sense is a critical area of research in mathematics education due to the role number sense plays in early mathematics learning. Specifically, number system knowledge-systematic relations among numerals and the use of number relations to solve arithmetic problems - has been identified as a key cognitive mechanism in number sense development. Number system knowledge is a component of number sense, and the researchers of this study hypothesize that it plays a critical role in second-grade students' understanding of relationships among numbers and adaptive expertise with mathematics problems. The purpose of this exploratory case study was to investigate the variations of an eight-year-old student's number system knowledge learning as she participated in an instructional treatment over nine weeks. The main research question of this study was: In what ways does a student struggling in mathematics develop number system knowledge during a nine-week period in her second-grade classroom as she engages in a number system knowledge instructional treatment? The case in this study was selected based on her low pretest score combined with her desire for making sense of mathematics. The data sources for this study were a number system knowledge assessment and student interviews. The analysis involved a multiple-cycle coding process that resulted in themes of adaptive expertise and the union of procedural and conceptual knowledge in mathematics instruction. The results suggest that this number system knowledge instructional treatment provided this case-study student to develop more pronounced adaptive expertise in solving mathematics problems. An in-depth analysis of how and why one struggling student develops number system knowledge during a nine-week instructional treatment within the context of her mathematics class provides exploratory evidence to help researchers and teachers develop and implement similar practices in elementary mathematics instruction.
\end{abstract}

\section{KEYWORDS}

Number Sense; Number System Knowledge; Mathematics Education; Whole Numbers and Operations; Elementary Education; Teaching and Learning; Case Study Research

\section{INTRODUCTION}

In mathematics education, number sense is defined in multiple ways because it is a complex construct of interconnected knowledge.,2 Overall, number sense includes components such as understandings of quantities, numbers, and number system knowledge. The importance of number sense is reflected in the Common Core State Standards of Mathematics, in which connected understandings of foundational number concepts, such as number sense are an important theme in the document. 3,4 The focus of this article is on number system knowledge, which is one component of number sense. This article is about one eight-year-old student's development of number system knowledge, which is defined as knowledge of systematic relationships among numbers and the ability to use number relationships to solve arithmetic problems. ${ }^{5}$ This student participated in nine weeks of a number system knowledge instructional treatment and completed pretest, benchmark, and posttest assessments and assessment interviews targeting number system knowledge understandings and skills. The purpose of this exploratory case study was to investigate the variations of the student's number system knowledge learning during the instructional treatments.

\section{THEORETICAL FRAMEWORK}

Number sense view

Number sense requires a theoretical analysis because of the complexity of the construct. ${ }^{6}$ The number sense view provides a theoretical lens for understanding students' number sense development. The number sense view is the perspective that students' development of interconnected number concepts (as opposed to isolated skills) leads to more meaningful mathematical understandings. The number sense view explains that as reasoning with numbers improves (i.e., number system knowledge concepts), computational fluency with arithmetic problems improves. ${ }^{7,8}$ It provides a lens for understanding how number system knowledge influences, and is connected to, computational fluency, number line estimation, and problem solving. 


\section{Adaptive expertise}

Adaptive expertise is developed when children are stimulated to develop a strong framework of number relations and flexibly use these relations for computation. ${ }^{9}$ Adaptive experts are experts who apply their schemas in adaptive and tuned ways. ${ }^{10}$ Adaptive experts tend to use creative and innovative approaches to solving problems, rather than simply the routine expertise of speed, accuracy, and automaticity of solving familiar problems. Key characteristics of adaptive experts include understanding why procedures work, ability to invent new procedures, and success in applying their knowledge to new situations.

Conceptual and procedural knowledge

Adaptive expertise involves a combination of deep conceptual and procedural knowledge along with flexibility in thinking. Conceptual knowledge provides metaphors and representations that can serve as a source of adaptive expertise. Conceptual knowledge can be defined as the comprehension of mathematical concepts, operations, and relations, whereas procedural knowledge is defined as skill in carrying out procedures flexibly, accurately, efficiently, and appropriately. ${ }^{11}$ Conceptual knowledge acts as a foundation that enables procedural knowledge, and it supports retention. Students with conceptual understanding know more than isolated facts and methods. They understand why a mathematical idea is important and the kinds of contexts in which it is useful. An instructional implication is such that meaning must be built for procedural knowledge. Flexibility in mathematics strategies should be a result of the eventual integration of conceptual and procedural knowledge. ${ }^{12}$

Overall, the theories of number sense, adaptive expertise, and conceptual/procedural knowledge frame the methodology for this study and the interpretation of the results. These theories emphasize the complexity and interconnectedness of number knowledge, and thereby, provide a lens for understanding the variations in an eight-year-old student's number system knowledge.

\section{RESEARCH QUESTIONS}

The purpose of this study was to explore an eight-year-old student's variations in number system knowledge learning outcomes as she participated in an instructional treatment over nine weeks. The main research question of this study was: In what ways does a student struggling in mathematics develop number system knowledge during a nine-week period in her second-grade classroom as she engages in a number system knowledge instructional treatment? Specifically, the study looked at her variations on the target assessments and in her explanations of her reasoning in interviews:

What are the variations in her performance on the Number Sets test?

What are the variations in her performance on the number line tasks?

What are the variations in her performance on the computational fluency tasks?

What are the variations in her performance on the story problem tasks?

How is her number system knowledge reflected in her discussions during the instructional treatment?

\section{METHODS}

Design

The design for this study was an exploratory case study to investigate the variations of eight-year-old Sarah's (pseudonym) number system knowledge learning as she participated in an instructional treatment over nine weeks. ${ }^{13}$ This case study was part of a larger pilot project that developed and used a series of 27 teaching episodes aimed at improving second-grade students' number system knowledge. Sarah, along with her classmates, took a pretest, two benchmark tests, and a posttest assessing their number system knowledge. Sarah participated in an interview at each measurement point to further explain her reasoning and strategies for the solutions on these tests.

\section{Participant, setting, and materials}

Based on her number system knowledge pretest score of $29 \%$, Sarah was selected for further in-depth analysis because her score was in the bottom quartile of her class's scores. Sarah is a Caucasian female who does not qualify for free/reduced lunch, English Language Learner services, or special education services. She attended second-grade in a charter school in the western United States. She began the study at 7 years, 7 months of age. Sarah expressed great interest in mathematics and enjoyed participating in mathematical conversations. Sarah worked very methodically on mathematics tasks and was particular about the strategies she chose to use, wanting to successfully accomplish the tasks.

Sarah and her 23 second-grade peers participated in regular mathematics instruction, which included daily number sense warmups (i.e., the number system knowledge instructional treatment) prior to the mathematics lesson. The classroom teacher and a researcher (the second author) taught the 27 teaching episodes at the meeting area of the classroom. These teaching episodes took place three days per week during the first 15 minutes of the mathematics instructional period. Each teaching episode for the instructional treatment followed a fairly standard format of the Quick Images number sense routine, ${ }^{14}$ in which the teacher shows an image of a quantity for only a few seconds, then facilitates a discussion about how many objects the students saw and how they figured it out. For example, Figure 1 shows three of the Quick Images the teacher used during one session of the instructional 
treatment. Students individually considered the total amount, engaged in a pair-share discussion with a partner about how they figured out the total, and finally, the teacher facilitated a whole-class discussion about the various strategies for figuring out the total amount. The teacher purposefully connected students' responses with written numerals and equations to explicitly link the quantity with numerals and equations that represent it.

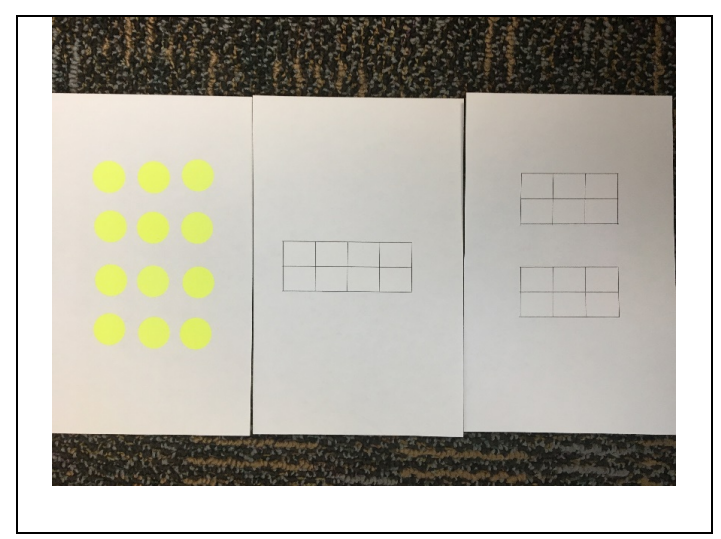

Figure 1. Three images of Quick Images quantities from one session of the instructional treatment.

This activity is theorized to activate students' number system knowledge in that students cannot possibly count each object. Instead, they rely on their sense of magnitude, subitizing abilities (i.e., perceptually recognize an amount without counting), and use relationships among numbers to figure out the total amount (e.g., benchmark numbers, part-whole ideas, and composing/decomposing amounts). Each teaching episode was characterized by a classroom discussion ${ }^{15}$ among students about the images of the quantities, eliciting number system knowledge ideas such as linking numerals to quantities, place value, decomposing and composing numbers, estimation, computation, and relationships among numbers. Each session included a symbolic representation linked with a non-symbolic representation. Since the sessions for the instructional treatment served as a warm-up activity, the classroom teacher continued to use her school-adopted curriculum materials as the main source for planning and teaching their regular mathematics lessons.

\section{Data sources}

Data were collected using number system knowledge assessments, clinical interviews, and classroom observations. Data were triangulated using these multiple sources.

Number System Knowledge Assessments. The number system knowledge pretest and posttest assessments included four sections: (1) The Number Sets Test (students match an anchor numerosity to a stimulus containing the same number of elements as the anchor), (2) The Number Line Tasks (students locate the position of seven different target numbers on a number line), (3) The Computational Fluency Test (students complete four minutes of single-digit addition and subtraction problems), and (4) Word Problem Situations (students solve four different word problems). The two benchmark assessments included different versions of the Computational Fluency and the Word Problems subtests. Percentages for each subtest were calculated and then averaged for an overall score on number system knowledge. Research indicates that these number system knowledge assessments better capture important variations in children's early mathematical development than performance on mathematics achievement tests. ${ }^{16}$

Clinical Interviews. The researchers used a semi-structured interview protocol asking Sarah about her strategies and reasoning for solving problems on the number system knowledge assessments. Sarah participated in four interviews (pretest, Benchmark 1, Benchmark 2, and posttest). The interviews were videotaped and portions of the interviews were transcribed for in-depth coding and analysis.

\section{Procedures}

The study occurred in three phases: 1) Pretreatment Phase, 2) Instructional Treatment Phase, and 3) Posttreatment Phase. During the Pretreatment Phase, researchers collected informed consent from the students' parents/guardians for participation in the study (IRB General \#7954). Once Sarah returned her signed informed consent, she completed the number system knowledge pretest and participated in a clinical interview about her mathematical reasoning and strategies. In the Instructional Treatment Phase, Sarah participated in the instructional treatment three times a week over nine weeks for a total of 27 sessions. Sarah was present at all 27 sessions. At weeks three and six of the instructional treatment sessions, Sarah completed the number system knowledge benchmark tests and again participated in clinical interviews for each benchmark test. Finally, during the Posttreatment Phase, Sarah completed the posttest and a final clinical interview. 


\section{Data analysis}

Quantitative data analysis involved visual analysis of measures of continual changes over time (e.g., graphs of means at each measurement point). Through this analysis, patterns and variations in the Sarah's number system knowledge were identified both holistically through the assessment score and discretely by subtest through the subtest scores. Analysis of the clinical interview data included open and axial coding for Sarah's written and verbal explanations of strategies for solving the mathematics problems. Beginning with open coding, the researchers analyzed the clinical interview video data and developed overarching concepts and categories, meaning general variations in Sarah's responses were coded. ${ }^{17}$ Next, the researchers used existing frameworks from the mathematics education literature to code Sarah's strategies with more specificity. ${ }^{18,19}$

\section{RESULTS}

The research questions for this study guided an investigation into Sarah's development of number system knowledge over a nineweek period of time. To answer the research questions, the results of her overall scores are presented and then the results are organized around Sarah's performance on the four subtests, along with her responses to interviews that addressed her use of strategies on each of the subtests. Due to the qualitative nature of the coding analysis, the major themes around her development of number sense and adaptive expertise are presented along within the results.

Overall test score variations

Sarah scored $29 \%$ on the number system knowledge pretest assessment and 38\% on the posttest assessment. Compared to her peers in the study, the mean pretest score for 23 students was $64 \%$, and the mean posttest score for 23 students was $66 \%$. The mean gain for students in Sarah's class was 2 percentage points. Sarah had a mean gain of 9 percentage points, which was the third highest gain in her class.

\section{Subtest variations}

Sarah's subtest scores varied in that she made pretest to posttest growth on all subtests except the target test for this study, the Number Sets Test in which her score decreased by over 10 percentage points. In addition, variations in her benchmark assessments across four measurement points for word problems and computational fluency alerted researchers to specific variations in her learning during the study, which were analyzed in-depth qualitatively. These results, disaggregated by subtest, provided more nuanced findings about Sarah's learning.

\section{Computational fluency subtest}

Sarah's computational fluency test scores increased from her pretest where she scored $18 \%$ to her posttest where she scored $23 \%$ (see Figure 2).

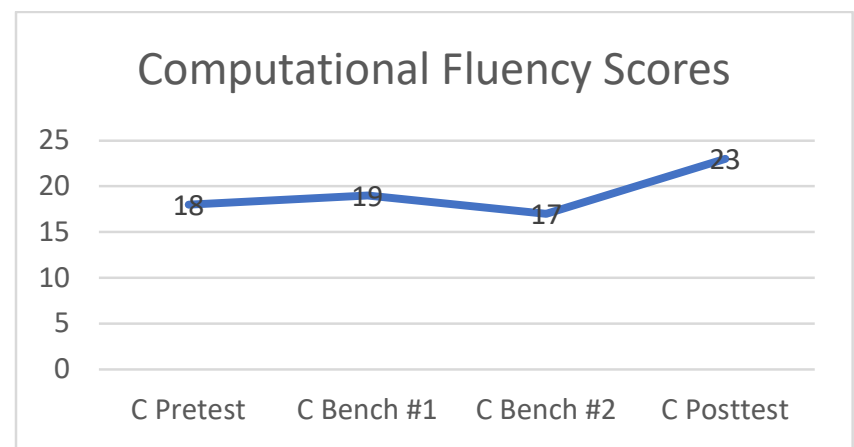

Figure 2. Line graph of Sarah's Computational Fluency subtest scores across measurement points.

Across measurement points, Sarah tended to use counting strategies most frequently, which is a lower level strategy. Sarah's interviews showed one to two more instances of reasoning strategies at each measurement point after the pretest and more instances of retrieval strategies on the posttest, which are more sophisticated strategies. Figure 3 highlights Sarah's strategy use over time. 


\begin{tabular}{|l|l|l|l|}
\hline Pretest: & Benchmark \#1: & Benchmark \#2: & Posttest: \\
Counting: $55 \%$ & Counting: 36\% & Counting: $45 \%$ & Counting: $31 \%$ \\
Reasoning: $11 \%$ & Reasoning: $18 \%$ & Reasoning: $23 \%$ \\
Retrieval: $33 \%$ & Retrieval: $27 \%$ & Retrieval: $36 \%$ & Retrieval: $46 \%$
\end{tabular}

Figure 3. Frequency of Sarah's use of strategies on the Computational Fluency subtest.

Throughout the study, Sarah described the counting strategy as "her" counting strategy, showing favoritism for and comfort in this anchor strategy. As such she would count on from the larger number with basic addition problems. For example, she demonstrated how she might count on using tallies or her fingers as she counted on from 7 to find the answer to the problem $4+$ 7, as seen in her work on Benchmark 2 in Figure 4.

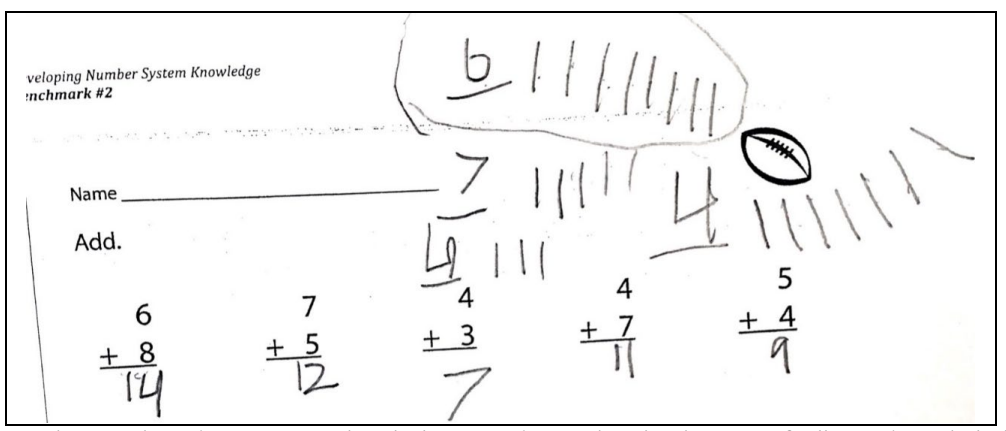

Figure 4. Sarah's written work on the Benchmark 2 Computational Fluency subtest, showing her use of tally marks to help her with her counting strategy.

When confronted with basic subtraction problems, Sarah would use her fingers or tallies more frequently to help her keep track of the counting sequence. When asked what she did when there was a number bigger than the number of fingers she had, she stated that she would use pencils or some other means to help her keep track as seen in the following transcript:

Interviewer: How did you know this one [Sarah]? Twelve minus eight is four?

Sarah: I had to use my fingers a lot on that one, and I just... was like... 12... and I, well, it was kind of hard and stuff because you don't have 12 fingers, and that one's a hard one sometimes, and if you can do a test at your desk I like to use pencils or something like that.

Interviewer: Okay, the last one I am going to ask you about is 18 minus 9.

Sarah: Um, that one... (laughs) it would be a hard one with my fingers too, like the first one. Um... because it's a really big number and stuff... but that's just that one.

Interviewer: Do you have a guess? What would your guess be?

Sarah: Probably... 9 or 7 or something. I don't know.

Interviewer: That's a good guess! Why would that be your guess?

Sarah: Well... it's just kind of some really high numbers, and so it would still be pretty high numbers, and yeah.

This pattern was seen to be used more frequently in the pretest where she used counting strategies on five of the nine computations she was interviewed about. When interviewed about the Benchmark 1 test, while Sarah still relied heavily on "her" counting strategy, she began to use more reasoning strategies where she would use patterns and relationships among numbers to invent reasoning strategies to solve unfamiliar problems. For instance, when confronted with the problem $9+2$, she took one from the two, and gave it to the nine in order to make ten, then added one more. The use of these strategies demonstrates a developing maturity and flexibility in Sarah's number sense. On the Benchmark 1 test, Sarah began to demonstrate more flexibility with her number sense development as she used counting, reasoning, and retrieval strategies with the same frequency. This progression was also seen in the results of Sarah's Benchmark 2 test. It was noted that Sarah tended to use more retrieval strategies where she was able to efficiently, appropriately, and adaptively produce sums and differences from a memory network. This shift in Sarah's thinking was seen with the problem 5+6 during her interviews across four measurement points (see Figure $5)$. 


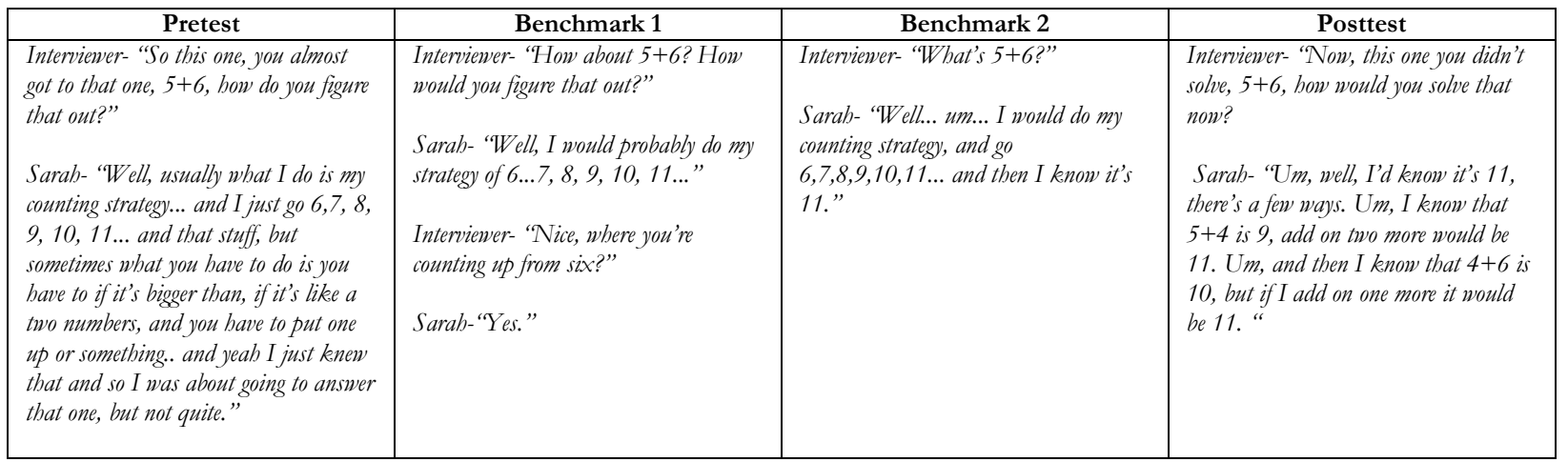

Figure 5. Sarah's verbal responses explaining her strategies for solving $5+6$ across four measurement points.

On the pretest, Benchmark 1 and Benchmark 2, Sarah would count on from six, using her fingers to keep track of what she had counted. On the posttest, however, she identified two new strategies she might use to solve the problem. This instance represents a breakthrough in Sarah's thinking as she moved to more sophisticated strategies and the idea that there are multiple ways to solve the problem.

While Sarah demonstrated this shift in understanding, she still held to her counting strategies in order to solve several of the computations. These strategies are something that Sarah saw as being reliable and familiar, and she trusted them to get her to the correct answer. This reliance on the counting strategies was still manifest in Sarah's posttest data where she continued to develop more retrieval strategies, yet held to those counting strategies she trusted. The counting strategies showed up more frequently in subtraction problems, which demonstrate Sarah's developing understanding of the properties of subtraction as she worked to develop more adaptive expertise in this unfamiliar area.

Word problems subtest

Figure 6 shows Sarah's test scores for the Word Problem subtest across the four measurement points. While the scores show an increase from $25 \%$ to $75 \%$ and a decrease to $50 \%$, her interviews explain or rival the trends in the test scores.

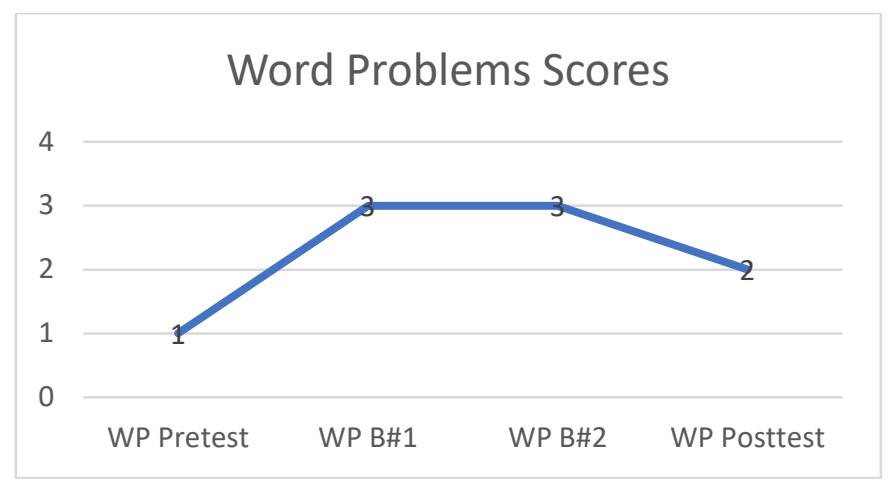

Figure 6. Line graph of Sarah's Word Problem subtest scores across measurement points.

On Sarah's pretest she frequently used a direct modeling strategy, the most basic strategy in our coding framework. Having concrete representations of the items addressed in the word problems helped Sarah to visualize the task and better find solutions. For example, Figure 7 shows that on the pretest, Sarah drew three boxes to represent each bag of cookies. She then drew 15 circles in each bag to represent each cookie in the bag, which are organized in rows of 5 . 


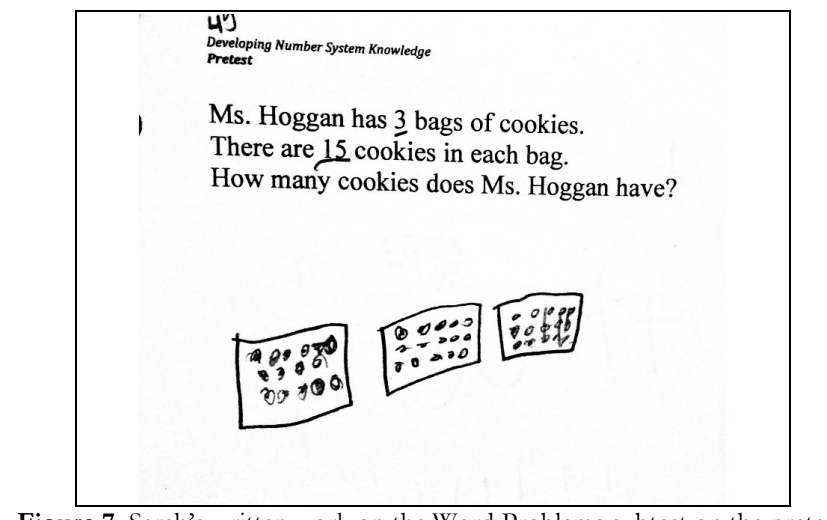

Figure 7. Sarah's written work on the Word Problems subtest on the pretest.

Sarah's counting strategies, on the Word Problems subtest, are slightly more sophisticated than the direct modeling strategies. One distinct instance where Sarah's use of counting strategies was highlighted was on Benchmark 1, as seen in Figure 8. Sarah started by writing a three, then proceeded to count up to twelve using tally marks to keep track. She eventually got to twelve and counted each tally mark, providing her with the answer of nine. This problem was one of many instances where Sarah relied on counting strategies to develop an answer.

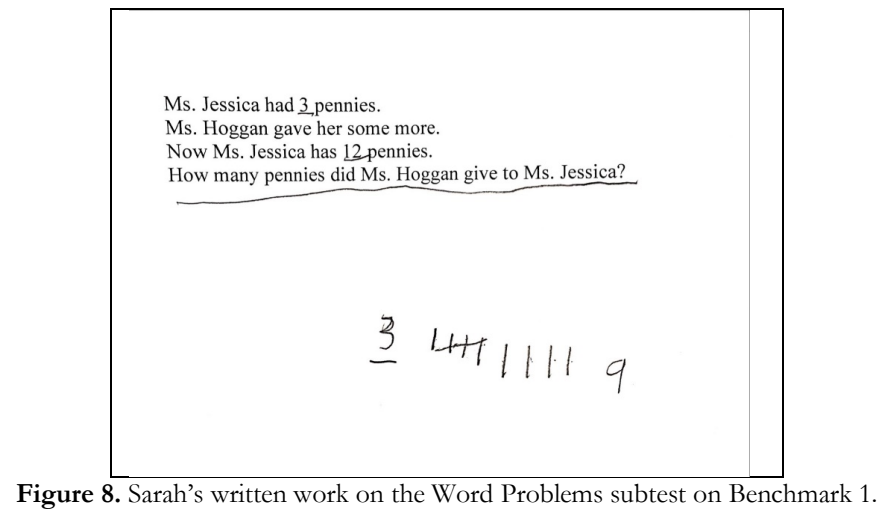

While not apparent in the test scores, the interviews elucidate a shift in Sarah's strategies at Benchmark 2. By Benchmark 2, Sarah began to move away from the direct modeling strategies and toward more counting and reasoning strategies. Sarah began to recognize that it was not necessary to physically construct and count the two sets described in a problem, and could see that there were more efficient methods. For example, during the Benchmark 2 interview, Sarah was asked to solve the following problem shown in Figure 9.

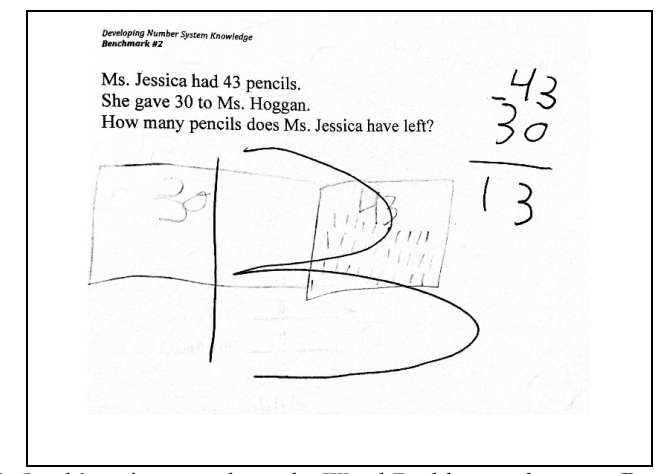

Figure 9. Sarah's written work on the Word Problems subtest on Benchmark 2.

The following conversation took place around her work in Figure 9:

Interviewer: What about this one? I saw you used an equation... you started a picture, but then what did you do? 
Sarah: Well, I was gonna do a picture, but I knew it would take longer and be harder. So, I did it with just that way because those ways are easier for me, and I got thirteen.

Interviewer: How did you get thirteen on this equation?

Sarah: Well, I took three, I did three take away zero, and it was still three. Then I took four away from three and... took three away from four and it was one.

The realization that there are more efficient strategies seemed to be monumental as Sarah began to complete the tasks with more accuracy. This transition from a conceptual to a more procedural understanding occurred after six weeks of participation in the Number System Knowledge instructional treatment. Sarah tended to use tally marks in order to keep track of the addends when needed, but was able to use invented strategies on $50 \%$ of the tasks on Benchmark 2.

This shift to more efficient strategies continued to develop through the next couple weeks as Sarah took her posttest and had only one instance where she used her counting strategy, but also used both invented strategies and the algorithm. On the multiplication problem in Figure 10, Sarah drew tallies to represent the cookies in each bag. She counted the tallies by five, and stated that there were $30+15$ tallies. However, as she made the shift to creating an equation to represent her picture, she had written $20+15$, coming to an incorrect answer of 35 .

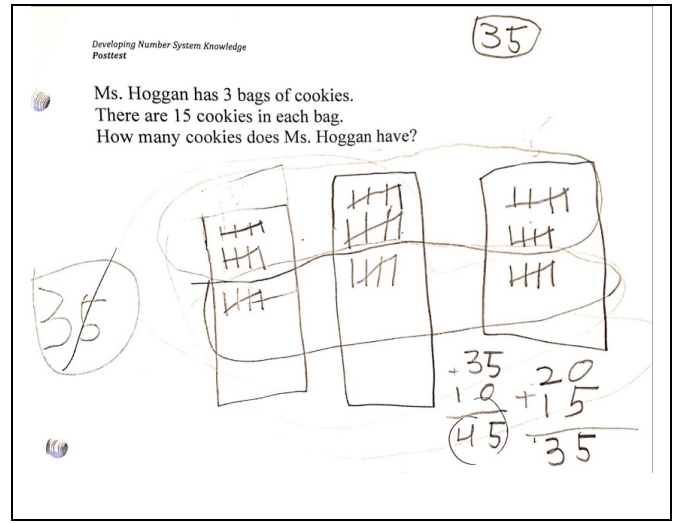

Figure 10. Sarah's written work on the Word Problems subtest on the posttest.

During Sarah's posttest interview, she was able to successfully see where she had made the mistake and revised her equation bringing her to the correct answer. This instance demonstrates Sarah's gradual shift from using direct modeling and counting strategies, to a more sophisticated use of invented strategies and algorithms. It is important to note that this shift is seen through the mathematical conversations in the interviews, however, the shift is hidden by the test scores. The test scores show a slight increase from the pretest but a decrease from Benchmark 2 to the posttest. This is an instance where the test scores and the interviews diverge. The counting strategies provided Sarah with a foundation upon which she built her number sense, and as she became more comfortable with her number sense capabilities, she trusted her ability to use more efficient strategies.

\section{Number line estimation subtest}

While there were four measurement points for the computation and word problems, the Number Line Estimation tasks were assessed only at the pretest and posttest. Sarah's score improved from $20 \%$ to $40 \%$. Figure 11 shows her improved accuracy from the pretest to the posttest for the number 61.

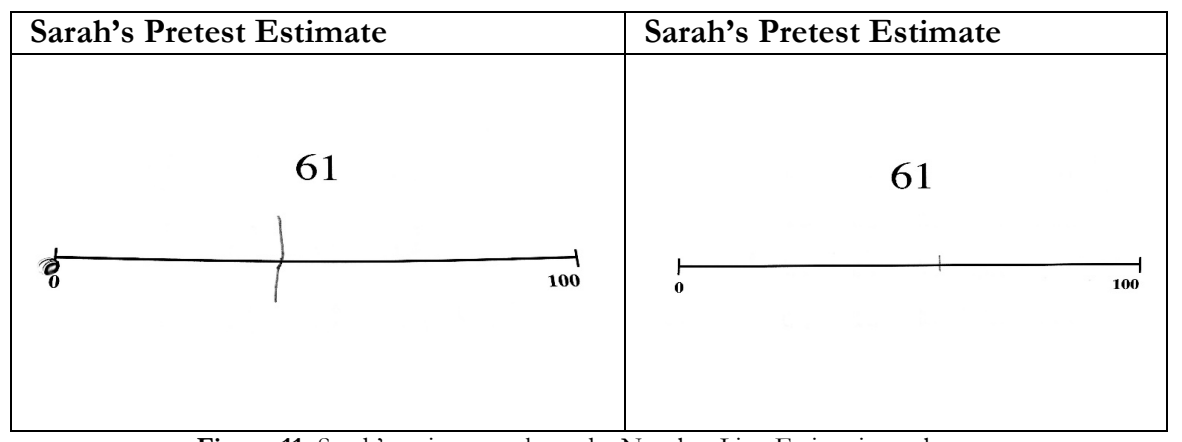

Figure 11. Sarah's written work on the Number Line Estimation subtest. 
In contrast, her interviews on the tasks were coded as a regression from measurement strategies to counting strategies. While regression was coded, Sarah's language as she described why a number belongs in her selected location on the number line showed more precision and attention to place in relation to numbers. On Sarah's pretest, she tended to look at the number line more holistically. She generally tried to use the benchmark numbers in order to orient herself. However, the benchmark numbers she chose to use were not always the most efficient, as seen in the following excerpt from her pretest interview:

Interviewer: How did you know that 8 belongs there on the number line?

Sarah: Well, I just thought that it was really less than 100, so I just put it kind of right there. Because I knew it was pretty less and not so much.

Interviewer: How did you know 84 belongs there?

Sarah: Well, I just knew that 8 was down here and it was kinda more ahead so I just put it there.

It is interesting to note that Sarah did not use any counting strategies on the number line on this particular test, but used her best estimate based on the numbers she knew. She did not use tick marks or any other method of keeping track that you might suspect she would choose to use given her choice of strategies on the other tasks involved in the assessment.

On the posttest, however, Sarah chose to use more counting strategies, yet she used this as a way of checking herself as seen in the following excerpt from her posttest interview:

Interviewer: How did you know 8 belongs there?

Sarah: Um, well, I just went like lower, I had it go a little lower, like a little more by the zero because...like... it could be like 1,2,3,4,5,6,7,8 [pointing to imaginary tick marks]...or something...and so like, I just do it in a place that I would guess.

She continued to use the same strategy as she placed the 84 :

Interviewer: How did you know that 84 belongs there?

Sarah: Because I knew that 80 would be more by 100 than it would be by 0 , so I put it a little closer over here, but I still remembered that we had 85, 86, 87, 88, 89, 90, 91, 92, 93, 94, 95, 96. 97, 98. 99. 100 [pointing to imaginary tick marks]. So, I still made sure there was some space.

On the posttest, Sarah used more logical benchmark numbers to know where to place the numbers, but relied on a counting strategy to verify that she had placed the number in the correct location on the number line. This merging of test score, holistic coding, and axial coding analyses helped to explain specific and subtle learning growth on the Number Line Estimation subtest.

\section{Number sets subtest}

This particular test was the targeted test for this study because it most directly aligned with the instructional intervention.

Researchers hypothesized students would improve the most on this subtest. It is curious, then, that Sarah's test scores went down on this subtest, where progress was seen in all other subtest areas. Her scores on the number sets subtest decreased from $51 \%$ to $40 \%$ (in both cases, the lowest test score among her peers). This difference could be contributed to the piloting of the test in this study and the varied time allotment given to students on each test (90 seconds on the pretest, 60 second on the posttest). With less time on the posttest, it was difficult to compare the scores from pretest to posttest. The other aspect to consider was that Sarah may have spent more time being thoughtful about her solutions. Her interview data showed that she matured in her mathematical thinking as her methods were more efficient. There was also evidence that Sarah developed more flexibility when working with different number combinations. For example, in Figure 12, Sarah's posttest response showed improvement in three ways. She attached an equation to the quantity, stated a sum, and showed more flexibility in her thinking (e.g., "there's a few ways").

\begin{tabular}{|l|l|l|l|}
\hline \multicolumn{2}{|l|}{ Assessment Item } & Pretest & \multicolumn{1}{|c|}{ Posttest } \\
\hline \multicolumn{1}{|l|}{} & It has two and then two and then one. & $\begin{array}{l}\text { So... there's a few ways. So, 2 plus 2 } \\
\text { equals 4 plus 1 equals 5. Or, I could put } \\
\text { this one here [pointing to the single dot } \\
\text { and moving it to the box with 2 dots] } \\
\text { and make 0, and 2 plus 3 equals 5. }\end{array}$ \\
\hline
\end{tabular}

Figure 12. Sarah's interview from pretest to posttest on one Number Sets subtest item.

Sarah used counting strategies much less frequently on the number sets test (particularly on the posttest) when compared to her strategy choices on the pretest. On the pretest, however, she alluded to having used her counting strategy as seen in the following transcript from her pretest interview:

Interviewer: When you were solving these problems, you were looking for groups that add up to five, or groups that add up to nine, do you remember that? 
Sarah: Yes.

Interviewer: Did you have a strategy for figuring it out?

Sarah: Well, what I really did is if there's one that was really hard, I just kind of like count the biggest number and then count the like just like say $5 \ldots$ like say 4 , and then 1 , and that's technically what I do. Then ones like 4 and 1 I kind of know 5 and 0 I kind of know pretty much but yeah...

It was evident that when she became unsure of the answer, she reverted to her counting strategies because she knew that these strategies were something she could count on. Sarah's continued use of counting strategies even into the posttest revealed her reluctance to make the shift to the symbolic realm and trust her ability to recognize certain combinations. For example, in Figure 13, her response from pretest to posttest on the symbolic problem 7 and 2 showed her use of the same strategy, but emerging understanding that there were other ways to figure it out.

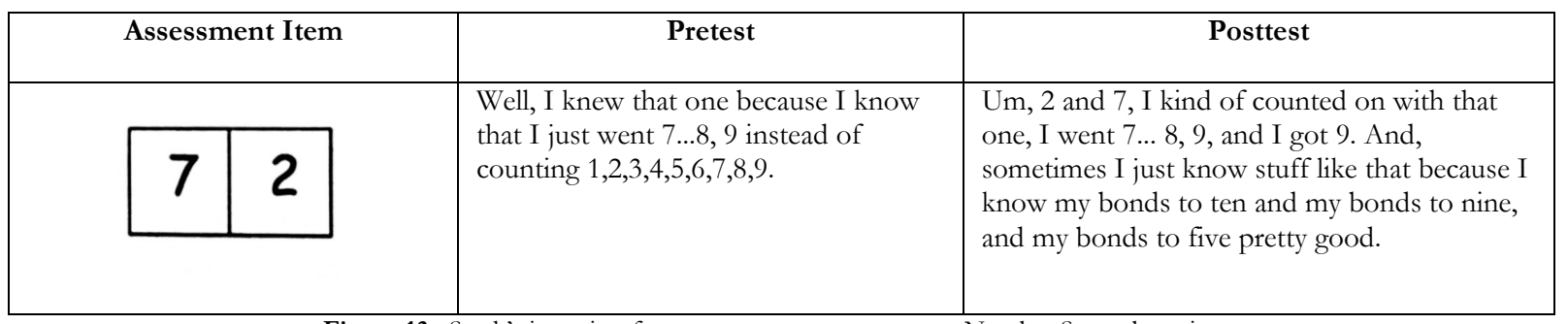

Figure 13. Sarah's interview from pretest to posttest on one Number Sets subtest item.

Even though Sarah stated that she did know bonds to nine and just "knows stuff like that," she still insisted on using a counting strategy with that particular problem. Counting was a strategy she was comfortable with, and the data reveal that she was hesitant to move to a retrieval strategy.

On the posttest, a theme developed where Sarah would manipulate the quantities in her mind in such a way that she could create a shape or a number that she could work with more easily. Sarah was able to successfully subitize many of the numbers, and those she could not, she would use spatial reasoning to develop an answer. Sarah became much more playful with the combinations of symbols and quantities and demonstrated more flexibility with her strategies as seen in the following transcript:

Interviewer: Did you kind of have a general strategy for figuring some of these out, or did it depend on the numbers? Sarah: Well, it kind of depended, but with like this first one, and some of these ones... I just technically like put that one in the middle and I made it look like a dice, and then made this look like a zero, and stuff like that.

Interviewer: So you kind of move the dots around in your head?

Sarah: Yeah, but I also kind of knew them like that, but there were some other ways that I did it too.

This creativity and use of spatial reasoning represented a significant development in Sarah's thinking as she became more sophisticated in her number system knowledge. She was able to use compensation strategies and played around spatially with the dots to make the problem easier to solve. In Sarah's posttest interview, she used the word 'count' much less frequently, which also showed her building trust in the new strategies she developed. Although the quantitative data show a decrease in Sarah's understanding, the qualitative data demonstrated positive nuanced shifts in her learning.

\section{DISCUSSION}

The purpose of this exploratory case study was to examine one eight-year-old student's development of number system knowledge during a nine-week instructional treatment. Results showed that Sarah increasingly put her number sense to work and developed more pronounced adaptive expertise in solving mathematical problems as evidenced in a combination of her test scores and explanations for strategies in her interviews. Sarah became more creative and flexible with her reasoning strategies across all assessment areas. Initially, Sarah relied on counting strategies to solve computation problems, word problems, and number sets problems. Over time, however, she began to demonstrate confidence in her ability to flexibly manipulate numbers and displayed the ability to think critically when faced with challenging problems. Sarah used more sophisticated strategies, demonstrated more efficiency and innovation, and showed awareness of strategies beyond her comfort-level counting strategies.

The instructional treatment in this study aimed to marry conceptual and procedural knowledge and provided a conceptual foundation upon which procedural knowledge could be based upon by linking numerals to quantities. This basis opened avenues through which Sarah could develop flexibility in her thinking and invent her own strategies. The data showed that Sarah not only developed a stronger conceptual basis, but also moved towards more fluent procedural processing where she was able to subitize with more automaticity and begin to use retrieval strategies. 
Psychologists and educators have long debated how number combinations are learned and how to best promote fluency. The results illuminated by this study are consistent with studies on adaptive expertise with basic addition and subtraction combinations in that conceptual learning plays a key role in developing number sense. ${ }^{20}$ Focusing on structure (underlying patterns and relations) makes the learning, retention, and transfer of any large body of factual knowledge more likely than memorizing individual facts by rote. The instructional treatment in the study provided students the opportunity to identify patterns and relations within numbers in an effort to extend their knowledge base of early number sense.

\section{CONCLUSIONS}

The results of the study provide an opportunity to understand number system knowledge in the context of one student's learning. There is consistent evidence that children's symbolic number system knowledge at the beginning of formal schooling predicts concurrent and later mathematics achievement. ${ }^{21}$ This evidence supports the need for focused instructional treatments at the early grade levels in order to secure future mathematics success.

The theory and knowledge gained through this study could influence the development of effective instructional practices and extend the knowledge base of early number sense. It highlights the need for teachers to implement number sense-based instructional practices as they enhance the learning, retention, and transfer of any large body of factual knowledge, more so than memorizing facts by rote. ${ }^{22}$ As seen in this case study, when teachers implement instructional practices that marry both procedural and conceptual strategies by linking numerals to quantities, students develop number sense and adaptive expertise. While it is important for students to develop procedural fluency with basic mathematical computations, it is also important that they have a conceptual base upon which procedural knowledge is built. Conceptual knowledge can lead to advances in procedural knowledge and ultimately contributes to the development of adaptive expertise through flexibility in self-constructed strategies.

\section{ACKNOWLEDGEMENTS}

The authors thank the case study student and classroom teacher that participated in the study.

\section{REFERENCES}

1. Berch, D. B. (2005). Making sense of number sense: Implication for children with mathematical disabilities. Journal of Learning Disabilities, 38(4), 333-339.

2. Locuniak, M. N., \& Jordan, N. C. (2008). Using kindergarten number sense to predict calculation fluency in second grade. Journal of Learning Disabilities, 41(5), 451-459.

3. Common Core State Standards Initiative. (2010). Common core state standards for mathematics. Retrieved from http://corestandards.org

4. Confrey, J., \& Krupa, E. (2010). Curriculum design, development, and implementation in an era of common core state standards: Summary report of a conference. Arlington, VA. Retrieved from http://www.mathcurriculumcenter.org/reports_ research.php

5. Geary, D. C., Hoard, M. K., Nugent, L., \& Bailey, D. H. (2013). Adolescents' functional numeracy is predicted by their school entry number system knowledge. PLOS ONE 8(1): e54651. doi:10.1371/journal.pone.0054651

6. Greeno, J. G. (1991). Number sense as situated knowing in a conceptual domain. Journal for Research in Mathematics Education, 22, 170-218. doi:10.2307/749074

7. Baroody, A. J., \& Rosu, L. (2006, April). Adaptive expertise with basic addition and subtraction combinations: The number sense view. In A. J. Baroody \& J. Torbeyns (Chairs), Developing adaptive expertise in elementary school arithmetic. Symposium conducted at the annual meeting of the American Educational Research Association, San Francisco, CA.

8. Baroody, A. J., Feil, Y., \& Johnson, A. R. (2007). An alternative reconceptualization of procedural and conceptual knowledge. Journal for Research in Mathematics Education, 38(2), 115-131.

9. Verschaffell, L., Luwel, K., Torbeyns, J., \& Van Dooren, W. (2009). Conceptualizing, investigating, and enhancing adaptive expertise in elementary mathematics education. European Journal of Psychology of Education, 24: 335. https://doi.org/10.1007/BF03174765

10. Hatano, G. \& Oura, Y. (2003). Reconceptualizing school learning using insight from expertise research. Educational Researcher, 32(8), 26-29.

11. National Research Council. (2001). Adding it up: Helping children learn mathematics. J. Kilpatrick, J. Swafford, and B. Findell (Eds.). Mathematics Learning Study Committee, Center for Education, Division of Behavioral and Social Sciences and Education. Washington, DC: National Academy Press.

12. Haapasalo, L. (2003). The conflict between conceptual and procedural knowledge: Should we need to understand in order to be able to do, or vice versa. Proceedings on the IXX Symposium of the Finnish Mathematics and Science Education Research Association, University of Joensuu, Bulletins of the Faculty of Education. Vol. 86.

13. Yin, R. K. (2014). Case study research: Design and methods, $5^{\text {th }}$ ed. Thousand Oaks, CA: Sage.

14. Shumway, J. F. (2011). Number sense routines: Building numerical literacy every day in grades K-3. Portland, ME: Stenhouse. 
15. Chapin, O’Conner, \& Anderson, 2009,

16. Geary, D. C., Hoard, M. K., Nugent, L., \& Bailey, D. H. (2013). Adolescents' functional numeracy is predicted by their school entry number system knowledge. PLOS ONE 8(1): e54651. doi:10.1371/journal.pone.0054651

17. Miles, M. B., \& Huberman, A. M. (1994). An expanded sourcebook: Qualitative data analysis (2nd ed.). Thousand Oaks, CA: Sage.

18. Carpenter, T. P., Fennema, E., Franke, M. L., Levi, L., \& Empson, S. B. (1999). Children's mathematics: Cognitively guided instruction. Portsmouth, NH: Heinemann.

19. Diezman \& Lowrie, 2006

20. Baroody, A. J., \& Rosu, L. (2006, April). Adaptive expertise with basic addition and subtraction combinations: The number sense view. In A. J. Baroody \& J. Torbeyns (Chairs), Developing adaptive expertise in elementary school arithmetic. Symposium conducted at the annual meeting of the American Educational Research Association, San Francisco, CA.

21. Geary, D. C. (2011). Cognitive Predictors of Achievement Growth in Mathematics: A 5-Year Longitudinal Study. Developmental Psychology, 47(6), 1539-1552.

22. Jordan, N.C., Glutting, J., \& Ramineni, C. (2010). The importance of number sense to mathematics achievement in first and third grades. Learning and Individual Differences, 20, 82-88.

\section{ABOUT STUDENT AUTHOR}

Cami C. Player graduated with a BA in Elementary Education from the School of Teacher Education and Leadership at Utah State University in 2017. She worked as an Undergraduate Research Assistant for the Early Math Research Group (EMRG) on the project "Developing Number System Knowledge: An Exploratory Study of Visual Quantities Instructional Tasks" during her senior year. She is currently a $5^{\text {th }}$ grade teacher at Woodruff Elementary School in Logan, Utah, and intends to pursue a master's degree in education.

\section{PRESS SUMMARY}

Instruction for developing students' number sense is a critical area of research in mathematics education due to the role number sense plays in early mathematics learning. Specifically, number system knowledge-systematic relations among numerals and the use of number relations to solve arithmetic problems - has been identified as a key cognitive mechanism in number sense development. The purpose of this exploratory case study was to investigate the variations of an eight-year-old student's number system knowledge learning as she participated in an instructional treatment over nine weeks. An in-depth analysis of how and why one struggling student develops number system knowledge during a nine-week instructional treatment within the context of her mathematics class provides exploratory evidence to help researchers and teachers develop and implement similar practices in elementary mathematics instruction. 


\title{
Measuring the Mechanical Properties of Laminated Wood Structures Using a Homemade Bending Tester
}

\author{
J. Weber, and A. J. Stollenwerk* \\ University of Northern Iowa, Department of Physics, 215 Begeman Hall, Cedar Falls, Iowa 50614-0150 \\ Students: weberjaw@uni.edu \\ Mentor: andrew.stollenwerk@uni.edu
}

\begin{abstract}
The choice of materials used to build a laminate recurve bow is crucial to optimizing performance. To this end, a low-cost bending tester was designed and built to measure the flexural modulus and modulus of rupture on a variety of wooden laminates. To gain a better understanding of the relationship between the properties of the laminates and the individual species comprising the laminates, woods with a wide range of elastic and strength properties were chosen. Differences between the expected and experimental results are attributed to the properties of the adhesive and defects in the wood.
\end{abstract}

\section{KEYWORDS}

bending test; recurve bow; wood; laminates; modulus of rupture; flexural modulus

\section{INTRODUCTION}

Spanning most cultures around the world, numerous types of bow have been developed to make use of available resources or meet specific needs. Each design has in common a pair of elastic limbs connected by a string attached at the nocking points located at either end of the bow. The side of the limb facing the string is known as the belly of the bow, the other side is known as the backing. Pulling the string back deforms the limbs, creating a compression in the belly and tension in the backing. Potential energy builds up in the limbs with increasing deformation and is converted to kinetic energy when released. Perhaps the simplest way to build a bow is to shape one from a single piece of wood, known as a self bow. Self bows are usually straight when unstrung such as the English longbow. In contrast to a straight bow, a recurve bow has limbs that curve away from the archer when unstrung. A comparison between a straight self bow and a recurve bow in unstrung, strung, and fully drawn states is shown in Fig. 1. The geometry of the recurve causes the lever arm of the limb to increase as it is flexed so that the force necessary to draw the bow increases rapidly at first before slowing quickly. Due to this change in mechanical advantage, a recurve is able to more efficiently store energy than a straight bow for the same force used to fully draw the bow. However, this places greater strain on the limbs, making the choice of materials crucial to success.

Modern recurve limbs are usually laminates created by bonding thin layers of material together with an adhesive. This process allows one to create the desired shape of the recurved limbs by clamping the layers in a mold as the adhesive dries. The materials comprising the laminate are chosen to optimize certain desired qualities. For example, materials capable of withstanding large amounts of stress due tension are ideal for the backing of the bow and those with good compression properties are desirable for the belly. A poor choice of materials can lead to mechanical failure via yield or fracture. A material yields when it undergoes a non-linear deformation and is typically caused by structural changes such as buckling of compressive fibers. However, bows typically fail due to a fracture characterized by a catastrophic splitting of the material due to tensile stress. The maximum tensile stress in a material before failure can be quantified by the modulus of rupture. Due to the way a bow propels an arrow, the elastic properties of the limbs are also of interest. The amount of force necessary to draw a bow with given dimensions can be adjusted by 


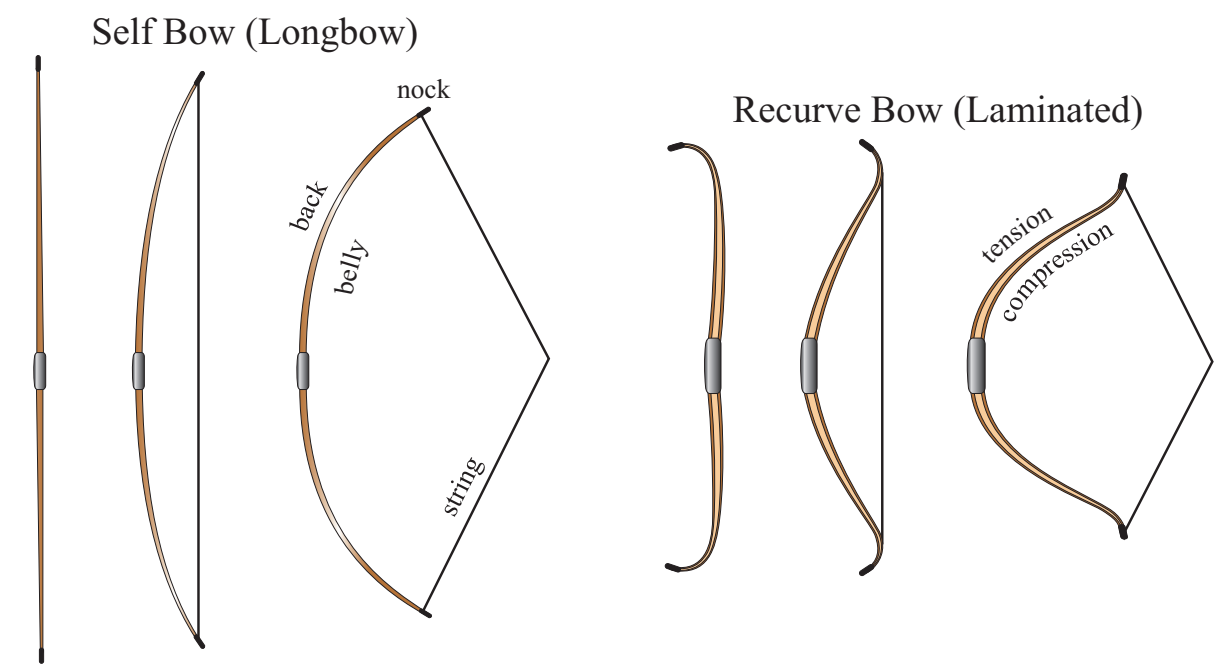

Figure 1. A comparison of a straight self bow and a recurve bow in unstrung, strung, and fully drawn states.

using materials with different flexural moduli, or resistance to bending. Most recurve bows are made by laminating a wood or carbon core with fiberglass to achieve these desired qualities. ${ }^{\mathbf{1}, \mathbf{2}}$ It is possible to build a recurve bow using only wooden layers, but care must be made when choosing the layers given the variability of properties among different species of wood.

In the this paper, a low-cost bending tester was designed and built to measure the flexural modulus and the modulus of rupture of wooden laminates constructed from several different species of woods. The flexural modulus was compared to expected values calculated from the properties of the individual species comprising the laminate. The modulus of rupture was compared to that of the species used as the backing layer.

\section{METHODS AND PROCEDURES}

A number of different wood species were purchased from a mill to fabricate the laminates: Peltogyne spp. (purple heart), Anadenanthera colubrina (curupay), Hymenaea courbaril (jatoba), Handroanthus spp. (ipe), Acer rubrum (red maple), and Carya laciniosa (shellbark hickory). Curupay, ipe, and hickory were selected as backing material due to their reported high moduli of rupture ${ }^{3}$ and availability. Other woods were selected to include a wide variety of elastic properties ${ }^{3}$ to explore how the flexural moduli of individual woods affect the overall stiffness of the combined layers. A table saw was used to cut kiln dried lumber into strips with cross-sectional dimensions of approximately $5 \times$ $35 \mathrm{~mm}$ and varying lengths. Given the effect on mechanical properties ${ }^{4}$, effort was made to ensure that the overall grain was parallel to the length of the strips to within $5^{\circ}$ in either direction. A thickness planer was used to smooth both sides and create a uniform thickness of $3.3 \mathrm{~mm}$ and width of $34 \mathrm{~mm}$. A number of laminates were created using various combinations of wood species. Each laminate stack consisted of three strips of wood bonded together with Titebond III ${ }^{\circledR}$ wood glue applied after lightly sanding the surface with 120 grit sand paper and removing any dust with a damp cloth. When used as a backing layer, Ipe stripes were cleaned using acetone to remove natural oils and increase adhesion. ${ }^{3}$ Laminates were compressed using spring clamps spaced approximately $2 \mathrm{~cm}$ as the glue cured over a 24 hour period. The final thickness after a 24 hour curing period was approximately $10.0 \pm 0.2 \mathrm{~mm}$. Laminated stacks were cut into sizes with width of approximately $15 \mathrm{~mm}$ and length of $16 \mathrm{~cm}$.

The mechanical properties of each sample were measured using a homemade three point bending tester. This setup is depicted in Fig. 2 and was used as a low-cost alternative to more expensive, commercially available systems not widely available at undergraduate institutions. A web strap, hand-operated winch was used to apply a force to the middle of the board via a flat U-bolt in series with an American Weigh TL-330 hanging scale with an accuracy of 


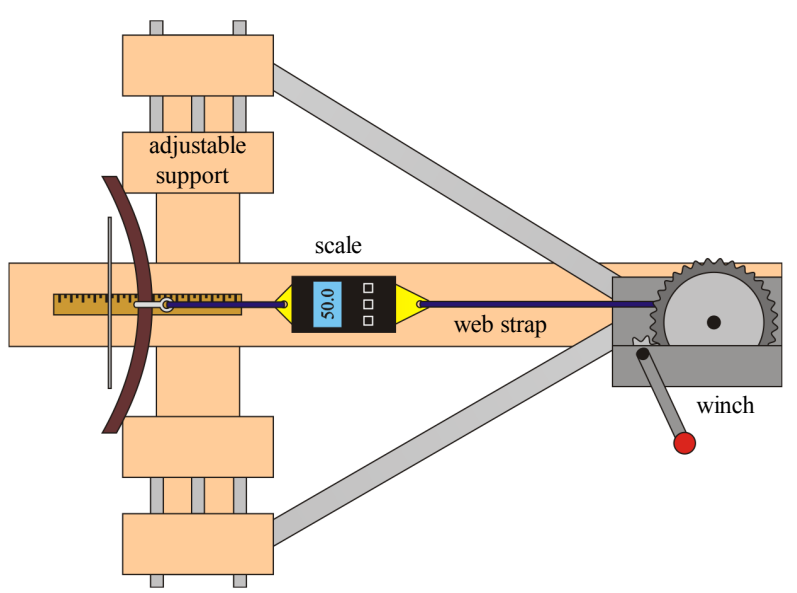

Figure 2. Schematic of the homemade three point bending setup.

$\pm 0.3 \mathrm{~kg}$. Samples of different lengths can be accommodated with adjustable support structures. Depending on the amount of stretch in the web strap, the sample was pulled back in increments of roughly $1.0-2.0 \mathrm{~mm}$ as measured using electronic calipers. The maximum displacement of the laminates prior to failure was also measured using electronic calipers. The maximum force up to sample failure was logged on the electronic scale.

The displacement and maximum force were used to calculate the flexural modulus and the modulus of rupture for each sample. For a sample with a rectangular cross section, the flexural modulus can be calculated from the displacement due to a force applied to the middle of the sample lengthwise, ${ }^{\mathbf{5}}$

$$
E_{i}=\frac{L^{3} F}{4 w t^{3} d}
$$

Here $F$ is the applied force, $d$ is the displacement, $L$ is the length of the sample, $w$ is the width, and $t$ is the thickness. The modulus of rupture for the same sample is determined from the maximum force applied prior to sample failure, ${ }^{6}$

$$
\sigma=\frac{3 F L}{2 w t^{2}}
$$

The effective flexural modulus for a multi layer laminate can be calculated from the flexural moduli of the comprising layers $\left(E_{i}\right)$ as, ${ }^{7}$

$$
E=\frac{\sum_{n=1}^{3} E_{i} I_{i}}{I_{t}}
$$

The area moment of inertia of each layer $\left(I_{i}\right)$ and the total area moment of inertial $\left(I_{t}\right)$ are determined relative to the neutral axis defined as the axis where the force acting on the cross-section is zero when the material is bent, ${ }^{\mathbf{8}}$

$$
\bar{y}=\frac{\sum_{n=1}^{3} y_{i} A_{i}}{A_{t}}
$$

Here $y_{i}$ is the distance from the centroid of each layer to the base of the laminate. The cross sectional area of each layer $\left(A_{i}\right)$ and the total cross sectional area $\left(A_{t}\right)$ are calculated using the principle of equivalent width where each layer is assumed to be of the same material with a corresponding width adjusted such that this homogeneous laminate has the same mechanical properties as the original laminate. For example, if the flexural modulus of material A is twice that of a material B then the equivalent of material A would be that of material B with half the width. The 
area moment of inertia of each rectangular layer ${ }^{8}$ is calculated using the parallel axis theorem ${ }^{\mathbf{9}}$ from the height $(h)$ and the equivalent width $(w)$,

$$
I_{i}=\frac{1}{12} w h^{3}+A_{i}\left(y_{i}-\bar{y}\right)^{2}
$$

\section{RESULTS AND DISCUSSION}

To have a basis for comparison, the mechanical properties were measured on individual species using a single strip of wood with a cross section of $3.3 \times 34 \mathrm{~mm}$ and length of $16 \mathrm{~cm}$. The results are summarized in Table 1 and are generally smaller than those found in literature by about $20 \%^{3}$ with the exception of curupay which is approximately $60 \%$ smaller than previous measurements. ${ }^{3}, \mathbf{1 0}$ This is not surprising given that each piece of wood is unique to the growth environment of the tree. ${ }^{11}$ Although attempts were made to ensure a parallel orientation, waviness in the grain around imperfections could create localized weak points. ${ }^{4}, 11$ The grain of the curupay used in this study was especially wavy compared to the other woods and is likely the reason for the large discrepancies as compared to values found in literature. Other factors may include differences in moisture content. ${ }^{12}$ While moisture content was not measured here, all samples were stored and tested in a controlled environment.

\begin{tabular}{|l||c|c|}
\hline Species & Flexural modulus $(\mathrm{GPa})$ & Modulus of rupture $(\mathrm{MPa})$ \\
\hline Purple heart & $13.1 \pm 0.6$ & $116.6 \pm 4.8$ \\
Curupay & $9.3 \pm 0.6$ & $95.7 \pm 5.0$ \\
Jatoba & $2.6 \pm 0.1$ & $70.1 \pm 2.8$ \\
Ipe & $15.0 \pm 0.7$ & $129.1 \pm 5.1$ \\
Red maple & $4.3 \pm 0.3$ & $68.0 \pm 3.2$ \\
Shellbark hickory & $5.6 \pm 0.4$ & $91.3 \pm 3.8$ \\
\hline
\end{tabular}

Table 1. Mechanical properties of individual species cut from a single piece of wood.

The flexural moduli for a variety of three layer laminates are plotted in Fig. 3 as filled squares. The open circles are the corresponding effective flexural moduli calculated from Eq. 3 using the dimensions of the woods comprising the laminate stack and the flexural moduli listed in Table 1. As seen in Fig. 3, the calculated effective flexural moduli consistently overestimate the experimental results to varying degrees. The reason for this difference may due to the glue, which is not included when calculating the effective flexural moduli. According to Eq. 3, the relatively thin layers of the glue are not expected to greatly contribute to the effective flexural modulus. However, the elasticity of the glue could permit a lateral shift between the layers of wood when bent. The greater the shift, the more the laminate will behave as three detached layers, resulting in a lower overall flexural modulus. In order to examine the effect of the glue on these samples, the flexural moduli was measured on triple layer laminates made from a single species. The resulting flexural moduli of homogenous laminates made from hickory, curupay, and ipe are $5.0 \pm 0.4$, $5.8 \pm 0.4$, and $11.3 \pm 1.7 \mathrm{GPa}$, respectively. In each case, the results are lower than those presented in Table 1, confirming that the glue itself plays a role in shaping the elastic properties of the samples.

The moduli of rupture of the laminate structures are plotted in Fig. 4 (filled squares). All samples in the present study fractured due to tensile stress. Because tensile stress is greatest along the outer curve, these data are compared to the moduli of rupture associated with the species used for the backing (open circles). In theory, these values should be equal since a tensile fracture is dependent only on the strength of the outer most fibers. The hickory and ipe backed samples are largely consistent with the single species hickory results. The curupay backed samples are somewhat less than their single species counterparts. Although the surface was lightly sanded as recommended, the high density of curupay presents known challenges when gluing. ${ }^{3}$ If a section of wood were to delaminate under strain, the sudden increase in tensile stress in this region would hasten failure. Visual inspection shows no obvious signs of delamination, but does not necessarily rule out poor bonding on a local scale that may weaken a small portion of the sample. For the most part, failures appear to be the result of a fracture of the outer fibers of the backing layer or a defect in the 


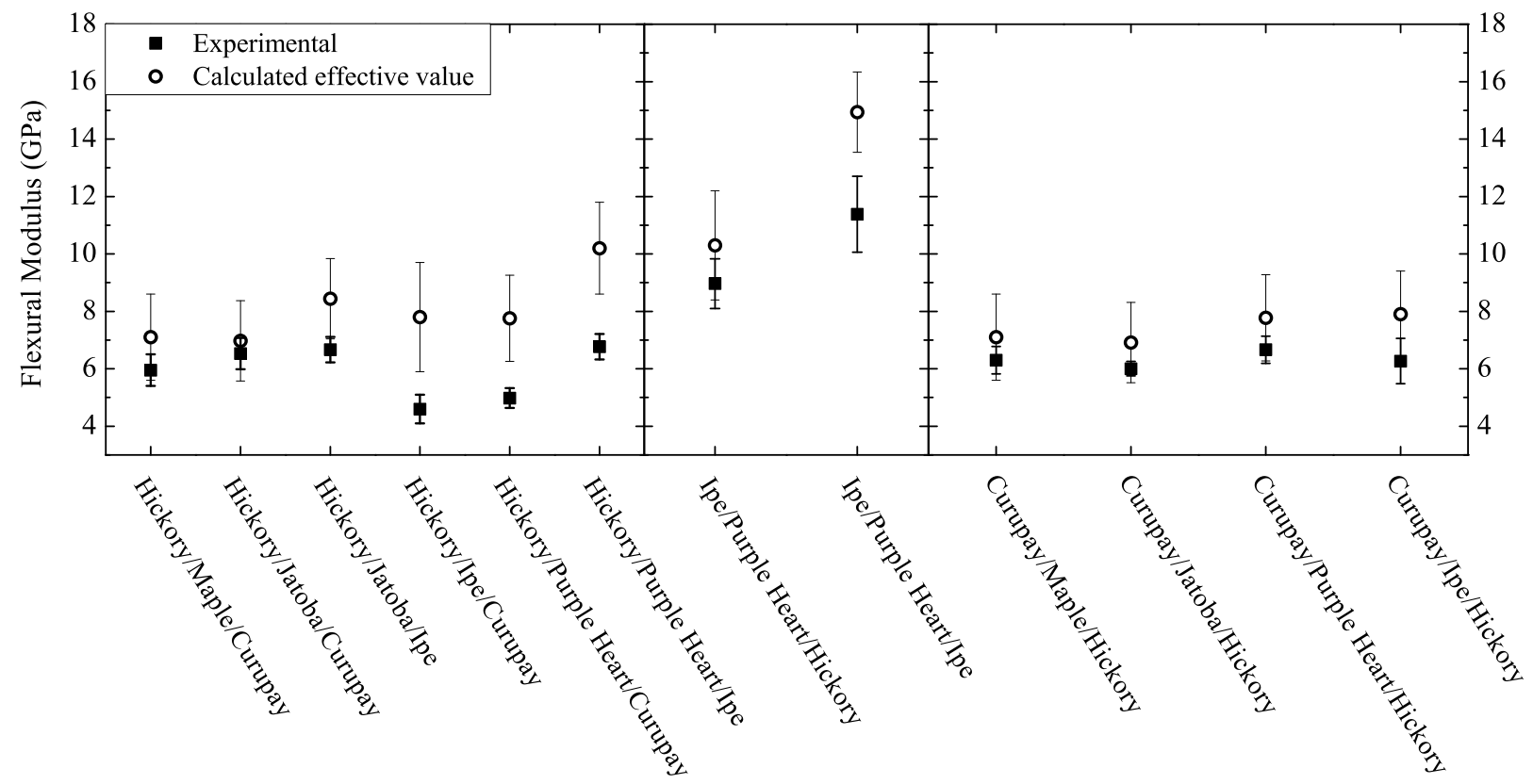

Figure 3. The effective flexural modulus of several non-homogeneous, triple layer laminates (closed squares) as compared to the effective flexural moduli (open circles) calculated from Eq. 3 using the values in Table 1.

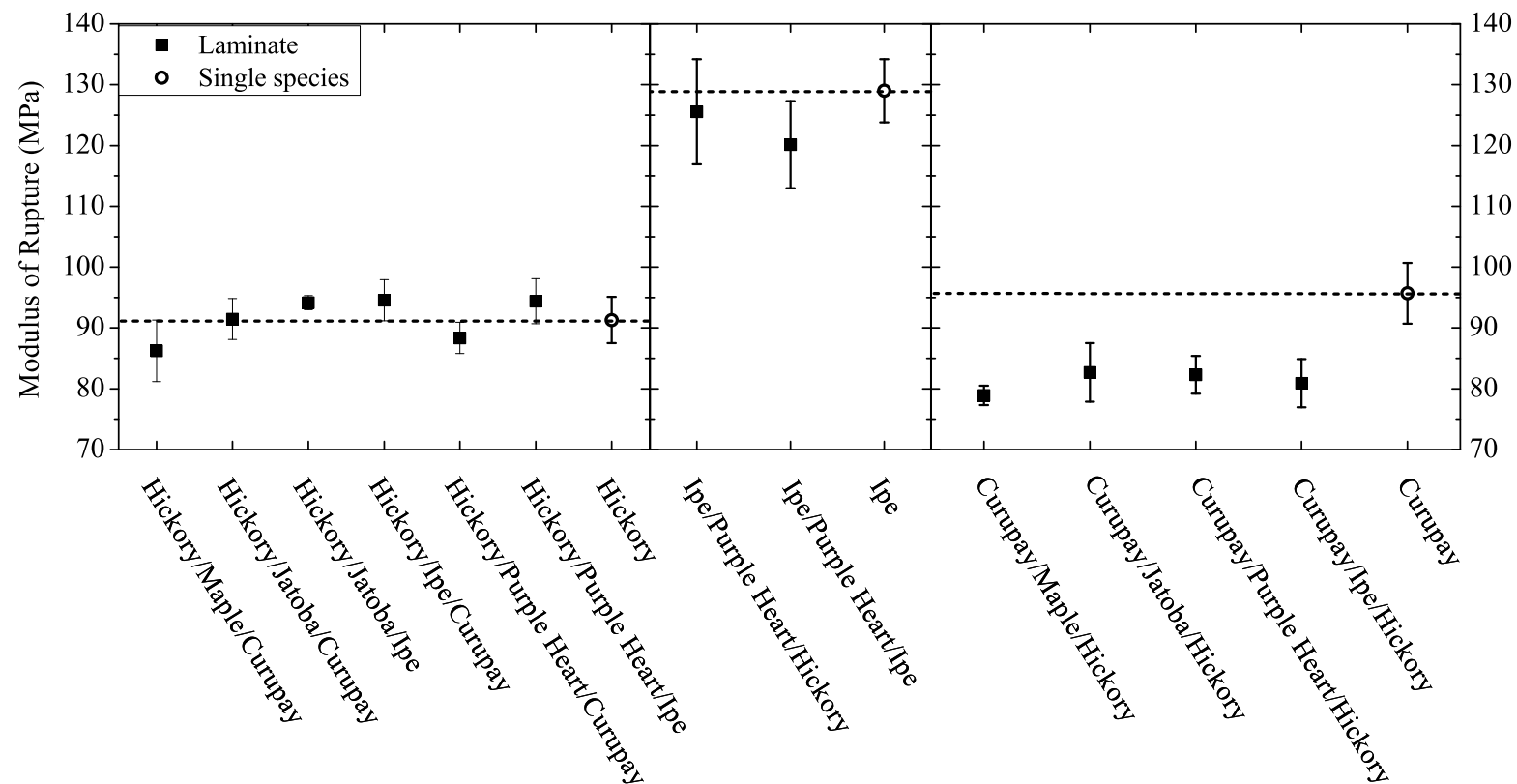

Figure 4. Modulus of rupture of non-homogeneous triple layer laminates compared to the value associated with species used for the backing layer.

grain structure that results in a crack that propagates through one of more layers. It would be interesting to repeat these experiments using curupay woods with different grain quality.

\section{CONCLUSIONS}

When choosing a wood to serve as the backing of a laminate bow it is important to have the highest possible modulus of rupture to create a strong limb. However, a strong backing won't be effective without a strong bond between layers, minimal defects in the wood, and a careful alignment of the grain. Aside from the backing, other layers can 
be chosen to tailor the properties of the bow for specific requirements. For example, a shorter bow must have thinner limbs to allow for the increased curvature when the bow is drawn. To maintain a large draw force in the thinner limbs additional layers should have a large flexural modulus.

\section{ACKNOWLEDGEMENTS}

This work was funded by a Student Opportunity for Academic Research (SOAR) grant through the University of Northern Iowa. The authors also thank C. K. Stollenwerk and M. D. Timmer for technical support.

\section{REFERENCES}

1. W. Marlow, American Journal of Physics 49, 320 (1981).

2. D. L. T. Schreiber et al., 4-H Archery Member Manual (2009).

3. E. Meier, Wood!: Identifying and Using Hundreds of Woods Worldwide (Wood Database, 2016).

4. R. B. Hoadley, Understanding wood: a craftsman's guide to wood technology (Taunton press, 2000).

5. C. Zweben, W. Smith, and M. Wardle, in Composite Materials: Testing and Design (Fifth Conference) (ASTM International, 1979).

6. R. Reeve, Methods of Soil Analysis. Part 1. Physical and Mineralogical Properties, Including Statistics of Measurement and Sampling, 466 (1965).

7. S. Girardon, L. Denaud, G. Pot, and I. Rahayu, Annals of Forest Science 73, 615 (2016).

8. R. M. Jones, Mechanics of composite materials (CRC press, 2014).

9. A. Abdulghany, American Journal of Physics 85, 791 (2017).

10. M. Chudnoff et al., Tropical timbers of the world, 607 (US Department of Agriculture, Forest Service Washington, DC, 1984).

11. D. Green, J. Winandy, and D. Kretschmann, Wood handbook: wood as an engineering material. USDA Forest Service, Forest Products Laboratory, Madison, WI, General technical report , 4 (1999).

12. C. C. Gerhards, Wood and Fiber Science 14, 4 (1982).

\section{ABOUT THE STUDENT AUTHOR}

Jacob Weber recently graduated from the University of Northern Iowa with a B.A. in Physics and is currently teaching at Bondurant-Farrar high school in Bondurant, IA

\section{PRESS SUMMARY}

This manuscript compares the mechanical properties of several different non-homogeneous laminates fabricated from an assortment of wood species. To varying degrees, the elastic properties of the laminates were less than expected due to the elastic properties of the adhesive. The strengths were largely consistent with the properties of the outermost laminate species. 


\title{
College Students' Well-Being: Use of Counseling Services
}

\author{
Morgan Huenergarde \\ Department of Psychology, University of the Cumberlands, Williamsburg, KY \\ Student: mbuenergarde4024@ucumberlands.edu \\ Mentor:eric.stephens@ucumberlands.edu
}

\begin{abstract}
A significant number of college students experience varying levels of stress, anxiety, homesickness, and depression which may negatively impact their academic performance or personal functioning. However, many college students do not seek professional help from campus counselors. Recent research supports the effectiveness of counseling centers in reducing the effect of stress, anxiety, homesickness, and depression on the students' well-being. The purpose to the current study was to analyze students' reports on their levels of stress, anxiety, homesickness, and depression, grouping them based on previous counseling participation. It was hypothesized that those who had gone to counseling or were currently attending counseling would report better overall improvement than those students who had never attended counseling. The following study included college students at a Southeastern university who have attended counseling or were currently attending counseling through the services provided by the University, or from any outside service. A group of students who had never attended counseling previously also participated. The research assessed varying levels of mood and academic performance and any differences between the groups. To gather a broader scope of knowledge, the study investigated demographic information and potential hindrances to treatment. It also focused on any barriers that would impact the likelihood of counseling attendance, and the manner in which students learned about the services offered. It was found that those students who attended six or more counseling sessions reported more positive perceived change in their levels of depression, anxiety, and stress than did students who attended five or fewer counseling sessions. Most students reported that they would not attend counseling due to not having enough time and suggested online or weekend sessions. Finally, students stated that they predominantly learned about services from advertisement.
\end{abstract}

\section{KEYWORDS}

Counseling; College Students; Depression; Homesickness; Anxiety; Stress; Mood; Academic Performance

\section{INTRODUCTION}

Traditional college students are often between the ages of 18 and 24 with a developing sense of identity. ${ }^{1}$ Often, a student's time at university is a period of exploration in interests, interpersonal and romantic relationships, and potential careers. These students have typically moved away from home and are experiencing a high level of independence. Without the presence of previous guidance, and often with the newer freedom expressed during college, new challenges and difficulties arise. Such new experiences and challenges can create situations that expose psychological disorders previously overlooked. During this time period, 12-25\% suffer from a diagnosable psychological disorder. ${ }^{2,3}$ By the age of $24,75 \%$ of all psychological disorders have manifested among college students. ${ }^{3}$ The most common psychological disorders noted on university campuses include anxiety disorders and mood disorders, often comorbid with substance abuse. ${ }^{1}$ There are a number of different factors that impact the likelihood of college students seeking professional help including social influences, cultural differences, stigmas, and gender. A holistic understanding of college students, their psychological disorders, and their reasons for seeking treatment need to be fully understood in order to effectively provide services.

Psychological disorders have often been associated with poor academic performance and ultimately school dropout. ${ }^{4}$ Most concerning, given the prevalence of psychological disorders on university campuses, is the fact that more than two-thirds of the students do not seek help or talk about their prevailing issues. ${ }^{3}$ In fact, while the rate of diagnosed psychological disorders has increased among college students, the percentage of students who seek professional services yearly has remained constant at an average of $9-15 \% .5,4$ Early intervention and psychological treatment is extremely vital in order to help prevent possible suicidal ideology and the later development of more severe psychological problems. ${ }^{5}$

Adjustment problems and homesickness are common concerns among students across universities. Adjustment problems have been associated with increased psychological distress that can generate symptoms of depression, anxiety, somatic distress, and low self-esteem. ${ }^{2}$ Researchers discovered that freshmen and transfer students are most prone to struggle with homesickness and 
adjustment. ${ }^{2}$ According to another study, cultural differences contribute to difficulties in adjustment. ${ }^{6}$ For international students, homesickness is more common and intense in comparison to other students. Moreover, these students tend to attend counseling services at lower rates than American students and are also less likely to return after the initial intake session. ${ }^{6}$ Researchers continue that adjustment concerns are a significant predictor of retention rates. ${ }^{6}$

Problems related to social and emotional adjustment were the most important determinant for predicting future college retention. ${ }^{2}$ Students who partake in counseling services have higher rates of college retention than students who do not. In fact, in a study with 10,009 college freshman and transfer students, seventy-nine percent of those who participated in counseling services designed to improve academic performance and retention remained enrolled the university for at least another four semesters. ${ }^{2}$ However, the study found that the services did not have a direct relationship with academic performance. ${ }^{2}$ It should be noted that these findings cannot be generalized to the entirety of counseling services as they were specifically designed to increase academic performance and retention and did not have a broader role in the services offered. However, another study conducted by researchers found results in opposition to previous findings, highlighting the mixed nature of the research. ${ }^{7}$ This opposing study concluded that counseling services had a positive impact on academic performance, regardless of whether or not academic concerns were the presenting problem. ${ }^{7}$ Seventy-nine percent of 1,369 students in this study reported that seeking professional help influenced their decisions to remain in school when they had previously considered dropping out. Researchers found that counseling services led to improvement in academic motivation and class attendance, academic performance, and academic focus among students who reported adjustment difficulty. ${ }^{7}$ Moreover, women and commuters (students who do not live on campus) reported more positive changes in their emotional well-being after attending counseling compared to men and residents (students who lived on campus). ${ }^{7}$ These findings are consistent with similar research. ${ }^{5,2}$

Many university students are subject to increased responsibilities in their social, work, school, and home lives. ${ }^{3}$ It is not surprising, therefore, that anxiety affects between $38-55 \%$ of college students. ${ }^{4}$ Anxiety symptoms are often expressed as decreased energy, decreased concentration, and sleep disturbances. ${ }^{8}$ Common stressors include academic performance, financial needs, finding a romantic or intimate partner, fitting into social groups, and issues of separation and individuation from family of origin. ${ }^{1-3}$ Further stressors include the use or abuse of alcohol and drugs, engaging in unwanted sexual experiences, dealing with unwanted pregnancies, sexually transmitted diseases (STD), or eating disorders. These often lead to academic difficulties, relationship problems, or eventual dropping out of school. ${ }^{1}$ Moreover, there are differences in anxiety expressions and treatment habits among differing cultures.

Depression is the most common and prevalent psychological disorder among college students. ${ }^{3}$ It affects more than $12 \%$ of college students every year. ${ }^{4}$ Symptoms include anxiety, prolonged and intense sadness, anger, guilt, hopelessness, irritability, withdrawal, loss of interest, lack of concentration, problems falling asleep or too little or too much sleep, body aches, and thoughts of suicide or attempts. ${ }^{3}$ It further affects mood, social interactions and relationships, cognition, and the ability of the individual to cope with life's stressors. Depressive symptoms are correlated with poor academic performance, strained personal relationships, and decreased psychosocial well-being overall. ${ }^{3}$ These depressive symptoms greatly impact motivation and productivity, and often lead to sleep disturbances, reduced energy, and difficulty maintaining concentration. ${ }^{8}$ Often, depression is masked by college students through the use of drugs, alcohol, tobacco, and food, as well as unsafe sex, reckless driving, vandalism, and self-harm. ${ }^{3}$ Moreover, loneliness is associated with depression and poorer physical health. ${ }^{6}$ Next, social hopelessness can be defined as a negative cognitive thought pattern in relation to one's interpersonal relationships, such as fear of never fitting in or having intimacy with a significant other. Specifically, symptoms of social hopelessness are an important distinguisher between students at risk of suicide in comparison to general hopelessness. ${ }^{6}$ As these levels of social hopelessness decrease, the levels for personal commitment and expectations to improve in counseling increase. ${ }^{3}$

Views and expression of depression, as well as attitudes towards seeking professional help, differ among cultures. ${ }^{3}$ Differences occur between men and women. Women are more likely to have a greater understanding of depression and depressive symptoms than men. ${ }^{3}$ They have a more positive attitude toward seeking help when compared to men. Researchers found that women are twice as likely to suffer from depression as men though that could be related to their habits of seeking professional help. ${ }^{3}$ Finally, freshmen have a greater number of psychological problems than older students. ${ }^{1}$ This is often attributed to the difficulty associated with initial adjustment, both in a social and academic context. However, the suicide rate for college freshmen is substantially lower than the suicide rate for their cohorts that are currently not in school. ${ }^{1}$ In addition, an average of $28 \%$ of college freshman do not return for their sophomore year as compared to $33 \%$ of students who drop out before six years. ${ }^{9}$ For university students, the average rate of suicide is estimated to be about 6.5 to 7.5 per every 100,000 students, with 3.4 per every 
100,000 falling between the ages of 17 and 19.4, 10 It could be that college freshman are more likely to drop out when feeling stressed than they are to commit suicide. Next, research further shows that both anxiety and depression respond well to brief treatment interventions. ${ }^{8}$ However, for students who struggle with severe depression, brief treatment interventions are often not as effective. As the intensity of depression increases, the students' improvement in academic performance following treatment decreases. Often, anxiety and depression are comorbid disorders among college students and have been associated with decreased academic performance. The research also highlights that there is a strong positive correlation between clinical treatment and decreased academic distress. This correlation was strongest for students with depression $(b=0.53)$, generalized anxiety $(b=0.40)$, and social anxiety $(b=0.37) .{ }^{8}$ These correlations are encouraging; although, one cannot determine the direct causal relationship between treatment and levels of distress.

Research supports the high prevalence rates of psychological disorders among college students and the effectiveness of counseling interventions. However, many students continue not to use the services offered. Many research studies have investigated possible impediments to student counseling attendance. First, stigmas still exist. ${ }^{3}$ They can be divided into a public-or self-stigma. ${ }^{11} \mathrm{~A}$ public-stigma is how the general public acts upon a stereotyped belief; whereas, a self-stigma is the internalization of a belief by an individual and how they act upon a stereotype. Stigmas are further defined as the general populations' negative attitude toward a specific psychological disorder, toward counseling services, toward individuals who have a psychological disorder, or in relation toward seeking treatment. ${ }^{3}$ Most often, these perceived stigmas or discriminations toward psychological disorders are created by the views of family and friends. ${ }^{3}$ If individuals perceive there to be stigmas, they are less likely to seek counseling services. This self-labeling that occurs due to stigmas has been associated with lower self-esteem and decreased levels of hope. ${ }^{3}$ Self-stigmas are often generated from the public-stigma and become a driving factor of the individual's thoughts. As these negative publicstigmas increase, the self-stigmas increase, resulting in a decrease of the attitudes related to seeking help. ${ }^{11}$

In addition, social influence is an important factor in the difficult decision-making process related to seeking professional help. Encouragement from family or peers increases the likelihood of the student's willingness to seek professional treatment. ${ }^{11}$ Studies show that young adults often consult with their social circles before making the final decision to attend counseling services. ${ }^{3}$ In fact, in most cases, friends are the first people who the student approaches for advice, followed by parents, faculty, and psychological services. ${ }^{12}$ A more recent study supports this finding, determining that college students tended to disclose more information to those to whom they felt close and did not disclose information when they felt that they would be misunderstood or judged. ${ }^{13}$

A significant amount of the research conducted in the last few years supports the correlation between counseling services and improved overall health. Students who attend counseling often report higher levels of social, academic, and emotional adjustment, and are more likely to graduate in six years than students who have not (with increased odds by a factor of three). ${ }^{4}$ These students also report gains in intrapersonal skills. ${ }^{7}$ Further changes include healthier lifestyles, increased understanding of one's identity, improvements in self-esteem and confidence, better critical thinking skills, and improvements in stress management and communication skills. Overall, students who use counseling services report significant reductions in severity of mental health symptoms and improvement in both personal and academic functioning. ${ }^{7}$ Brief treatment practices on university campuses are effective at treating high levels of generalized anxiety, social anxiety, eating concerns, hostility, and substance abuse and supports findings of increased retention rates among students who use counseling services. ${ }^{8}$

The opinion, attitude, and perception that a student has of counseling services are vital indicators of seeking treatment. ${ }^{12} \mathrm{~A}$ recent study found that if students have low expectations of either counseling or the outcomes, they are less likely to go to counseling. ${ }^{3}$ While many of the negative perceptions of counseling have diminished, students who tend to struggle with more severe psychological problems still avoid seeking treatment due to fear of diagnosis or alienation from peers. ${ }^{1,5}$ However, there have been mixed results; for students in general, the more serious the problem is, the more likely they are to seek services. ${ }^{11}$ Students further reported that they did not feel their issues were important enough or severe enough for treatment. ${ }^{12}$ To elaborate, many of the issues discussed are normal occurrences that a large proportion of students deal with. It is difficult to determine when they become a problem. For example, sleep disturbances are considered a normal happenstance as one out of three students suffer from regular and severe sleep problems. ${ }^{6}$ Sleep disturbance is second to stress in the negative impact it has on academic performance. Furthermore, related specifically to substance use, students tend to overestimate the drinking behaviors of their peers and are less likely to notice when someone else or they themselves need help. ${ }^{6}$ Researchers further reported that students also felt uncomfortable at the idea of counseling as well as the limitations of confidentiality that it would present, especially when students do not consider professionals to be competent. ${ }^{12,14}$ Men tend to have more negative attitudes toward seeking help from 
counseling services than women. ${ }^{9}$ Finally, some of the barriers surrounding counseling services and their continual lack of use include negative stigmas and a lack of understanding of psychological disorders as well as what services are offered. Researchers state that higher levels of mental health literacy among students on college campuses are equated with increased help-seeking attitudes and levels of acceptance and support among peers. ${ }^{3}$ Limitations to the above research include the sample size and participants, the generalizability to all university campuses, cultural diversity, and mental health literacy among students.

The present study was conducted to determine students' perceived effectiveness of counseling services at a Southeastern university while also generating common perceptions and knowledge about counseling services. Homesickness, overall adjustment, mood, depression, anxiety, demographic information, and academic performance were compared in students who had and had not attended counseling services. Stereotypes and stigmas were analyzed along with students' knowledge about counseling services. Gender and other cultural differences were also analyzed and correlated with the above-mentioned variables. The study also evaluated the effect of social influence on counseling attendance rates by assessing the means from which students learned about the services offered. It was hypothesized that students who had gone to counseling would report better mood overall, or improvement in mood, as well as a perceived increase in academic functioning when compared to students who had never gone to counseling. The researcher believes that differences in demographic information will appear between the two groups, and that stigmas may affect the participation rate of those who do not attend counseling.

- Research Question: The primary research question of interest in the study was whether or not college students that go to counseling services have better adjustment, mood, and academic performance than students who do not go to counseling.

- Hypothesis 1: It is predicted that students who have gone to counseling will report better overall mood or improvement in mood when compared to students that have never gone to counseling

- Hypothesis 2: It is predicted that students who have gone to counseling will report a perceived increase in academic functioning when compared to students that have never gone to counseling.

- Hypothesis 3: It is predicted there will be gender differences in overall mood and academic performance.

- Hypothesis 4: It is predicted that students who attend more counseling sessions will report more significant changes in overall mood than those that do not attend many sessions.

\section{METHOD AND PROCEDURES}

\section{Participants}

A campus-wide email was sent to all undergraduate students, receiving 277 responses. Approximately $20 \%$ of enrolled students participated in the survey. However, three responses were eliminated given one participant was under the age of 18 years and could legally not provide informed consent, and two other participants did not fully complete the survey $(\mathrm{N}=274)$. Fifty-four reported that they have gone or are currently going to counseling (20\%). Of those who participated, 79 were men (28.8\%) and 195 were women $(71.2 \%)$. The age of the participants ranged from 18-49, with the largest percentage being 19 years of age $(24.8 \%)$. Furthermore, the academic class of the participants was well distributed (Freshman $/ 1 \mathrm{st} \mathrm{Year}=28.8 \%$; Sophomore $=$ $21.2 \%$; Junior $=23.0 \%$; Senior $=21.9 \%$; and, Fifth Year $=5.1 \%$ ). Moreover, 53 students had majors in the Arts and Humanities (Art, History, English, Communication, Spanish, Missions and Ministry, Theater, Music and Journalism); 110 in the Sciences (Chemistry, Math, Physics, Biology, Public Health, Fitness and Sport Science, Exercise and Sports Science, and Health and Physical Education); 53 in Business (Accounting, Business Administration, and Information Technology); 54 in Education; 105 in the Social Sciences (Human Services, Psychology, Criminal Justice, and Political Science); and 6 in Other disciplines (5 Undecided and 1 Independent Directions Program). Many students indicated having double or triple majors. Ethnic diversity of the participants included 252 Caucasians (92\%), 13 African Americans (4.7\%), 6 Asians (2.2\%), and 9 Hispanic or Latino students $(3.3 \%)$, with some reporting to be of mixed race. Finally, the state or country in which the participants were from was compiled into geographical regions based on the census division. ${ }^{15}$ Two-hundred and fourteen students were from the South, with the largest regional group composing 193 participants in East South Central. Thirty students were from the Midwest, 12 were from the West, and 3 were from the Northeast. From the participant pool, 12 were International. Three responses were omitted as two provided their country of origin rather than region, and the other listed none.

\section{Materials}

Mood (including anxiety, depression, stress, and homesickness) and academic performance were measured using a survey that was constructed by the researcher for use in the present study (See Appendix A). This survey collected demographic information: age, race, major, academic year, home state, gender, barriers to seeking counseling, and the likelihood of counseling service attendance. 
Most of the demographic questions were forced choice. However, questions related to age, major, and home state/country of origin were open response. Next, there were two yes or no questions that determined the questions that followed. If participants had utilized counseling services currently or in the past through the Southeastern University or through another party, they responded to a Likert scale in relation to how their mood had improved or deteriorated since their attendance. They were also asked to report the range of the number of sessions they had attended. This range was determined after speaking with the Director of Behavioral Health, who stated that most students self-report improvement after three to seven sessions. If the respondent had not attended counseling, s/he skipped ahead to question 15, where s/he answered questions on a Likert Scale related to his/her levels of the differing emotions. Both Likert scales were on a scale from 1-5 and had instructions on the levels of functioning that each number represents. Afterward, all participants responded to questions about their academic performance. They selected one option from a limited number, which was given a scoring system, followed by a Likert scale for their satisfaction perception. The Cronbach's alpha for the 10 Likert scale items was 0.79 . The last question the participants were asked to complete was related to barriers to counseling. Students had a selection of options where they could choose any number of hindrances as well as add their own.

\section{Procedure}

After receiving approval to conduct the study by the Institutional Review Board, a campus-wide email was sent to all undergraduate students from the Dean of Undergraduate Studies. Students were asked to complete the survey by clicking on a link. The survey was created using Survey Monkey. The first screen that appeared displayed the informed consent form. Only those affirming informed consent could access the survey. Next, participants saw the first survey question. There was only one question on the screen at a time, except regarding demographic questions, and participants could not move on until the previous question had been answered. The first six questions were demographic, including age, gender, and race. The participants then continued on to the survey questions. They were asked if they had attended counseling services, either at a university while an undergraduate student or within a two-year time frame elsewhere. Depending on the answer, participants were directed to specific questions using a Likert scale to rate the features of mood. The researcher had no contact with the participants. The survey was available for the participants to complete at any convenient time during a 3-week time frame between midterm and final exams of the Fall semester. Once students had completed the survey, they submitted their responses, and nothing further was necessary. Finally, participants had the option to include their email to be entered into a drawing for the chance to win a $\$ 25$ Amazon gift card. A random selection was made by an online number random generator and the winner was notified and able to pick up the gift card at a designated campus office.

\section{RESULTS}

\section{Operational Definitions}

One variable of interest was whether the students have received counseling services either on campus or from an outside service. Other variables for this study were the differing moods, including stress, homesickness, anxiety, and depression, as well as the academic performance of the participants. Stress was operationally defined as a state of mental tension and worry/anxiety caused by problems in life related to work, school, etc. that can be exhibited as a physical force or pressure. ${ }^{16}$ Next, the operational definition for anxiety was characterized as a feeling of worry, nervousness, or unease, typically about an imminent event or something with an uncertain outcome. Depression was operationally defined as repeated feelings of sadness, significant weight loss or gain, lack of energy, inability to concentrate, feelings of worthlessness, and loss of interest. ${ }^{16}$ In addition, homesickness was operationally defined as the distress or anxiety caused by being separated from home. It was further characterized by feelings of longing due to separation from one's home environment or loved ones. ${ }^{17}$ Finally, academic performance satisfaction was defined as the extent to which a student has achieved their educational goals. ${ }^{8}$ Academic performance was defined as the grade point average (GPA) accumulated while at the university. Overall mood was defined as the students' rating of their current mood, taking into consideration their levels of anxiety, stress, homesickness, and depression. These variables were given a Likert scale rating (see Table 1). 


\begin{tabular}{|l|l|l|l|l|l|}
\hline Rating: & \multicolumn{1}{|c|}{$\mathbf{1}$} & \multicolumn{1}{c|}{$\mathbf{2}$} & \multicolumn{1}{c|}{$\mathbf{3}$} & \multicolumn{1}{c|}{$\mathbf{4}$} & \multicolumn{1}{c|}{$\mathbf{5}$} \\
\hline $\begin{array}{l}\text { Anxiety, Depression, Homesickness, } \\
\text { \& Stress for Counseling }\end{array}$ & $\begin{array}{l}\text { Significantly } \\
\text { Decreased }\end{array}$ & $\begin{array}{l}\text { Somewhat } \\
\text { Decreased }\end{array}$ & $\begin{array}{l}\text { Neutral/No } \\
\text { Change }\end{array}$ & $\begin{array}{l}\text { Somewhat } \\
\text { Increased }\end{array}$ & $\begin{array}{l}\text { Significantly } \\
\text { Increased }\end{array}$ \\
\hline $\begin{array}{l}\text { Anxiety, Depression, Homesickness, } \\
\text { \& Stress for No Counseling }\end{array}$ & None & $\begin{array}{l}\text { Below } \\
\text { Average }\end{array}$ & Average & $\begin{array}{l}\text { Above } \\
\text { Average }\end{array}$ & Very High \\
\hline Overall Mood & Very Poor & Poor & Acceptable & Good & Very Good \\
\hline Academic Performance Satisfaction & $\begin{array}{l}\text { Very } \\
\text { Dissatisfied }\end{array}$ & Dissatisfied & Neutral & Satisfied & Very Satisfied \\
\hline
\end{tabular}

Table 1: Rating scale measures for operational definitions.

\section{Counseling}

Students who had attended counseling rated perceived changes to their levels of anxiety, depression, stress, and homesickness on a Likert Scale, and the averages of the responses were analyzed. Responses of a two indicated somewhat decreased levels of the abovementioned moods; whereas, a three indicated no perceived change. A score of four, however, indicated somewhat increased levels of the differing moods. First, anxiety $(\mathrm{M}=2.58, \mathrm{SD}=0.94)$ was reported to have the largest decrease in levels compared to the other three variables (see Table 2). Scores tended to range from 1 to 4, indicating a wide range of scores that were considered to be the average response (see Figure 1). Typically, scores ranged between somewhat decreased to no perceived change in levels of anxiety. Stress and homesickness were slightly decreased $(\mathrm{M}=2.83, \mathrm{SD}=1.04 ; \mathrm{M}=2.83, \mathrm{SD}=0.88$ respectively). The majority of scores for stress ranged from 1 to 5 . Again, this is a wide range with some scores reflecting somewhat decreased levels in stress since attending counseling; whereas, others indicated a perception of significant increase. The average response places stress as only slightly decreased and close to no perceived change. Compared to anxiety, levels of stress had less decreased results. Homesickness scores typically ranged from 1 to 5 . Similar to stress, the results indicated very little decrease in levels of homesickness on average. The results typically indicate no perceived change. Finally, depression scores $(\mathrm{M}=2.63 ; \mathrm{SD}=1.07)$ typically ranged from 1 to 5 . Once more, this is a wide range with some scores reflecting somewhat decreased levels in depression as well as somewhat increased levels. On average, students reported no perceived change in their levels of depression.

\begin{tabular}{|l|c|c|c|}
\hline & N & M & SD \\
\hline Anxiety Level & 52 & 2.58 & 0.94 \\
\hline Depression Level & 54 & 2.63 & 1.07 \\
\hline Stress Level & 54 & 2.83 & 1.04 \\
\hline Homesickness Levels & 54 & 2.83 & 0.88 \\
\hline
\end{tabular}

Table 2: Means for counseling. $1=$ significantly decreased; $2=$ somewhat decreased; $3=$ no change; $4=$ somewhat increased; $5=$ significantly increased; $\mathrm{N}=$ number of participants; $\mathrm{M}=$ mean; $\mathrm{SD}=$ standard deviation.

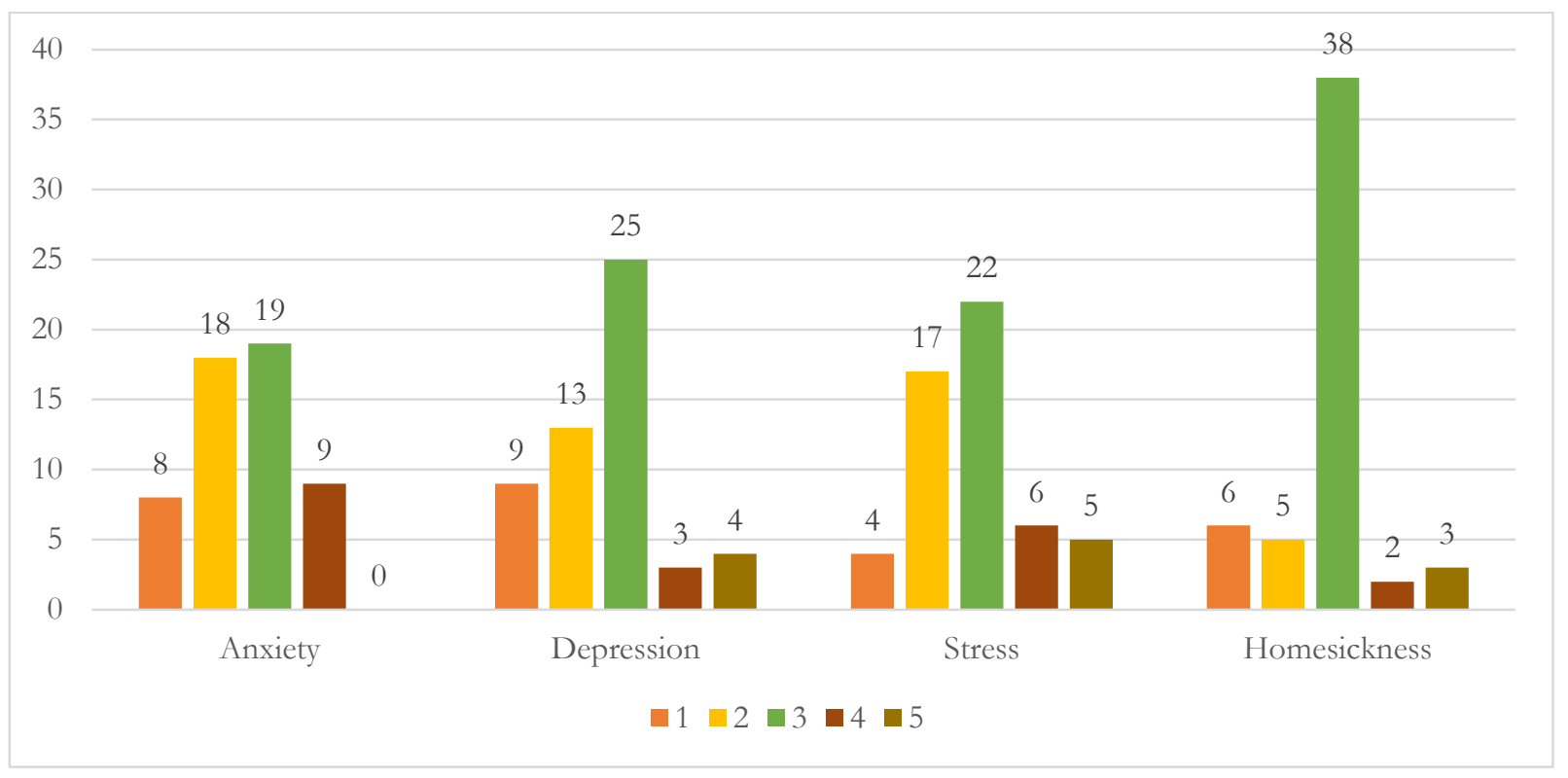

Figure 1: Frequency responses of Likert scale ratings by counseling attendance. 


\section{Non-Counseling}

Next, students who had never attended counseling also provided Likert scale ratings of their levels of anxiety, depression, stress, and homesickness which were also analyzed using the average response. In this case, a score of three indicated average levels of the differing moods listed above. A response of two conveyed below average levels and a four indicated above average levels of anxiety, depression, stress, and homesickness. First, anxiety level scores $(M=3.18, S D=1.03)$ ranged from 1 to 5 . Typically, anxiety levels ranged from below average to above average, although the majority of students had slightly higher than average levels of anxiety. Scores for depression levels $(M=2.53, S D=1.14)$ ranged from 1 to 5 (see Figure 2). Similar to anxiety, depression scores ranged from below average to only slightly above average. Typically, depression levels for students who do not attend counseling are below average. Stress $(\mathrm{M}=3.54, \mathrm{SD}=0.91)$ was reported to be the highest of the four differing levels of mood with an average response of above average. Scores typically ranged from 1 to 5 or ranged from average levels to slightly above average levels of stress. Finally, homesickness levels $(\mathrm{M}=2.25, \mathrm{SD}=1.08)$ were below average. Scores ranged from 1, or no homesickness, to 5, or very high levels of homesickness, with the majority of responses being average (see Table 3 ).

\begin{tabular}{|l|c|c|c|}
\hline & N & M & SD \\
\hline Anxiety Level & 216 & 3.19 & 1.03 \\
\hline Depression Level & 216 & 2.53 & 1.14 \\
\hline Stress Level & 216 & 3.56 & 0.91 \\
\hline Homesickness Levels & 216 & 2.25 & 1.08 \\
\hline
\end{tabular}

Table 3: Means for non-counseling. $1=$ none; $2=$ below average; $3=$ average; $4=$ above average; $5=$ very high. $\mathrm{N}=$ number of participants; $\mathrm{M}=$ mean; $\mathrm{SD}=$ standard deviation.

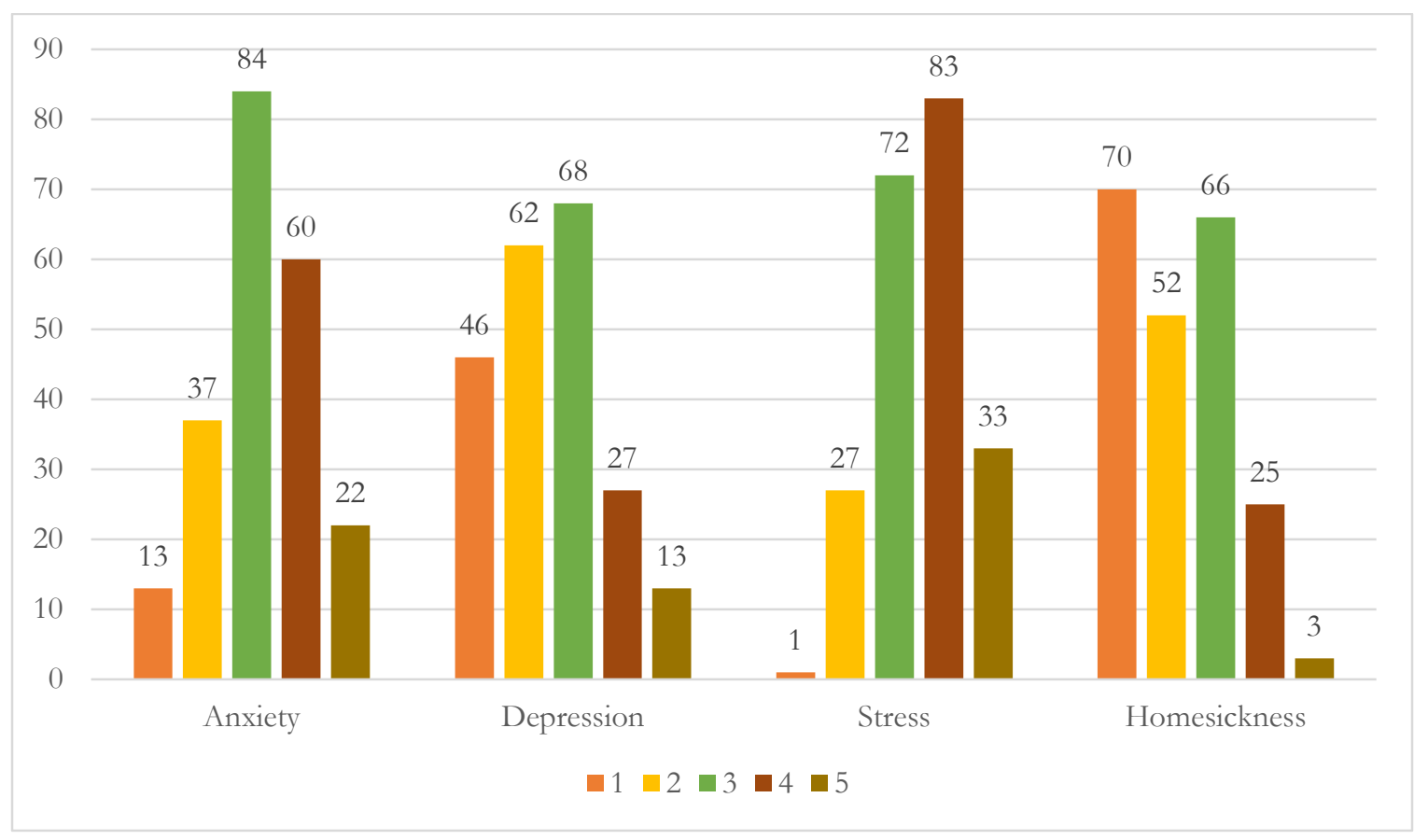

Figure 2: Frequency responses of Likert scale ratings by non-counseling attendance.

Overall Mood and Academic Performance Satisfaction

An independent samples t-test was conducted to compare the means of the responses to overall mood and academic performance satisfaction (see Table 4) between both students who had attended counseling previously with those who have never gone to counseling. However, neither overall $\operatorname{mood}[\mathrm{t}(267)=-1.66, \mathrm{p}=0.098 ; \mathrm{d}=0.26]$ nor academic performance satisfaction $[\mathrm{t}(264)=1.27, \mathrm{p}=0.204 ; \mathrm{d}=0.19]$ were significantly different between counseling $(\mathrm{M}=3.22, \mathrm{SD}=1.03 ; \mathrm{M}=3.85$, $\mathrm{SD}=0.95$ respectively) and non-counseling $(\mathrm{M}=3.48, \mathrm{SD}=0.97 ; \mathrm{M}=3.67, \mathrm{SD}=0.93$ respectively). 


\begin{tabular}{|l|c|c|c|c|c|c|}
\hline & \multicolumn{3}{|c|}{ Counseling } & \multicolumn{3}{c|}{ Non-Counseling } \\
\hline & N & M & SD & N & M & SD \\
\hline Overall Mood & 53 & 3.23 & 1.03 & 213 & 3.48 & 0.97 \\
\hline $\begin{array}{l}\text { Academic } \\
\text { Performance } \\
\text { Satisfaction }\end{array}$ & 53 & 3.85 & 0.95 & 213 & 3.67 & 0.93 \\
\end{tabular}

Table 4: Independent samples T-test to compare means between counseling and non-counseling attendance. For overall mood, $1=$ very poor; $2=$ poor; $3=$ acceptable; $4=$ good; $5=$ very good. For academic performance satisfaction, $1=$ very dissatisfied; $2=$ dissatisfied; $3=$ neutral; $4=$ satisfied;

Gender $5=$ very satisfied.

A second independent samples t-test was conducted to compare the means of the responses to anxiety levels, depression levels, stress levels, homesickness levels, overall mood, and academic performance satisfaction between men and women students whether or not they have attended counseling previously (see Table 5). The factor of anxiety level was determined to be significant $[\mathrm{t}(266)=-4.47, \mathrm{p}=0.001 ; \mathrm{d}=0.60]$ between men $(\mathrm{M}=2.65, \mathrm{SD}=1.00)$ and women $(\mathrm{M}=3.25, \mathrm{SD}=1.00)$. Depression levels were also determined to be significant $[\mathrm{t}(268)=-1.99, \mathrm{p}=0.048 ; \mathrm{d}=0.28]$ between men $(\mathrm{M}=2.34, \mathrm{SD}=0.99)$ and women $(M=2.64, S D=1.16)$. Another significant result was for the variable of stress levels $[t(268)=-3.55, p=0.001 ; d=0.47] b e t w e e n$ men $(\mathrm{M}=3.09, \mathrm{SD}=0.95)$ and women $(\mathrm{M}=3.54, \mathrm{SD}=0.97)$. The levels of homesickness also had significant differences between the sexes $[\mathrm{t}(268)=-2.83, \mathrm{p}=0.005 ; \mathrm{d}=0.38]$ of men $(\mathrm{M}=2.09, \mathrm{SD}=1.10)$ and women $(\mathrm{M}=2.49, \mathrm{SD}=1.03)$. Next, overall mood was indicated to be significant $[\mathrm{t}(176.39)=4.90, \mathrm{p}=0.001 ; \mathrm{d}=0.63]$ between men $(\mathrm{M}=3.84, \mathrm{SD}=0.82)$ and women $(\mathrm{M}=1.00, \mathrm{SD}=1.00)$. Finally, academic performance satisfaction was significant $[\mathrm{t}(264)=-2.15, \mathrm{p}=0.036 ; \mathrm{d}=0.29]$ between men $(\mathrm{M}=3.51, \mathrm{SD}=0.95)$ and women $(\mathrm{M}=0.92, \mathrm{SD}=0.92)$.

\begin{tabular}{|l|c|c|c|c|c|c|}
\hline & \multicolumn{2}{|c|}{ Men } & \multicolumn{2}{c|}{ Women } \\
\hline & N & M & SD & N & M & SD \\
\hline Anxiety Levels & 79 & 2.65 & 1.00 & 189 & 3.25 & 1.00 \\
\hline Depression Levels & 79 & 2.34 & 0.99 & 191 & 2.64 & 1.16 \\
\hline Stress Levels & 79 & 3.09 & 0.95 & 191 & 3.54 & 0.97 \\
\hline $\begin{array}{l}\text { Homesickness } \\
\text { Levels }\end{array}$ & 79 & 2.09 & 1.10 & 191 & 2.49 & 1.03 \\
\hline Overall Mood & 79 & 3.84 & 0.82 & 190 & 3.26 & 1.00 \\
\hline $\begin{array}{l}\text { Academic } \\
\text { Performance } \\
\text { Satisfaction }\end{array}$ & 78 & 3.51 & 0.95 & 188 & 3.78 & 0.92 \\
\hline
\end{tabular}

Table 5: Independent samples T-test to compare means between men and women. For the differing levels of mood:1= none; $2=$ below average; $3=$ average; $4=$ above average; $5=$ very high. For overall mood: $1=$ very poor; $2=$ poor; $3=$ acceptable; $4=$ good; $5=$ very good. For academic performance satisfaction: $1=$ very dissatisfied; $2=$ dissatisfied; $3=$ neutral; $4=$ satisfied; $5=$ very satisfied. $\mathrm{N}=$ number of participants; $\mathrm{M}=$ mean; $\mathrm{SD}=$ standard deviation.

\section{Counseling Attendance Based on Sessions}

While not initially part of the study, the opportunity presented itself to delve deeper into the counseling group to evaluate the perceived effectiveness of the differing attendance of counseling services. A third independent samples t-test was used to evaluate the means of the differing levels of anxiety, depression, stress, and homesickness between students who had attended counseling. These students were grouped by the number of counseling sessions that they had attended (see Table 6). Based on frequency results revealing nearly half the distribution had attended 6 or more sessions, the participants were divided into two groups: $1-5$ sessions and 6 and more sessions (see Table 7).

\begin{tabular}{|l|c|c|c|c|c|c|}
\hline & \multicolumn{3}{|c|}{ 1-5 Sessions } & \multicolumn{3}{c|}{ 6 or more Sessions } \\
\hline & N & M & SD & N & M & SD \\
\hline Anxiety Levels & 27 & 2.89 & 0.89 & 27 & 2.19 & 0.88 \\
\hline Depression Levels & 27 & 3.15 & 0.82 & 27 & 2.11 & 1.05 \\
\hline Stress Levels & 27 & 3.11 & 1.12 & 27 & 2.56 & 0.89 \\
\hline $\begin{array}{l}\text { Homesickness } \\
\text { Levels }\end{array}$ & 27 & 2.93 & 0.78 & 27 & 2.74 & 0.98 \\
\hline
\end{tabular}

Table 6: Independent samples $T$-test to compare means between sessions. $1=$ significantly decreased; $2=$ somewhat decreased; $3=$ no change; $4=$ somewhat increased; $5=$ significantly increased. $\mathrm{N}=$ number of participants; $\mathrm{M}=$ mean; $\mathrm{SD}=$ standard deviation. 
Anxiety levels were significant $[\mathrm{t}(52)=2.92, \mathrm{p}=0.005 ; \mathrm{d}=0.79]$ between students who had attended $1-5$ sessions $(\mathrm{M}=2.89$, $\mathrm{SD}=0.89)$ and those who had gone to 6 sessions or more $(\mathrm{M}=2.19, \mathrm{SD}=0.88)$. Next, depression levels were significant $[\mathrm{t}(52)=4.05, \mathrm{p}=0.001 ; \mathrm{d}=1.10]$ between the $1-5$ session group $(\mathrm{M}=3.15, \mathrm{SD}=0.82)$ and the 6 and greater group $(\mathrm{M}=2.11$, $\mathrm{SD}=1.05)$. Finally, the results indicated that the levels of stress were also significant $[\mathrm{t}(52)=2.02, \mathrm{p}=0.049 ; \mathrm{d}=0.54] \mathrm{between}$ participants who had gone to $1-5$ sessions $(M=3.11, S D=1.12)$ and those who had gone to 6 or more sessions $(M=2.56$, $\mathrm{SD}=0.89)$. However, the levels of homesickness were not significant $[\mathrm{t}(52)=0.77, \mathrm{p}=0.447 ; \mathrm{d}=0.21]$ between the two groups $(\mathrm{M}=2.93, \mathrm{SD}=0.78 ; \mathrm{M}=2.74, \mathrm{SD}=0.98$, respectively).

\begin{tabular}{|l|c|c|c|}
\hline & Frequency & Percent & Cumulative Percent \\
\hline 1-2 Sessions & 20 & 7.3 & 34.5 \\
\hline 3-5 Sessions & 10 & 3.6 & 51.7 \\
\hline 6-9 Sessions & 13 & 4.7 & 74.1 \\
\hline 10 or more sessions & 15 & 5.5 & 100.0 \\
\hline
\end{tabular}

Pearson Correlation

A Pearson correlation analysis was completed among all participants, those that had attended and had not attended counseling, between the variables of age, academic class (e.g. Freshman, Sophomore, Junior, Senior, and Fifth year), gender, race, academic performance satisfaction, geographical states, geographical regions, students' first, second, and/or third major(s), overall mood, academic performance based on GPA, and counseling/non-counseling. Not surprisingly, results of the correlation indicated that there was a significantly moderate and positive association between age and academic class $[\mathrm{r}(274)=0.486, \mathrm{p}=0.001]$. The correlation analysis also found a weak and positive relationship between the variables of academic class and academic performance satisfaction to be significant $[\mathrm{r}(266)=0.125, \mathrm{p}=0.042]$. There was a significant weak and negative correlation between academic class and major $[\mathrm{r}(274)=-0.125, \mathrm{p}=0.038)]$. The variable of gender correlated weakly according to the results of the Pearson correlation with the variables of academic satisfaction $[\mathrm{r}(266)=0.131, \mathrm{p}=0.032]$ and overall $\operatorname{mood}[\mathrm{r}(269)=-0.267$, $\mathrm{p}=0.001]$. While the direction of the relationship between gender and overall mood was negative, the results indicated a positive correlation between gender and geographical states $[\mathrm{r}(259)=0.137, \mathrm{p}=0.028]$, and gender and academic satisfaction. However, the Pearson correlation results indicated a weak and negative correlation between race and academic performance satisfaction $[\mathrm{r}(266)=-0.127, \mathrm{p}=0.038]$. Finally, the results indicated a weak and positive correlation between academic performance satisfaction and overall mood $[\mathrm{r}(266)=0.128, \mathrm{p}=0.036]$, and a moderate and positive relationship between academic performance satisfaction and academic performance based on GPA $[\mathrm{r}(266)=0.541, \mathrm{p}=0.001]$. To be noted, no significant correlation coefficient occurred between any of the variables and counseling/non-counseling.

\section{Methods of Receiving Information}

Participants were asked to respond to three qualitative measures of data. The first asked for student awareness of free counseling services offered at the university. Students responded to a fixed response of "yes" or "no" before having the opportunity to elaborate on their response. Of the 274 participants who responded, 211 (77.01\%) had heard of the services, while 63 (22.99\%) stated that they were unaware that such services were offered. Two-hundred and eighteen participants elaborated on how they learned of the services, and these responses were then coded between two observers into one of seven categories (with a strong interrater reliability of $77.78 \%$; see Chart 1 ). The coders were given the list of responses and then grouped similar responses, providing a title with no interaction between them. The largest proportion of participants stated that they had learned of the services through advertisement, including pamphlets, flyers, emails, and memos in the resident halls $(\mathrm{N}=67)$. Fifty-five of the respondents stated that they were informed from informational settings or events, such as freshman or resident assistant orientation, resource fairs, and engage events among others. Nonprofessional relationships, such as peers, friends, or word of mouth, were other popular means of sharing information $(\mathrm{N}=54)$. Professional relationships followed $(\mathrm{N}=52)$ : teachers, Student Services, coaches, resident assistants, and peer leaders. Twenty-two participants responded that they heard about the counseling services on campus from the school website, 6 participants are attendees, and 9 were categorized as other. 


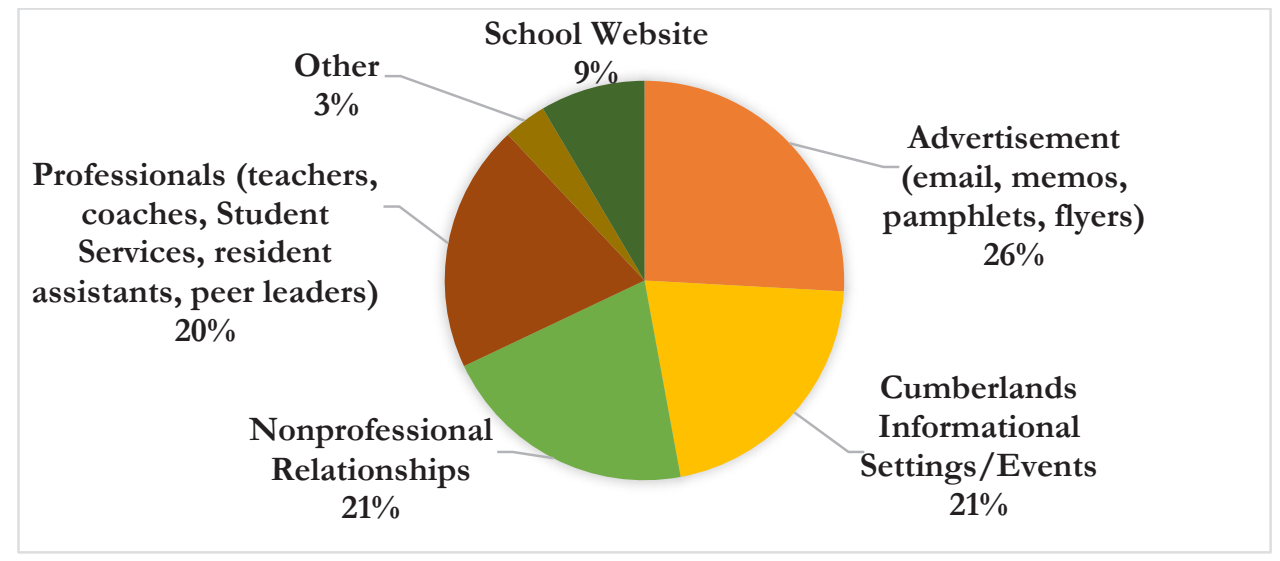

Chart 1: Methods of receiving information.

Reasons Why Students Would Not Attend Counseling

Moreover, participants were asked to choose the reasons why they might not attend counseling in a forced choice question, but also had the option of creating a response of their own (See Appendix A). An analysis of the open-ended responses between two independent raters (interrater agreement $=80 \%$ ) revealed five themes of responses (see Chart 2). The most frequent response to impediments to seeking counseling was related to students not having enough time, or having a busy schedule $(\mathrm{N}=169)$. The next largest response $(\mathrm{N}=82)$ was that students would attend counseling. To be noted, participants were also asked previously to rate their likelihood of counseling attendance on a scale of 1-5, with 1 being very unlikely, 2 being unlikely, 3 being undecided, 4 being likely, and 5 being very likely. Of the 269 participants who responded to the question, 18.59\% stated that they were very unlikely to attend, $27.51 \%$ rated their attendance as unlikely, $33.83 \%$ chose undecided, $13.38 \%$ responded with likely, and $6.69 \%$ stated that their attendance was very likely. Such results need to be considered alongside the 17\% who responded that they would attend counseling in a later question. Moreover, fear of judgment was a frequent concern $(\mathrm{N}=70)$, followed by confidentiality worries $(\mathrm{N}=33)$, unawareness of services $(\mathrm{N}=28)$, and misconceptions or beliefs of "couch" therapy, or the stigma often associated with services $(\mathrm{N}=27)$. Next, participants stated that they would not attend due to counselor unavailability $(\mathrm{N}=16)$ or due to a perception of specific problems within the program $(\mathrm{N}=9)$. Such problems included negative previous experiences and misunderstandings. Other barriers to seeking counseling included cultural/language barrier $(\mathrm{N}=5)$, participants already having a support system $(\mathrm{N}=4)$, or other $(\mathrm{N}=2)$.

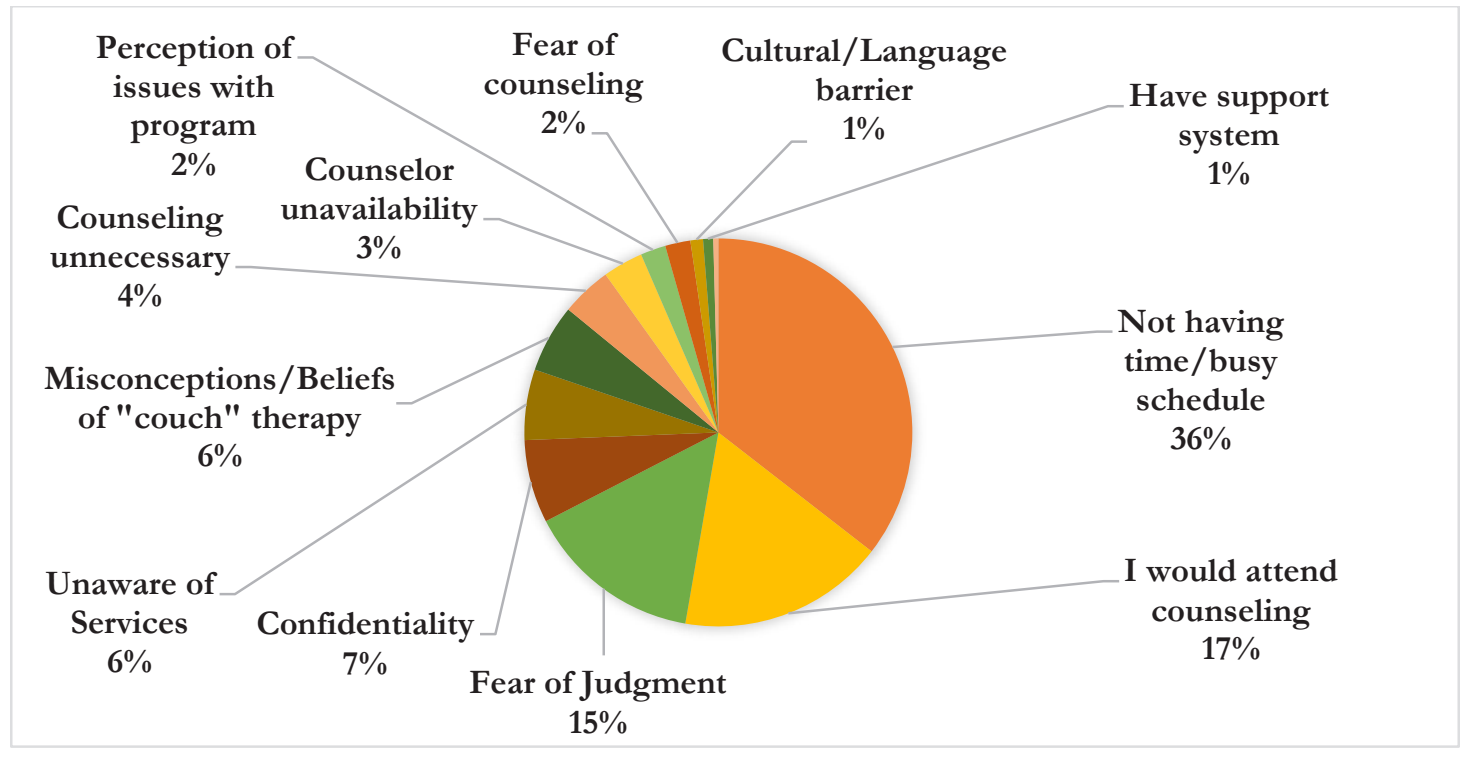

Chart 2: Reasons students would not attend counseling. 


\section{DISCUSSION}

\section{Gender Differences}

The purpose of this study was to evaluate participants' reported scores on their perceived levels of mood and academic performance between those who had and those who had not gone to counseling. A large amount of research has been conducted on the effectiveness of counseling services in the treatment of college students' depression, anxiety, stress, and homesickness. In fact, depression is one of the most prevalent concerns among students, with women reporting more depression than men. ${ }^{3}$ Similar results were obtained in this experiment as women reported higher levels of depression. However, past research has found counseling to be effective in reducing depressive symptoms. ${ }^{3}$ Such results were not universally supported in this study, as the students who had attended counseling reported no significant perceived changes in their levels of depression since receiving services; although, those students who had gone to six or more sessions did report more significantly decreased levels. Students who had not gone to counseling reported lower than average levels of depression. Moreover, women also reported higher levels of anxiety, stress, and homesickness than men did. Past research has shown that men tend to report more positive emotional well-being than women. ${ }^{7}$ This study found similar results as men reported more positive overall moods than women. Finally, in the comparison between men and women, the results indicated that women reported more satisfaction with their academic performance.

\section{Perceived Effectiveness and Relationship of Counseling}

Overall, much research supports that counseling attendance has led to improvement in academic focus and motivation. ${ }^{7}$ While similar results were expected, such conclusions did not seem to be supported by the present research. Counseling services did not seem to have any perceived effect, either positive or negative, on the levels of homesickness. Participants reported no perceived change in their homesickness levels no matter their counseling attendance length, and while past research has found homesickness to be of great concern for many college students, the non-counseling group reported below average levels of homesickness and did not seem to be in need of services. ${ }^{6}$ This could indicate that students who have significantly high levels of homesickness typically do not remain at college past their first year. Future research could focus on homesickness to see if there is the possibility of such feelings to decrease naturally over time, indicating that treatment measures are not always necessary. Moreover, counseling did not seem to have a relationship in either increasing or decreasing students' reported stress levels for those who attended less than 6 counseling sessions. For those who completed 6 or more sessions, counseling did lead to reported decreased levels of stress. Similar to homesickness, students who have never gone to counseling reported only slightly higher than average levels of stress, rendering no need for assistance. Such higher than average levels of stress could be attributed to scheduling of the survey between midterms and finals. This final portion of the semester can involve multiple projects and assignments coming due, which can be quite stressful to students.

Participants who did not attend counseling reported levels of anxiety that were only slightly higher than average, but lower than above average, indicating the perception that there was no pressing need for services. Again, this in large part could be attributed to the timing of the survey. The students who went to counseling reported little perceived change in their anxiety levels. Overall, the portion of the sample that had never attended counseling seemed to be rather healthy and had limited perceived need to attend counseling. However, those students who sought counseling for less than 5 sessions report no perceived improvements, which could bring into question the relationship of the services offered and the length of time treatment, or that some students may be unwilling or unable to adhere to a lengthier counseling process, although this cannot be gathered in certainty in the present study. Future studies could look more in-depth at the length of counseling service attendance. Much of the open response data touched on student perception of a number of different issues about the counseling program. For instance, most college students do not disclose information when they feel they will be misunderstood or judged. ${ }^{13}$ Qualitative data from the present study highlighted much mistrust among many students: students stated that they would not attend for fear of judgment from peers or family; concerns of not being taken seriously as having a need; and, fears of scaring counselors.

Stigmas also exist and affect student attendance and potential intervention effects. ${ }^{3}$ Students expressed a need to eliminate the stigma of counseling being equated with an individual as having a problem, recognizing it as a hindrance to attendance. Perceived stigmas were reasons that some would not seek counseling and were also expressed as a need to be overcome in considerations of improvements of the counseling program on the university campus. Many of the statements illustrated misunderstandings of what actually happens during a counseling session, which could be remedied by providing better information. Students expressed the importance of counseling, but also focused on many issues perceived as hindrances to effective treatment. The lower the expectations that students have for the effectiveness of counseling, the less likely they are to seek professional help. ${ }^{3}$ Similar 
results were found in the qualitative data as many students who had previously attended stopped going after less than six sessions due to a number of different factors such as schedule conflicts, perceived judgment, and perceived problems with counselors.

Students who attended six or more sessions reported significantly perceived decreased scores on anxiety, stress, and depression than did students who attended five or fewer sessions. Homesickness was not found to be significantly different between the two groups based on length of counseling attendance. The students who only attended one to five sessions of counseling tended to report no perceived change in their levels of anxiety, stress, and depression. The longer the student was in counseling, the more perceived changes that occurred and, thus, the more effective counseling was perceived to be. Unfortunately, based on participant comments, many students reported negative experiences or feeling worse rather than better after meeting with a counselor. Many felt that counseling did not help and did not return for further sessions. Importantly, students reported that a common means of communication among them is through word of mouth from peers and friends. As such, many perceptions about the services could be spread by the student body in a very negative way based on students' previous experience. Students who have had negative experiences share it with peers, as evidenced in many of the comments in response to why students would not attend counseling. Most students also consult social circles before going to counseling. ${ }^{3}$ Similar results were found in this study as some students stated that they would not attend counseling because they feel that they have a sufficient support system.

\section{Correlational Interpretations}

Results of the study also indicated a weak relationship between academic class and academic performance satisfaction. The results suggest that the longer the student has been in college, the more likely s/he is to be satisfied with his/her grade point average (GPA). However, this correlation is rather weak and indicates that other factors could impact their satisfaction with their GPA. Future research could focus on such factors, exploring possible confounds such as emotional development and academic expectations. In other words, older students are more aware of what to expect from their classes and are more emotionally and cognitively mature than younger students. Another relatively weak correlation suggests that women tended to be more satisfied with their academic performance than men. These findings support previous findings with self-report measures. Again, the relationship between gender and academic performance satisfaction was rather weak, indicating the need for further research on other factors that could impact satisfaction. In addition, another weak relationship indicated that women tend to have more negative overall moods than men which does support previous findings. Once more, additional research is necessary to see what other factors could also impact the variable of overall mood. Next, White students seemed to have the greatest academic performance satisfaction, followed by African Americans, Asians, Latinos, and those of mixed race. However, the relationship is very weak and the majority of the sample size was White. The survey did not sample a large enough minority group to reasonably determine the strength of the relationship. There is a need for further studies to corroborate such data. Additionally, academic performance satisfaction is a small factor in determining overall mood. Again, such a relationship is weak and future research could focus on other impacting factors. Finally, as GPA increases, so too does a students' academic performance satisfaction. GPA moderately impacts satisfaction, and thus, GPA also affects overall mood. Further research is necessary to completely understand the relationship between GPA and overall mood however.

Research in the past has found a correlation between counseling services and overall mood. ${ }^{4}$ While similar results were expected, they were not found. Counseling was not correlated with overall mood, academic performance, or any of the demographic information. In other words, one demographically comparable group of students was not more likely to go to counseling than another. For example, a student's major, and whether it is predominantly human service based or science based, did not determine whether the student was more likely to go to counseling. Moreover, women were not more likely to attend over men, students from the United States were not more likely to attend over international students, and a certain race was not more likely to attend counseling than another, among many other variables. Such data indicates the universality of acceptance of counseling services, most specifically on campus. One specific group of students is not more likely to attend than a different group, highlighting the larger acceptance of counseling as a whole. Many of the comments stated that students would attend counseling if they felt that there was a need. The services offered are not specific to one population of student, which is very encouraging given students from all backgrounds seem to be neither more nor less likely to attend based on a specific demographic variable.

Finally, the likelihood of student attendance differed on two different questions. The first was a Likert scale for the likelihood of counseling attendance. The majority of respondents stated that they were very unlikely or unlikely to attend. However, when students were later asked to respond to the question on possible impediments to counseling attendance, a large percent stated that they would attend counseling as no other variables impacted their decision. Many respondents even stated that they had no problems with counseling, and would go if they felt it necessary. As indicated by early discussion, many of the students who went 
to counseling report average levels of homesickness, stress, depression, and anxiety. The population is relatively healthy, but many are not opposed to seeking counseling if they felt it necessary. However, many perceived barriers should be addressed first. Many indicated that they would not attend due to counselor unavailability. Overall, students are very aware of the services offered and are not completely opposed to counseling.

\section{Potential Confounds and Limitations}

The reliability of self-reported scores as to the effectiveness of counseling needs to be considered. It is possible that students who have gone to counseling may not understand themselves well enough to notice any possible improvements or deterioration. A student's perception is his/her reality and his/her understanding of his/her anxiety, stress, homesickness, and depression is subject to personal interpretation. The survey asked for subjective responses on the levels of the differing variables of mood (stress, depression, anxiety, and homesickness) which are based on the interpretation and understanding of the rater. To illustrate, one student may not handle anxiety as well as another, rating it as much stronger than another might. Finally, another limitation is that students may not accurately, nor truthfully, report their levels of mood, which typically tend to fluctuate. Other potential confounds include the possibility that students with a strong opinion, either negative or positive, toward the counseling department might have been more likely to respond to the survey than students who had more positive, or more neutral experiences. The survey was given towards the latter half of the Fall semester. For example, it is possible that students may have been more overwhelmed by their responsibilities, generating higher, but temporary, levels of stress. It is possible that at this point of the semester, students do not feel as homesick, since they have had the opportunity to make friends and create healthier relationships with other students and faculty.

While careful considerations were taken, there are always limitations or extraneous variables that could have had an effect on the results revealed in this study. First, the sample size was rather small and limited to students from a smaller, Southeastern, faithbased university. Most of the students were born in the United States, and while a number of different states were represented, the vast majority was from the Southeast. Moreover, the sample size included a larger proportion of women than men and the White race was overly represented. While such results may be representative of the attending undergraduate population at this Southeastern University, the results do not have much external validity as it cannot be generalized to the population outside of campus. Two possible threats to internal validity that have been noted are selection, as only a select and interested group may have responded to the survey, and demand characteristics, as the participants may have responded in manners that they believe they should have. For example, students who have gone to counseling may inflate their overall improvement scores with the belief that they should feel better, and thus, respond accordingly. To address these problems, the study could be replicated at other colleges and universities using a larger and more diverse sample. Other limitations included self-selection bias, as students chose whether or not to participate, and retrospective reporting. Further, there was no confirmation of counseling attendance, thus, students could have falsely reported their previous counseling history. Importantly, the study used non-valid assessment measures in the assessment of the variables.

\section{Future Directions}

Overall, previous research supports the effectiveness of counseling services for college students. Moreover, college students today are reported to have increased rates of anxiety and depression in comparison to previous cohorts, while the number of those students who seek professional help remains constant. These trends highlight the importance of counseling service centers on campuses. Understanding student concerns and possible impediments to counseling attendance could help create effective means of increasing student attendance rates. The findings from this study highlight the importance of educating students on available services and minimizing potential barriers when students need to seek counseling. This study also suggests students could benefit from multiple counseling sessions when addressing symptoms of anxiety, stress, and depression. Future research is warranted on strategies to promote regular counseling attendance by college students when needed. Given the potential benefit of counseling services to the well-being of college students, the best practices for advertising and delivering these services must be understood.

\section{ACKNOWLEDGMENTS}

The author thanks Dr. Eric Stephens for critical suggestions and edits to the content of this manuscript, as well as Dr. Haley Turner, Dr. Jane Whitaker, Dr. Dennis Trickett, and Dr. Kiersten Baughman for their editorial suggestions to the manuscript, and their support throughout the research process. I also thank the University of the Cumberlands' students for making this study a success. 


\section{REFERENCES}

1. Francis, P. C. (2016). Counseling issues in college students. In I. Marini, M. A. Stebnicki (Eds.), The professional counselor's desk reference, 2nd ed. (pp. 483-487).

2. Lee, D., Olson, E. A., Locke, B., Michelson, S. T., Odes, E. (2009). The effects of college counseling services on academic performance and retention. Journal of College Student Development, 50(3), 305-319. The Johns Hopkins University Press.

3. D’Amico, N., Mechling, B., Kemppainen, J., Ahern, N. R., \& Lee, J. (2016). American college students' views on depression and utilization of on-campus counseling services. Journal of the American Psychiatric Nurses Association, 22(4), 302-311. doi: 10.1177/1078390316648777.

4. Francis, P. C., Horn, A. S., \& Midwestern Higher Education (2016). Counseling-based practices for promoting student success: Counseling services. Research brief. Midwestern Higher Education Compact.

5. Kim, J. E., Park, S. S., La, A., Chang, J., \& Zane, N. (2016). Counseling services for Asian, Latino/a and White American students: Initial severity, session attendance, and outcome. Cultural Diversity and Ethnic Minority Psychology, 22(3), 299-310. doi: $10.1037 / \mathrm{cdp} 0000069$

6. Iarovici, D. (2014). Mental Health issues and the University Student. Retrieved from EBSCOhost.

7. Winterrowd, E., Priniski, S. J., Achter, J., \& Abhold, J.J. (2016). Correlates of satisfaction, intrapersonal learning, and academic outcomes at counseling centers in a university system. College Student Journal, 50(2), 288-301.

8. Kharas, K. E. (2015). College counseling center treatment outcomes: Examining the relationship between clinical improvement and academic function. Dissertation Abstracts International, 76(5-B)(E).

9. National Center for Education Statistics. (2017, April). The Condition of Education-Postsecondary Education-Programs, Courses, and Completions-Undergraduate Retention and Graduation Rates-Indicator April (2017). Retrieved from https://nces.ed.gov/programs/coe/indicator_ctr.asp

10. Neumann University. (2002). National Data on Campus Suicide and Depression. Retrieved from https://www.neumann.edu/life/counseling/mental_health/suicide/national_data.htm

11. Hoey, S. (2015). College students and help-seeking behavior: How students make the final decision to seek counseling services. Dissertation Abstracts International, 76(5-B)(E).

12. Snyder, J. F., Hill, C. E., \& Derksen, T. P. (1972). Why some students do not use university counseling facilities. Journal of Counseling Psychology, 19(4), 263-268. doi: 10.1037/h0033075.

13. Satterwhite, D. B., Lauer, M., Bakaeva, G., \& Hill, C. E. (2015). Disclosure and nondisclosure about being in counseling. Counseling Psychology Quarterly, 30(2), 115-133. doi: 10.1080/09515070.2016.1158154.

14. Wants, R. A., \& Firmin, M. (2011). Perceptions of professional counselors: Survey of college student views. The Professional Counselor, 1(1), 71-81. doi:10.15241/raw.1.1.71

15. U.S. Census Bureau. (2017). Census Bureau regions and divisions with state FIPS codes. Retrieved from www2.census.gov

16. Gerrig, R. J. \& Zimbardo, P. G. (2002). Psychology and life (16th ed.). Boston, MA: Allyn \& Bacon. Retrieved from http://www.apa.org/research/action/glossary.aspx?tab=2.

17. Terry, M. L, Leary, M. R., \& Mehta, S. (2012). Self-compassion as a buffer against homesickness, depression, and dissatisfaction in the transition to college. Self and Identity (1), 1-13. doi: 10.1080/15298868.2012.667913. 


\section{ABOUT STUDENT AUTHOR}

Morgan Huenergarde worked on this project during her junior year at the University of the Cumberlands. She will graduate in May of 2019 and intends to pursue a doctorate degree in Clinical Psychology the following year. Her goal is to become a licensed clinician, working with juveniles in the administration of assessments and evaluations.

\section{PRESS SUMMARY}

A lot of college students suffer from stress, anxiety, homesickness, and depression which may negatively impact their academic performance or daily lives. However, while such negative feelings are common, many college students do not seek professional help from campus counselors. Recent research supports the importance of counseling centers to help students address the abovementioned issues. The following study included college students at a Southeastern university who have attended counseling or are currently attending counseling through the services provided by the University, or from any outside service. Students who had also never attended counseling participated in the study. The research asked students to consider their varying levels of mood and academic performance, and then compared the responses between the two groups. To better understand students, the study also asked for demographic information and potential reasons why they would not attend counseling. It also focused on how students learned about services offered to better understand how students communicate on campus. The study found that college students who went to six or more perceived changes of less anxiety, depression, and stress than did students who only went to five or fewer sessions. Most students stated that they did not have to attend counseling and suggested online or weekend sessions. Finally, students mentioned that they learned about counseling services through advertisement. 


\section{APPENDIX A}

Survey

1. Age: (fill in)

2. Academic Standing: (please choose one)
- Freshman $/ 1^{\text {st }}$ Year
- Sophomore
- Junior
- Senior
○ Fifth Year

3. Major(s): (fill in)

4. Gender:
- Male
- Female

5. Race: (please choose all that apply)
○ White
- Native Hawaiian or Other Pacific Islander
- Black or African American
- Asian
- American Indian or Alaska Native
- Hispanic or Latino
o Other:

6. Location (U.S. state or country) where you are from. Example: TN or Tennessee: (fill in)

7. Are you aware that the University offers free counseling services? If yes, please indicate how you heard about it.
○ Yes. Comment:
$\circ \quad$ No

8. Have you ever gone to/sought services at the counseling center at the University?
$\circ$ Yes
○ No

9. Have you ever gone to/sought services at counseling centers other than those attributed to the University in the last two years?

$$
\text { - Yes }
$$

If yes, answers automatically skip to questions 10-14.

If no, answers automatically skip to question 15-19.

10. Given the list below, please indicate how many counseling sessions you have attended, either at the University's counseling center or another location.
○ $1-2$
$0 \quad 3-5$
$\circ \quad 6-9$
○ 10 or greater

Please choose the number that most accurately describes your response to the question using the following guide:
1. Significantly Decreased
2. Somewhat Decreased
3. Neutral
4. Somewhat Increased
5. Significantly Increased 
11. Anxiety is characterized as a feeling of worry, nervousness, or unease, typically about an imminent event or something with an uncertain outcome. How would you rate your level of anxiety since receiving counseling services?

\begin{tabular}{|l|l|l|l|l|}
\hline 1 & 2 & 3 & 4 & 5 \\
\hline
\end{tabular}

Please choose the number that most accurately describes your response to the question using the following guide:

1. Significantly Decreased

2. Somewhat Decreased

3. Neutral

4. Somewhat Increased

5. Significantly Increased

12. Depression is characterized as a repeated feeling of sadness, significant weight loss or gain, lack of energy, inability to concentrate, feelings of worthlessness, and loss of interest. How would you rate your level of depression since receiving counseling services?

\begin{tabular}{|l|l|l|l|l|}
\hline 1 & 2 & 3 & 4 & 5 \\
\hline
\end{tabular}

Please choose the number that most accurately describes your response to the question using the following guide:
1. Significantly Decreased
2. Somewhat Decreased
3. Neutral
4. Somewhat Increased
5. Significantly Increased

13. Stress is characterized by a state of mental tension and worry/anxiety caused by problems in life related to work, school, etc. that can be exhibited as a physical force or pressure. How would you rate your level of stress since receiving counseling services?

\begin{tabular}{|l|l|l|l|l|}
\hline 1 & 2 & 3 & 4 & 5 \\
\hline
\end{tabular}

Please choose the number that most accurately describes your response to the question using the following guide:

1. Significantly Decreased

2. Somewhat Decreased

3. Neutral

4. Somewhat Increased

5. Significantly Increased

14. Homesickness is classified as the distress or anxiety caused by being separated from home. It is further characterized by feelings of longing due to separation from one's home environment or loved ones. How would you rate your level of stress homesickness since receiving counseling services?

\begin{tabular}{|l|l|l|l|l|}
\hline 1 & 2 & 3 & 4 & 5 \\
\hline
\end{tabular}

After completing question 10-14, survey skips automatically to question 20. 
15. On a scale of 1 to 5 , how likely are you to use the counseling services:

1. Very unlikely

2. Unlikely

3. Undecided

4. Likely

5. Very likely

\begin{tabular}{|l|l|l|l|l|}
\hline 1 & 2 & 3 & 4 & 5 \\
\hline
\end{tabular}

Please choose the number that most accurately describes your response to the question using the following guide:
1. None
2. Below Average
3. Average
4. Above Average
5. Very High

16. Anxiety is characterized as a feeling of worry, nervousness, or unease, typically about an imminent event or something with an uncertain outcome. How would you rate your levels of anxiety?

\begin{tabular}{l|l|l|l|l}
1 & 2 & 3 & 4 & 5
\end{tabular}

Please choose the number that most accurately describes your response to the question using the following guide:
1. None
2. Below Average
3. Average
4. Above Average
5. Very High

17. Depression is characterized as a repeated feeling of sadness, significant weight loss or gain, lack of energy, inability to concentrate, feelings of worthlessness, and loss of interest. How would you rate your levels of depression?

\begin{tabular}{l|l|l|l|l|}
1 & 2 & 3 & 4 & 5 \\
\hline
\end{tabular}

Please choose the number that most accurately describes your response to the question using the following guide:
1. None
2. Below Average
3. Average
4. Above Average
5. Very High

18. Stress is characterized by a state of mental tension and worry/anxiety caused by problems in life related to work, school, etc. that can be exhibited as a physical force or pressure. How would you rate your levels of stress?

\begin{tabular}{|l|l|l|l|l|}
\hline 1 & 2 & 3 & 4 & 5 \\
\hline
\end{tabular}

Please choose the number that most accurately describes your response to the question using the following guide:
1. None
2. Below Average
3. Average
4. Above Average
5. Very High 
19. Homesickness is classified as the distress or anxiety caused by being separated from home. It is further characterized by feelings of longing due to separation from one's home environment or loved ones. How would you rate your levels of homesickness?

\begin{tabular}{|l|l|l|l|l|}
1 & 2 & 3 & 4 & 5 \\
\hline
\end{tabular}

Please choose the number that most accurately describes your response to the question using the following guide:
1. Very Poor
2. Poor
3. Acceptable
4. Good
5. Very Good

20. Mood includes the factors of anxiety, depression, stress, and homesickness. How would you rate your overall mood at this particular point in time?

\begin{tabular}{|l|l|l|l|l|}
\hline 1 & 2 & 3 & 4 & 5 \\
\hline
\end{tabular}

21. For what reasons would you not attend the counseling services on campus? Please choose all that apply.

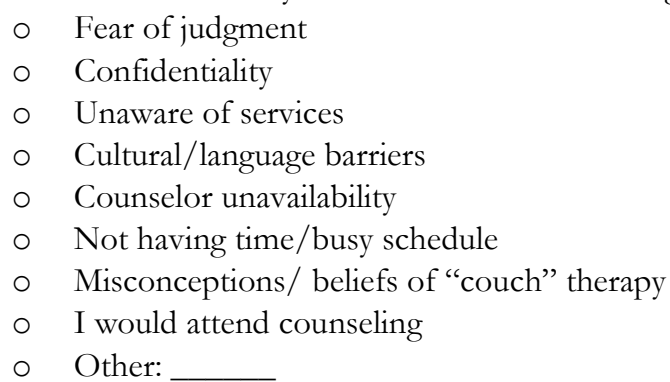

22. In what ways do you think that the counseling services on campus or the information related to the services offered can be improved?

- Comments:

23. Academic Performance is the extent to which a student has achieved their educational goals. Please indicate your cumulative GPA
○ GPA: $3.5-4.0$
○ GPA: $2.5-3.49$
○ GPA: $1.5-2.49$
- GPA: Below 1.5

Please choose the number that most accurately describes your response to the following question using the guide below:
1. Very Dissatisfied
2. Dissatisfied
3. Neutral
4. Satisfied
5. Very Satisfied

24. Academic Performance is the extent to which a student has achieved their educational goals. How would you rate your academic performance satisfaction at the University of the Cumberlands at this time?

\begin{tabular}{|l|l|l|l|l|}
\hline 1 & 2 & 3 & 4 & 5 \\
\hline
\end{tabular}

Thank you for your time. If you would like to include any email address (not limited to the University email address) in order to be entered into a random, anonymous drawing to win a $\$ 25$ Amazon gift card, please do so here (optional):

Email: 


\title{
Underneath it All: Soil Differences May Explain Contrasting Outcomes of Adjacent Prairie Restorations in Madison, Wisconsin
}

\author{
Krista Marshall, Nick J. Balster * \& Alex W. Bajcz., \\ ${ }^{a}$ Department of Soil Science, University of Wisconsin-Madison, Madison, WI \\ ${ }^{b}$ Department of Biology, Drew University, Madison, NJ \\ Student:knmarshall@wisc.edu \\ Mentors:njbalster@wisc.edu*,abajc々@drew.edu
}

\begin{abstract}
The evaluation of prairie restorations tends to focus on aboveground properties such as changes in plant diversity and the encroachment of non-native species. As a result, knowledge gaps persist concerning belowground controls of restoration success. To address these gaps at a 13-year-old prairie restoration site in Madison, Wisconsin, we spatially compared soil chemical, physical, and hydrological properties in two adjacent parcels that differed markedly in response to a tallgrass prairie restoration. We hypothesized that soil properties and their heterogeneity would differ significantly between the two parcels and that these differences would help explain the divergent response. In support of this hypothesis, soil organic matter, $\mathrm{pH}$, and total nitrogen were significantly lower $(p=0.007, p<0.001$, and $p=0.006$, respectively) in the restored parcel compared to the parcel that has yet to respond to any restoration efforts. Moreover, despite no significant difference in soil average bulk density between the two parcels, the restored parcel had significantly lower sand and silt fractions overall $(p=0.039$ and $p=0.040$, respectively). In contrast, except for total nitrogen, there were no apparent differences in the spatial heterogeneity of the measured soil properties between the restored and unrestored parcels, which did not support the second hypothesis of this study. These results demonstrate the utility of measuring belowground properties when assessing unexpected outcomes of prairie restorations as well as inform future hypothesis-driven experiments to determine which soil properties impede restoration and under what circumstances.
\end{abstract}

\section{KEYWORDS}

Prairie Restoration; Bulk Density; Soil Organic Matter; Soil Properties; Soil Texture; Spatial Heterogeneity

\section{INTRODUCTION}

Prairie restoration has become a widely accepted practice for reclaiming degraded grasslands through the reintroduction and management of native plant species that promote a biodiverse and functional ecosystem. Restoration practices are also being investigated as a potential method for provisioning of ecosystem services such as nutrient cycling, water quality, carbon storage, and recreation. ${ }^{1}$ Although less than $1 \%$ of historic native prairies in the Midwestern U.S. remain today, ${ }^{2}$ programs like the Conservation Reserve Program (CRP) have contributed to the restoration of native plant communities across more than 14.8 million hectares of land in the Midwest. ${ }^{3}$ However, most research projects and evaluations of restorations continue to focus on aboveground responses, with little incorporation of belowground processes (but see ${ }^{4,5}$ ). As a consequence of this omission, the ecological trajectory of restorations is often difficult to predict and evaluate.

A review of the literature concluded that current approaches used to evaluate prairie restorations can be grouped into three broad categories: diversity-based, vegetation structure-based, and ecology-based. ${ }^{6}$ Quantitative metrics of diversity and vegetative structure include measures of species richness, the abundance of organisms at different trophic levels, the extent of vegetative cover, plant cover density, and total plant biomass - all measures focused on aboveground properties. By contrast, ecology-based approaches place greater emphasis on belowground properties, focusing on aspects such as biological interactions, nutrient cycling, and soil organic matter. Moreover, ecological approaches typically couple belowground properties explicitly with the more visible aboveground properties. Despite the usefulness of assessments that include these belowground metrics, such approaches have not been widely used to evaluate prairie restorations, perhaps in part due to their higher cost and time relative to more aboveground-focused approaches. ${ }^{7,8}$ Despite these drawbacks, incorporating belowground responses, especially those related to soil properties, into assessments of restoration efforts will likely improve our holistic understanding of the factors that determine the success or failure of these efforts.

Because soil properties often dictate the responses of plant communities ${ }^{9}$, they serve as proximate controls over plant productivity, community succession, and, ultimately, species diversity within restored ecosystems ${ }^{10}$. By extension, the spatial variability of soil properties influences the responses of plants to restoration efforts as well as the establishment of native plant species over time. ${ }^{11,12}$ For example, a study of seven different soil series in a large tallgrass prairie concluded that each series 
contained its own unique assemblage of locally abundant plant species, ${ }^{13}$ which suggests a possible relationship between variation in soil properties and the prairie plant communities they support (or co-evolutionary changes between plants and soils). Further, individual soil properties may contribute disproportionately to the establishment and growth of certain plant species. Soil carbon content, for example, has been shown to facilitate the growth of native species, whereas high levels of nitrate decreased the abundance of native flora and increased the establishment of weeds in a five-year-old tallgrass prairie in southern Minnesota. ${ }^{14}$ Another study concluded that excess soil nutrients resulting from years of soil degradation or fertilization tended to impede the establishment of native species in grassland ecosystems. ${ }^{5}$

The objective of this study was to explore whether potential differences in soil physical, chemical, and hydrologic properties or their spatial variability help explain the disparate responses of two systems to native prairie restoration: A restored 13-year-old prairie and an adjacent parcel with a history of resistance to native vegetation establishment. The hypotheses were that (1) the restored and unrestored prairies would display significant differences in soil properties (e.g., soil bulk density, soil organic matter, soil texture, volumetric water content, etc.) and (2) that the heterogeneity of soil properties in the resistant parcel would exceed that of the established prairie.

\section{METHODS AND PROCEDURES}

Study system

This study was conducted at the University of Wisconsin-Madison (UW-Madison) Biocore Prairie located in Madison, Wisconsin, USA. The property was composed of soils classified as Dodge silt-loams and Kidder silt loams, ${ }^{15}$ both of which are commonly used for agriculture in the Midwestern United States. An eleven-acre parcel of land in this region was once part of a research station used throughout the 1900s for experimental agriculture until it was phased out in the 1960s and left fallow. During this period, a portion of the property was used as disposal grounds for algal mats from a nearby lake along with construction materials and organic waste. In 1997, the entire property was incorporated into the Biocore Program at UW-Madison and subsequently managed with the goal of restoring it to a mesic tallgrass prairie for student learning and collaborative research on prairie restoration processes and its usefulness for restoring degraded environments.

In 2005, two adjacent sections of land were placed under similar tallgrass prairie restoration treatments by the UW-Madison Biocore Prairie staff. One of these, a 2-ha parcel (Area 3), continues to support a vegetative community of 50 of the 53 native species initially introduced in 2006 (Figure 1a). By contrast, an adjacent 1-ha parcel (Area 6) has yet to respond to the initial seeding or to any subsequent intervention (Figure 1b). The unrestored parcel contains few native plant species and is largely composed of stinging nettle (Uritca dioica L.), crown vetch (Securigera varia L.), reed canary grass (Phalaris arundinacea L.), and Canada thistle (Cirsium arvense L.). In an effort to combat the growth of these invasive plants, the unrestored prairie was subjected to mowing, tilling, and two growing seasons of cover crop plantings of oats in an effort to reduce the availability of soil nutrients thought to facilitate the proliferation of these aggressive taxa. However, these techniques have been unsuccessful. Thus, in an effort to explain the response differences between these adjacent parcels, their physiochemical soil properties and the spatial heterogeneity of these properties were investigated.

Thirty-two soil samples were collected during June and July of 2017 by establishing a $20 \times 20 \mathrm{~m}$ grid across the two parcels (Figure 1c). This design yielded 15 grid points in the restored prairie and 17 grid points in the unrestored parcel. Of the 32 grid points, three points located in the restored prairie and two points located in the unrestored parcel lie along a transitional strip that marks a border between the parcels. Soil physical, chemical, and hydrologic properties at three depth intervals $(0-5 \mathrm{~cm}, 10-20 \mathrm{~cm}$, and $25-35 \mathrm{~cm})$ were measured at each grid point. The soil physical properties measured were penetrative resistance $(\mathrm{kPa})$, soil bulk density $\left(\mathrm{g} / \mathrm{cm}^{3}\right)$, and texture (\% sand, silt, and clay). Five soil chemical properties (total nitrogen (\%), soil organic matter (\%), soil $\mathrm{pH}$, available phosphorus ( $\mathrm{ppm}$ ), and exchangeable potassium ( $\mathrm{ppm})$ ) were used to evaluate soil fertility. Finally, volumetric water content was measured at each point 72 hours after approximately $2 \mathrm{~cm}$ of rainfall at the property.

\section{Penetrative resistance}

The soil penetrative resistance, or the force needed to drive a cone penetrometer into a soil pedon, ${ }^{16}$ was measured over two days in June approximately $30 \mathrm{~cm}$ north of each grid point. This metric was used as a proxy for soil structure and relative density as well as to determine the presence of compacted layers within the soil profile. ${ }^{17}$ The cone of the penetrometer was first pressed vertically into the surface residue until it was completely buried. The sliding hammer was then dropped repeatedly at 5-cm increments until a total depth of $35 \mathrm{~cm}$ was reached, gauged by graduations on the instrument. At each increment, the number of hammer drops required was recorded. The data were collected over the course of two days to minimize the effect of changes in moisture content and in soil macrofauna. ${ }^{18}$ An Energy-Work theorem developed by Halliday and Resnick (1963) was used to calculate the work done by the soil to resist penetration and, subsequently, the soil penetrative resistance using the following equation: ${ }^{19}$ 


$$
\mathrm{R}=\frac{\mathrm{W} / \mathrm{d}}{\mathrm{SA}_{\text {cone }}}
$$

Equation 1.

where soil penetrative resistance $(\mathrm{R})$ in $\mathrm{kPa}$ was calculated for each $5 \mathrm{~cm}$ increment by dividing the work term (W) by the approximate incremental distance traveled by the penetrometer cone $(\mathrm{d})$ and then by the surface area of the cone $\left(\mathrm{SA}_{\text {cone). }}\right.$ The work done on the soil was calculated by assuming that all the kinetic energy transfers from the hammer to the cone penetrometer as the hammer strikes the plate and movement stops, i.e., the soil resists penetration by the penetrometer.

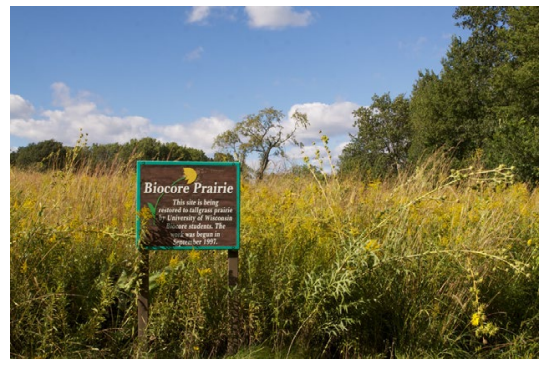

(a)

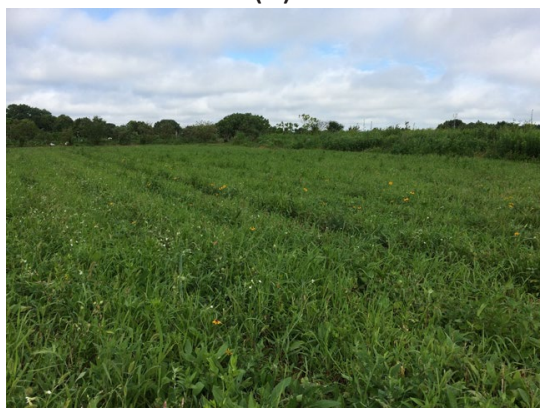

(b)

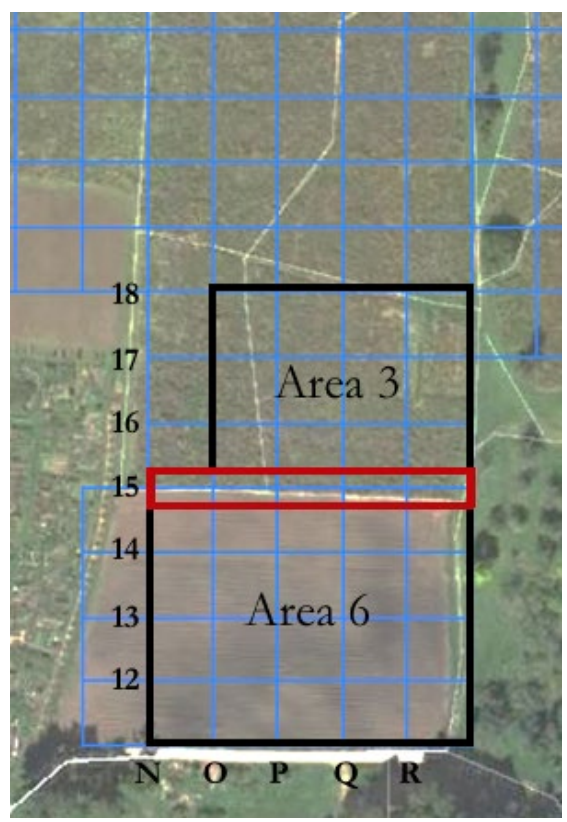

(c)

Figures 1a-c. Satellite view of the study site in Madison, Wisconsin, USA (1c), acquired by the University of Wisconsin-Madison Biocore in 1997, showing the property prior to prairie restoration. Area 3 is the successfully restored parcel studied here (1a), whereas Area 6 is the parcel that has not responded to restoration efforts (1b). A transitional strip between the restored and unrestored parcels of the prairie is delineated in red. The leftmost three points within this strip were deemed to lie in Area 6 (unrestored), whereas the other two were deemed to lie in Area 3 (restored).

\section{Soil bulk density}

Bulk density (BD) describes the ratio of the oven-dried mass of soil particles to the volume of the soil, including pore space. ${ }^{20}$ Soil samples were taken during July over two days at each grid point using a 3.5 inch diameter soil core to a depth of $40 \mathrm{~cm}$ and processed for their bulk density over three depth increments $(0-5,10-20$, and $25-35 \mathrm{~cm})$. The samples were cut into the separate depth increments and placed in an oven $\left(104^{\circ} \mathrm{C}\right)$ to dry for 72 hours to achieve a constant mass. Once the samples reached a constant mass, the oven-dry mass was divided by the volume of the increment to determine bulk density.

\section{Soil texture}

The relative percentages of sand, silt, and clay define a soil's texture. Samples were taken in June from the 10-20 cm depth range approximately $15 \mathrm{~cm}$ from each grid point. After the samples were collected, they were oven-dried (at $104^{\circ} \mathrm{C}$ ) and preserved. The samples were placed in hydrogen peroxide to help remove soil organic matter before the textural analysis. During this process, the samples were heated to $60^{\circ} \mathrm{C}$ to help catalyze the reaction (modified from ${ }^{21}$ ). We assume the majority of the organic matter was removed but we did not verify this assumption. To eliminate the possibility of including soil particles outside the sand, silt, and, clay size range, approximately $40 \mathrm{~g}$ of each sample was gently ground using a mortar and pestle until the samples were able to pass through a 2-mm sieve and subsequently weighed. After this was done, soil texture was determined using the standard hydrometer method. Hydrometer readings for settling of the sand fraction were taken at 40 seconds. Readings were taken again at four hours to measure the amount of clay particles in suspension. In addition to analysis of particle size fractions, a textural triangle was used to classify each soil sample. ${ }^{22}$ 


\section{Soil fertility}

Properties commonly used to describe soil fertility include soil organic matter (SOM), total nitrogen (N), available phosphorus $(\mathrm{P})$, exchangeable potassium $(\mathrm{K})$, and soil $\mathrm{pH} \cdot{ }^{14,23-24}$ Soil samples from the $10-20 \mathrm{~cm}$ depth range were taken at each grid point in June 2017. Each sample was then dried to $104^{\circ} \mathrm{C}$, sieved to exclude any particles $>2 \mathrm{~mm}$ in diameter, and sent to the UW Soil and Forage Lab for analysis. Methods used to test these properties were Loss on Ignition for SOM, total Kjeldahl nitrogen for total N, Bray 1 extraction for P \& $\mathrm{K}$, and a 1:1 water:soil paste to measure $\mathrm{pH}$.

\section{Volumetric water content}

The volumetric water content at a depth of $10 \mathrm{~cm}$ was calculated at each grid point $72 \mathrm{~h}$ after a $2 \mathrm{~cm}$ rainfall in July. A ThetaProbe was used to measure the volumetric water content at each grid point, reported on a percentage basis. ${ }^{25}$ The Thetaprobe applies a $100 \mathrm{MHz}$ signal through a transmission line whose impendence changes as the impendence of the soil changes. These changes are converted to voltage readings that are proportional to the volumetric soil moisture content (in percent ${ }^{25}$ ). The 72 -hour sample was taken to assess soil water drawdown after a period of evapotranspirative loss.

\section{Analyses}

The data were explored and analyzed using $\mathrm{R}$ version 3.3.3. ${ }^{26} \mathrm{It}$ is a common assumption that soil properties will be autocorrelated. To account for this interrelatedness, a correlation matrix was generated (Table 1). Soil organic matter and total $\mathrm{N}$ were highly correlated (Pearson's $r=0.972$ ). Additionally, the sand and silt fractions were strongly correlated (Pearson's $r=-0.918$ ). These correlations were considered when evaluating the results; most soil properties do not exist in isolation and are frequently interrelated to other soil properties. Properties that were measured at a single depth of 10-20 cm were analyzed using ANOVA. For soil properties anticipated to vary over depth (i.e., soil penetrative resistance, bulk density, and volumetric water content), mixed-effect ANCOVA was used.

\begin{tabular}{|c|c|c|c|c|c|c|c|c|c|c|}
\hline & $\begin{array}{c}\text { Sand } \\
\% \\
\end{array}$ & $\begin{array}{c}\text { Clay } \\
\% \\
\end{array}$ & SOM & $\mathbf{N}$ & $\mathbf{P}$ & $\mathbf{K}$ & $\mathrm{pH}$ & $\begin{array}{c}\text { Bulk } \\
\text { density }\end{array}$ & $\begin{array}{r}\text { VMC } \\
\text { at } 72 \mathrm{~h}\end{array}$ & $\begin{array}{c}\text { Silt } \\
\%\end{array}$ \\
\hline 1 & 1 & & & & & & & & & \\
\hline 2 & -0.432 & 1 & & & & & & & & \\
\hline 3 & 0.543 & -0.215 & 1 & & & & & & & \\
\hline 4 & 0.519 & -0.280 & 0.972 & 1 & & & & & & \\
\hline 5 & -0.367 & -0.038 & 0.028 & 0.098 & 1 & & & & & \\
\hline 6 & -0.339 & 0.004 & 0.083 & 0.169 & 0.755 & 1 & & & & \\
\hline 7 & 0.558 & -0.189 & 0.292 & 0.286 & -0.061 & -0.097 & 1 & & & \\
\hline 8 & -0.037 & 0.270 & -0.430 & -0.422 & -0.222 & -0.092 & -0.065 & 1 & & \\
\hline 9 & -0.258 & 0.175 & -0.018 & -0.067 & 0.092 & 0.081 & -0.220 & -0.354 & 1 & \\
\hline 10 & -0.918 & 0.039 & -0.507 & -0.452 & 0.424 & 0.374 & -0.535 & -0.078 & 0.209 & 1 \\
\hline
\end{tabular}

Table 1. Correlation matrix of Pearson's $r$ values used to quantify the strength of correlations between soil properties measured in this study. The order of properties across columns is the same as down rows.

ANOVA was used to determine the statistical significance of the differences in soil properties between the restored and unrestored parcels of the prairie. The ANOVA models for sand, silt, clay, SOM, N, P, K, and pH were confirmed to exhibit homoscedasticity and approximate linearity and to have normally distributed residuals. Plots of standardized residuals versus fitted values, Q-Q plots, leverage plots, and histograms were used to validate these assumptions. Additionally, data were analyzed with and without prospective outliers and deemed non-influential. Probability values $<0.05$ were considered significant, and values $<$ 0.1 but $>0.05$ were deemed marginally significant. Graphs were produced using goplot $2 .{ }^{27}$ Heat maps were used to qualitatively assess our second hypothesis of whether the spatial heterogeneity of the soil properties listed above differed noticeably between the two parcels. 
Properties that varied over depth were analyzed using linear mixed-effects ANCOVA (analysis of covariance) using the $\mathrm{lme} 4,{ }^{28}$ lmerTest, ${ }^{29}$ and pbkrtest ${ }^{30}$ packages. Bulk density and volumetric water content were sampled at three depth increments (0-5, 10-20, and 25-35 cm), yielding 96 data points, 32 at each depth increment. Penetrative resistance was calculated at seven depths at each grid point $(5,10,15,20,25,30$, and $35 \mathrm{~cm})$, resulting in 224 data points. Mixed-effects ANCOVA was used to model differences between the restored and unrestored prairies across multiple depths. The grid point was the grouping factor for these mixedeffects ANCOVAs, and the fixed factors for each model were area, depth, and the area-by-depth interaction. Prospective outliers were analyzed and deemed non-influential. Probability values $<0.05$ for the interaction term were used to conclude that a soil property changed with depth at different rates between the restored and unrestored parcels of the prairie.

\section{RESULTS}

We used the ANOVA results to discern whether the soil properties of the two sites differed significantly. The mean values for soil $\mathrm{pH}$ and organic matter were significantly different between the restored and unrestored parcels of the prairie at $\alpha=0.05$ (Table 2). The mean soil $\mathrm{pH}$ in the restored prairie was significantly lower $(\mathrm{pH}=6.6 \pm 0.07)$ than the average soil $\mathrm{pH}$ across the unrestored prairie $(7.1 \pm 0.06$; Table 2$)$. The restored parcel of the prairie also had significantly lower SOM $(2.49 \% \pm 0.129 \%)$ than the unrestored parcel $(4.24 \% \pm 0.550 \% ; p=0.007$; Table 2$)$. Total nitrogen, highly correlated with SOM in our data, was also significantly higher in the unrestored parcel of the prairie $(0.279 \% \pm 0.033 \%)$ than in the restored parcel $(0.171 \% \pm 0.01 \% ; p$ $<0.006$; Table 2; Figure 2). A qualitative assessment of a heat map generated for total nitrogen (Figure 2) suggests that the restored parcel of the prairie was more homogenous for this soil property than the unrestored parcel. However, heat maps generated for all other soil properties (not presented) did not show distinctly different levels of heterogeneity between the two parcels.

\begin{tabular}{ccccc|cccc|cccc}
\hline \multicolumn{7}{c|}{ Unrestored } & \multicolumn{5}{c|}{ Restored } & \multicolumn{3}{c}{ ANOVA results } \\
\hline & Min & Mean & Max & SE & Min & Mean & Max & SE & Area & $\beta_{\mathbf{0}}$ & t & $\boldsymbol{p}$ \\
\hline Sand & 15.8 & 23.3 & 48.6 & 2.15 & 15.1 & 33.0 & 63.1 & 3.73 & 9.65 & 23.3 & 7.17 & $\mathbf{0 . 0 3 9}$ \\
Silt & 33.5 & 53.9 & 68.2 & 2.17 & 20.5 & 45.2 & 72.8 & 3.26 & -8.64 & 53.9 & -2.15 & $\mathbf{0 . 0 4 0}$ \\
Clay & 9.90 & 22.8 & 31.9 & 1.50 & 12.1 & 21.8 & 29.1 & 1.18 & -1.01 & 22.8 & -0.531 & 0.599 \\
\hline SOM & 1.60 & 2.49 & 3.50 & 0.130 & 2.30 & 4.24 & 10.4 & 0.550 & 1.75 & 2.49 & 5.72 & $\mathbf{0 . 0 0 7}$ \\
N & 0.0590 & 0.171 & 0.239 & 0.010 & 0.156 & 0.279 & 0.690 & 0.0330 & 0.108 & 0.171 & 2.98 & $\mathbf{0 . 0 0 6}$ \\
P & 41.0 & 76.3 & 142 & 7.81 & 30.0 & 83.7 & 173 & 10.5 & 7.37 & 76.3 & 7.85 & 0.585 \\
K & 62.0 & 100 & 173 & 7.90 & 45.0 & 145 & 480 & 29.2 & 44.5 & 100 & 4.30 & 0.174 \\
pH & 6.1 & 6.6 & 7 & 0.07 & 6.7 & 7.1 & 7.5 & 0.055 & 0.438 & 6.6 & 106 & $<\mathbf{0 . 0 0 1}$ \\
\hline
\end{tabular}

Table 2. Soil physical (top half) and fertility-related (bottom half) property metadata (means, ranges, and SEs) from the 10-20 cm depth interval of the restored and unrestored parcels of the Biocore Prairie in Madison, Wisconsin, USA. ANOVA (right side) was used to evaluate the strength of differences in soil properties between the two land parcels. The $\mathrm{t}$ and $p$ values in the table are for the Area main-effect terms (i.e., these have been omitted for the intercept terms), and significant differences at $\alpha=0.05$ are noted in bold.

Analysis of the sand, silt, and clay fractions revealed that the soil texture varied between the restored and unrestored parcels of the prairie at the 10-20 cm depth (Table 2; Figure 3). While the mean clay contents of the restored $(22.8 \% \pm 0.52 \%)$ and unrestored $(21.8 \% \pm 1.18 \%)$ parcels were not significantly different $(p=0.599)$, the mean sand fraction in the restored parcel of the prairie $(23.3 \% \pm 2.15 \%)$ was significantly lower $(p=0.039)$ than in the unrestored parcel $(33.0 \% \pm 3.73 \%$; Table 2$)$. Additionally, the variance in the sand fraction data in the unrestored parcel was greater than in the restored parcel of the prairie (Figure 3). The majority of the soil samples $(73 \%)$ from the restored prairie were classified as silt loams, ${ }^{30}$ whereas no one textural class dominated the unrestored prairie; soils there were classified as silt loams (41\%), loams (35\%), and clay and sandy loams (12\% each).

Mixed-effect ANCOVA was used to assess whether soil properties varied significantly with depth as well as whether these rates of change differed between these two adjacent parcels of the prairie (Table 3). The mean bulk density across all depths between the restored and unrestored parcels of the prairie did not differ significantly (Table 3). However, bulk density increased faster with depth in the unrestored prairie than in the restored prairie $(p=0.048$; Figure 4; Table 3). The mean soil penetrative resistance between the restored and unrestored prairies was not significantly different $(p=0.129)$ throughout the $35 \mathrm{~cm}$ soil profile sampled (Table 3). Although these parcels did not differ significantly for this property, the standard error in the unrestored parcel increased dramatically after a depth of $20 \mathrm{~cm}$ (data not shown), whereas standard error values in the restored prairie tended to be less variable throughout the soil profile. Volumetric water content sampled 72 hours after a rainfall event did not significantly differ between the restored and unrestored parcels of the prairie $(p=0.253$; Table 3$)$. 


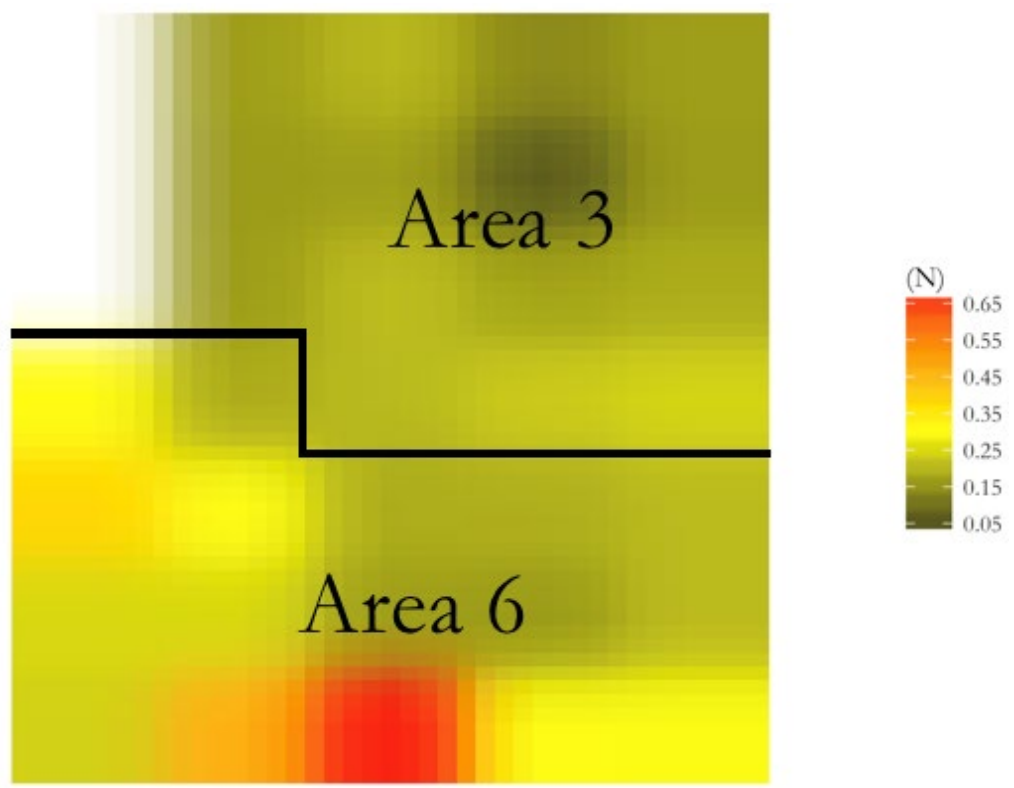

Figure 2. A heat map of total nitrogen (\% Kjeldahl $\mathrm{N}$ by mass) for the unrestored parcel (Area 6 ) of the Biocore prairie in Madison, Wisconsin, USA versus the restored parcel (Area 3). The 32 grid points sampled (see Figure 1) were interpolated to smooth the heat map, producing a gradient of colors based on total nitrogen value (highest $=$ red, lowest $=$ green).

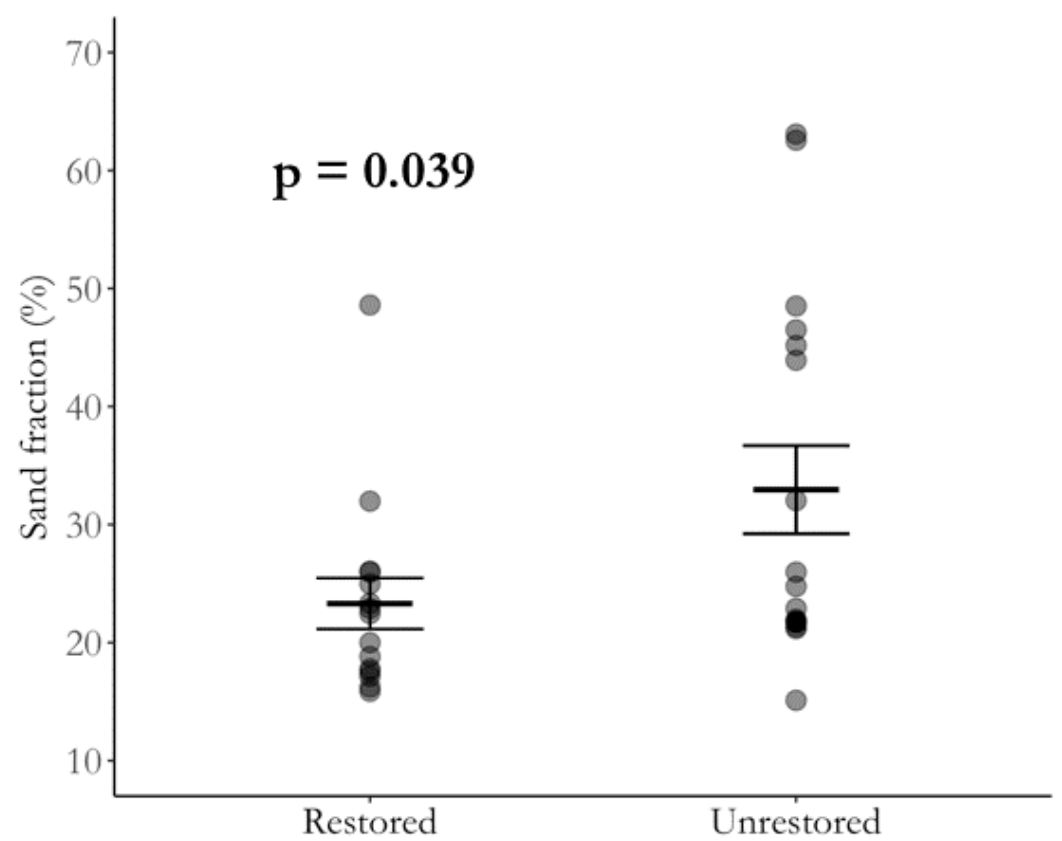

Figure 3. Data on the sand fraction of soils (y axis) from the successfully restored and unrestored parcels ( $\mathrm{x}$ axis) of the Biocore prairie in Madison, Wisconsin, USA. The thick horizontal line represents the mean values for the two parcels, and the error bars are one standard error. Points are semi-transparent; darker colors indicate where points are overplotted. 


\begin{tabular}{ccccccc}
\hline & & $\boldsymbol{\beta}$ & ddf & SE & t & $p$ \\
Penetrative & Intercept & 711.4 & 101.3 & 290.8 & 2.446 & 0.179 \\
resistance & Depth & -157.4 & 101.3 & 399.0 & -0.395 & 0.694 \\
& Area & 273.7 & 204.5 & 204.5 & 5.384 & $<0.001$ \\
& Area $\times$ depth & 106.3 & 204.5 & 204.5 & 1.524 & 0.129 \\
\hline Bulk & Intercept & 0.6847 & 89.16 & 0.03870 & 17.69 & $<0.001$ \\
density & Depth & -0.09390 & 89.16 & 0.05310 & -1.769 & 0.080 \\
& Area & 0.2517 & 62.00 & 0.01490 & -16.94 & $<0.001$ \\
& Area $\times$ depth & 0.04110 & 62.00 & 0.02040 & -2.015 & $\mathbf{0 . 0 4 8}$ \\
\hline Volumetric & Intercept & 35.39 & 87.36 & 1.505 & 25.52 & $<0.001$ \\
Water & Depth & 0.4305 & 87.36 & 2.065 & 0.208 & 0.853 \\
Content & Area & 0.6900 & 62.00 & 0.5660 & 1.268 & 0.210 \\
at 72 h & Area $\times$ depth & -0.8959 & 62.00 & 0.7766 & -1.154 & 0.253 \\
\hline
\end{tabular}

Table 3. Mixed-effect ANCOVA results used to determine whether soil properties that varied with depth (i.e., penetrative resistance, bulk density, and volumetric water content) did so differently in the restored versus unrestored parcels of the Biocore prairie. The $p$ value for the Area $\times$ depth interaction term was used to determine whether these rates of change with depth differed significantly between the two parcels. Significant differences in this regard are noted in bold.

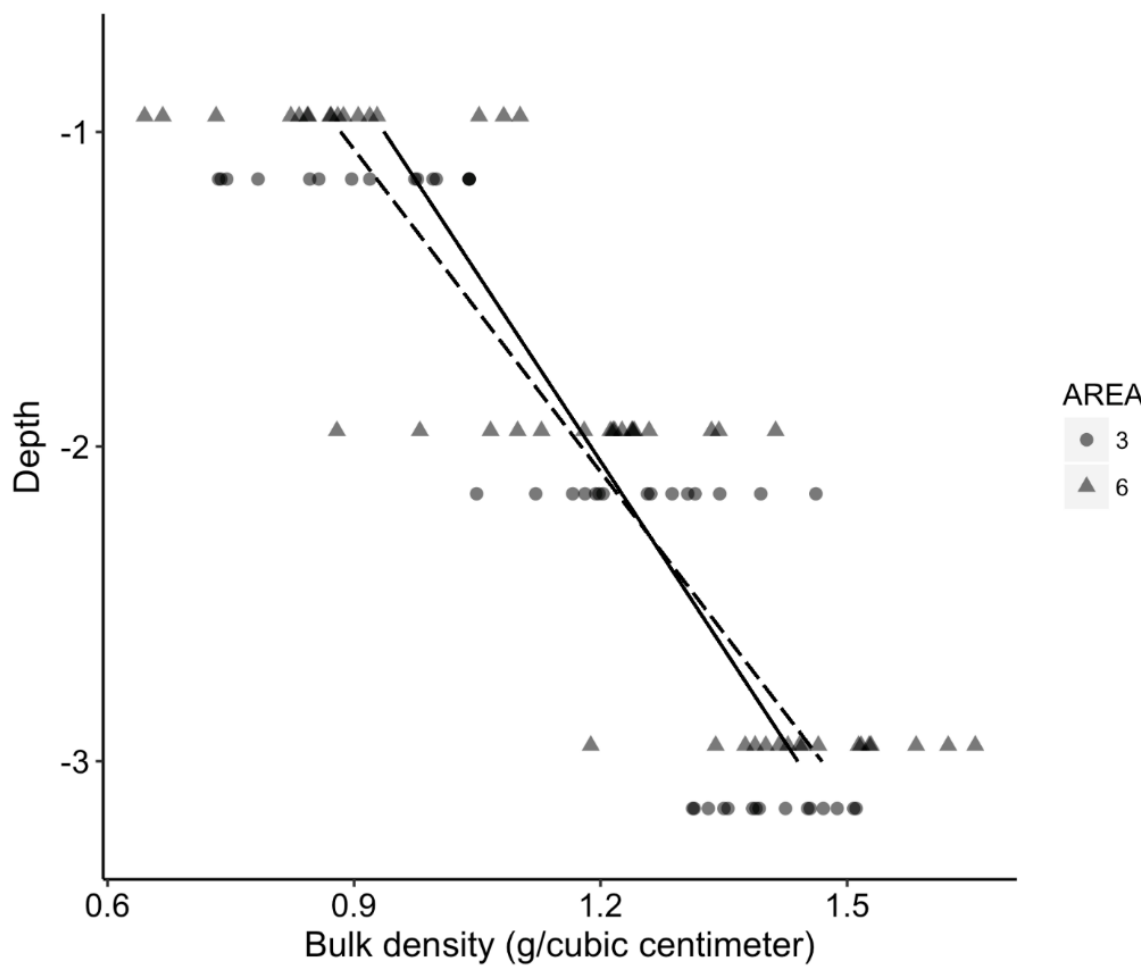

Figure 4. Bulk density ( $\mathrm{x}$ axis) data by depth interval (y axis) in the unrestored parcel of the prairie (Area 6; dashed line) and in the restored parcel (Area 3; solid line) of the Biocore prairie in Madison, Wisconsin, USA. All grid points were sampled at depths of 0-5 cm (labeled 1), 10-20 cm (labeled 2), and 25-35 cm (labeled 3) and plotted as either circles (restored parcel) or triangles (unrestored parcel). Points have been offset vertically at each depth interval by Area. Points are semitransparent; darker colors indicate where points are overplotted.

\section{DISCUSSION}

In support of our first hypothesis, soil properties differed between the restored prairie and the parcel that has been resistant to restoration (unrestored) at the Biocore property. On average, the unrestored section had higher soil organic matter, total nitrogen, and percent silt and sand than the restored section, as well as a more alkaline soil $\mathrm{pH}$. The difference in soil organic matter was particularly noteworthy because it contradicts prevailing research suggesting that prairie restoration increases soil organic matter over time. ${ }^{32-36}$ Alternatively, the difference may be a legacy effect from prior anthropogenic disturbances that occurred at this site. The unrestored parcel also had a higher total nitrogen content overall, a nutrient that, at excessive levels, is expected to favor the encroachment of non-native species ${ }^{14}$, and a higher soil $\mathrm{pH}$, which mediates the availability of nitrogen and other key nutrients. ${ }^{24}$ 
However, except for total nitrogen, the heterogeneity of the measured soil properties did not differ markedly between the restored and unrestored parcels. Research on the relationship between resource heterogeneity, particularly that of nitrogen, and the establishment and diversity of native species has been mixed, with some studies finding positive relationships ${ }^{37}$ and others, including ours, suggesting less influence of soil heterogeneity. ${ }^{38,39}$ These data suggest that the mean differences in soil properties are likely more important than the heterogeneity of these properties in helping to explain the disparity in restoration success between the two parcels in the Biocore prairie.

The unrestored section of the prairie contained almost twice as much soil organic matter as the restored prairie, which is inconsistent with studies finding an accumulation of organic matter as restored prairies develop. ${ }^{36}$ Our results, however, corroborate an alternate body of research that challenges assumptions concerning changes in organic matter during prairie restoration. Some studies have observed that prairie restorations have little effect on soil organic matter ${ }^{39,40}$ or that concentrations in restorations may even decrease over time. ${ }^{41}$ For example, a recent study of urban grasslands in Illinois found that soil organic matter at a long-term restoration site was significantly lower $(4.7 \%)$ than at an unmanaged comparison site $(6.1 \%) .41 \mathrm{These}$ conflicting results suggest multiple competing factors (e.g., soil microbial activity and abiotic changes) may drive changes in soil organic matter during the restoration of prairie ecosystems. Therefore, controlled experiments may be needed to fully understand how and why soil organic matter changes as restored prairies develop.

Despite efforts to combat the growth of non-native vegetation through nitrogen-reducing management practices in the unrestored section of the prairie, total nitrogen, a nutrient expected to increase the success of invasive species in prairie ecosystems ${ }^{14}$, was still higher in the unrestored section than in the restored section. It is possible that high nitrogen content in the unrestored section has permitted invasive species to outcompete native plants there. In addition, plant-available forms of nitrogen are attracted to the charged sites on soil organic matter, ${ }^{42}$ a soil property that was also found to be higher in the unrestored section than in the restored section and which was highly correlated with total nitrogen in this study. Thus, the higher soil organic matter content in the unrestored section may have facilitated a positive feedback with respect to soil nitrogen availability, allowing increased growth of invasive flora and decreased establishment of native flora.

Soil $\mathrm{pH}$, a controlling factor in the availability of essential plant nutrients, ${ }^{24}$ was lower in the restored section of the prairie relative to the unrestored section, which may be central to explaining the contrasting responses between the two sections. Most macroand micronutrients, including plant-available forms of nitrogen, are more readily available for plant uptake at soil $\mathrm{pH}$ values between 6.0 and $7.0^{43}$. All $\mathrm{pH}$ values in the restored section fell within this range, whereas the majority of soil $\mathrm{pH}$ values in the unrestored parcel were higher than this range. A similar study of a successfully restored tallgrass mesic prairie approximately 30 $\mathrm{km}$ from our study site also found that annual measurements of soil $\mathrm{pH}$ ranged from approximately 6.0 to $6.3,{ }^{44}$ consistent with the results for the restored section presented here. Based on these studies, although we did not measure the availability of all relevant plant nutrients, we speculate that the higher $\mathrm{pH}$ range in the unrestored section may thus be prohibiting access to essential nutrients for native plant species. An experimental decrease in $\mathrm{pH}$ in the unrestored section (e.g., via sulfur application ${ }^{45}$ ) could be used to test whether a reduction in $\mathrm{pH}$ would indeed facilitate the establishment of native prairie flora there.

While considering soil $\mathrm{pH}$ in relation to the availability of essential nutrients is appropriate, evaluating how soil $\mathrm{pH}$ relates to microbial activity may yield a more holistic understanding of varied restoration success at sites like the Biocore prairie. For example, the establishment and activity of soil microbial communities is particularly sensitive to changes in soil $\mathrm{pH}{ }^{46,47} \mathrm{~A}$ recent study of a prairie restoration in Kansas found that soil microbial biomass was negatively correlated with soil $\mathrm{pH}$ (Pearson's $\mathrm{r}=$ 0.83). ${ }^{47}$ Although soil microbial analyses were not included in the present study, other studies have indicated that microbial biomass and diversity both increase throughout a prairie restoration and could serve as useful metrics for assessing progress. ${ }^{47-50}$ Despite this, soil microbial characteristics are rarely incorporated into restoration evaluations, largely due to the time and cost associated with quantifying them. ${ }^{6}$ However, given the soil $\mathrm{pH}$ differences observed in this study, these measurements may be informative for understanding the disparate restoration outcomes we observed.

Soil texture influences a suite of soil properties, including water-holding capacity and the size of carbon and nitrogen pools, and thus contributes to the success of prairie restorations. ${ }^{39}$ The sand fraction in the unrestored section of the prairie was greater than in the restored prairie, and this section also had greater variation in soil textural classes than the restored section. In contrast, just one soil textural class dominated the restored section. An analogous study of a restored mesic tallgrass prairie in southern Wisconsin ${ }^{44}$ found their site to be largely composed of silt loams, similar to the successfully restored parcel in the current study. In addition, the same study ${ }^{44}$ found that soil properties ( $\mathrm{pH}, \mathrm{NPK}$, soil organic matter, and drainage) at that restored site approached similar values as those observed in other nearby remnant prairies. Taken together, the above results suggest that the textural properties of the unrestored section of the Biocore prairie may be further limiting the establishment of a native plant community there. 
Given the results of the textural analysis, we expected that bulk density would be lower in the restored prairie than in the unrestored section. However, the two sections did not differ in this physical property. This result concurs with a similar finding in another study conducted in southern Wisconsin, ${ }^{40}$ although it conflicts with several past restoration studies that observed lower bulk densities in restored prairies. ${ }^{50-52}$ For example, the results of a six-year study of a restored prairie found bulk density to increase in the $0-10 \mathrm{~cm}\left(1.25\right.$ to $\left.1.45 \mathrm{~g} / \mathrm{cm}^{3}\right), 20-35 \mathrm{~cm}\left(1.2\right.$ to $\left.1.3 \mathrm{~g} / \mathrm{cm}^{3}\right)$, and $35-50 \mathrm{~cm}\left(1.18\right.$ to $\left.1.4 \mathrm{~g} / \mathrm{cm}^{3}\right)$ depth intervals. ${ }^{53}$ The similarity in mean bulk density between the sections in our study may be partially explained by two contrasting effects involving marked differences in soil organic matter and sand content. Increases in soil organic matter tend to decrease bulk density, ${ }^{54}$ whereas increasing sand content tends to have the opposite effect. ${ }^{55}$ The unrestored section had significantly higher soil organic matter, which would suggest a lower bulk density. However, the greater sand fraction in the unrestored section may have offset this effect, resulting in a nonsignificant difference overall in bulk density between the restored prairie and the section so far resistant to restoration. Therefore, we contend that bulk density may not be a reliable diagnostic of restoration success by itself because it is fundamentally interconnected with other belowground properties such as soil organic matter. ${ }^{56}$

In general, the results presented here do not corroborate the idea that resource heterogeneity drives species diversity in grassland ecosystems ${ }^{37}$. However, some soil properties, particularly total nitrogen, were somewhat more heterogeneous in the unrestored section than in the restored section of the prairie. The heat map of total nitrogen (Figure 2) appears to show that not only was the unrestored section qualitatively more heterogeneous than the restored section, but it also contained the largest nitrogen values overall. While some studies have found both species richness and diversity to increase with nutrient resource heterogeneity, ${ }^{57-58}$ other studies suggest that the raw availability of a resource itself may be a better predictor of how similar the restored plant community becomes to a native prairie. ${ }^{38,39}$ For example, a restoration of a lowland agricultural field in Kansas indicated that establishment of non-native vegetation was lowest in treatments with lower nitrogen availability. ${ }^{39}$ The authors of that study concluded that total nitrogen availability in each treatment was a better predictor of the resulting community composition than was the spatial heterogeneity of nitrogen. ${ }^{39}$ Although total nitrogen heterogeneity was analyzed using a qualitative approach, more rigorous quantitative analyses may reveal a more conclusive explanation for the disparate outcomes at the Biocore property.

\section{CONCLUSIONS}

The disparate outcomes observed in adjacent parcels within a 13-year old prairie restoration provided an opportunity to assess the explanatory power of differences in soil properties and their spatial heterogeneity. Mean soil organic matter and bulk density, two metrics that are commonly used to measure restoration progress, did not corroborate past research that suggests prairie restoration decreases bulk density and increases soil organic matter. Several other soil properties (i.e., soil pH, \% sand, \% silt, and total nitrogen) not traditionally included in restoration progress evaluations differed between the restored parcel and the one resistant to restoration efforts. In addition, this study found that except for total nitrogen, the heterogeneity of the measured soil properties was not noticeably different between the restored and unrestored parcels. This finding did not support our second hypothesis and does not support the assumed causal relationship between resource heterogeneity and species diversity. Nevertheless, we suspect that the differences in the soil properties we observed are likely contributing to the contrasting levels of restoration success at this site and, as such, advocate for including soil properties in the study of aboveground outcomes of prairie restorations. Documented relationships between changes in soil hydraulic properties ${ }^{59}$ and soil microbial communities ${ }^{47}$, for example, and the establishment of prairie plant communities demonstrate the usefulness of coupling these above- and belowground facets of prairies under restoration.

\section{ACKNOWLEDGMENTS}

The authors thank the Friends of the Lakeshore Nature Preserve for sponsoring the Student Engagement Grant received by the first author of this study. Many thanks also to Dr. J. Batzli and S. McGee from the UW Biocore program for offering the Biocore prairie as a study site. Finally, we would like to acknowledge undergraduates D. Dryer, L. Johnson, and R. Aschenbrenner for their enthusiasm and willingness to spend hot summer days lugging around sampling equipment and helping to take measurements for this project.

\section{REFERENCES}

1. Dodds WK et al (2008) Comparing ecosystem goods and services provided by restored and native lands. In : Bioscience Magazine 58(9) : 837-845. https://doi.org/10.1641/B580909

2. Kessler R (2012) In Midwest, bringing back native prairies yard by yard. In: Yale Environment 360. https:/ / e360.yale.edu/features/in_us_midwest_restoring_native_prairie_ecosystems_kessler.

3. Kindscher K, Tieszen LL (1998) Floristic and soil organic matter changes after five and thirty-five years of native tallgrass prairie restoration. Restoration Ecol 6:181-196. doi: 10.1111/j.1526-100X.1998.06210.x

4. Wells AJ, Balster NJ, VanWychen S, Harrington J (2008) Differences in belowground heterogeneity within a restoration of a dewatered reservoir in southwestern wreisconsin. Restoration Ecol 16:678-688. doi: 10.1111/j.1526-100X.2008.00487.x 
5. Heneghan L, Miller SP, Baer S, Callaham MA, Montgomery J, Pavao-Zuckerman M, Rhoades CC, Richardson S (2008) Integrating soil ecological knowledge into restoration management. Restoration Ecol 16:608-617. doi: 10.1111/j.1526100X.2008.00477.x

6. Ruiz-Jaen MC, Mitchell Aide T (2005) Restoration success: How is it being measured? Restoration Ecol 13:569-577. doi: 10.1111/j.1526-100X.2005.00072.x

7. Chambers JC, MacMahaon JA, Wade GL (1992) Differences in successional processes among biomes: importance in obtaining and evaluating reclamation success. Northeastern Forest Experimental Station, United States Department of Agriculture Forest Service, Radnor, Pennsylvania

8. Herrick JE (2000) Soil quality: an indicator of sustainable land management? Appl Soil Ecol 15:75-83. doi: 10.1016/S09291393(00)00073-1

9. Callaham MA, Rhoades CC, Heneghan L (2008) A striking profile: Soil ecological knowledge in restoration management and science. Restoration Ecol 16:604-607. doi: 10.1111/j.1526-100X.2008.00490.x

10. Lane DR, BassiriRad H (2005) Diminishing spatial heterogeneity in soil organic matter across a prairie restoration chronosequence. Restoration Ecol 13:403-412. doi: 10.1111/j.1526-100X.2005.00050.x

11. Wang L, Coles N, Wu C, Wu J (2014) Effect of long-term reclamation on soil properties on a coastal plain, Southeast China. J Coastal Res 296:661-669. doi: 10.2112/JCOASTRES-D-13-00129.1

12. Zuo X, Zhao X, Zhao H, Zhang T, Guo Y, Li Y, Huang Y (2009) Spatial heterogeneity of soil properties and vegetation-soil relationships following vegetation restoration of mobile dunes in Horqin Sandy Land, Northern China. Plant Soil 318:153167. doi: 10.1007/s11104-008-9826-7

13. Gotelli NJ, Simberloff D (1987) The distribution and abundance of tallgrass prairie plants: A test of the core-satellite hypothesis. Amer Nat 130:18-35. doi: 10.1086/284695

14. Blumenthal DM, Jordan NR, Russelle MP (2003) Soil carbon addition controls weeds and facilitates prairie restoration. Ecol Appl 13:605-615. doi: 10.1890/1051-0761(2003)013[0605:SCACWA]2.0.CO;2

15. Natural Resources Conservation Service (2017) Web Soil Survey.

16. Herrick JE, Jones TL (2002) A dynamic cone penetrometer for measuring soil penetration resistance. Soil Sci Soc Am J 66:1320-1324.

17. Moraes MT de, Debiasi H, Carlesso R, Franchini JC, Silva VR da (2014) Critical limits of soil penetration resistance in a rhodic Eutrudox. Rev Bras Ciênc Solo 38:288-298. doi: 10.1590/S0100-06832014000100029

18. Ayers PD, Perumpral JV (1982) Moisture and density effect on cone index. Trans ASAE 25:1169-1172. doi: $10.13031 / 2013.33691$

19. Halliday D, Resnick R (1963) Physics for students of science and engineering, combined edition. John Wiley and Sons, Inc., New York, NY

20. Blake GR, Hartge KH (1986) Bulk density. In: Klute A (ed) Methods of Soil Analysis, Part 1_Physical and Mineralogical Methods, 2nd Edition. Soil Science Society of America, Madison, WI, pp 363-382

21. Kunze GW, Rich CI (1959) Mineralogical methods. In: Rich CI, Seatz LF, Kunze GW. Certain properties of selected southeastern United States soils and mineralogical procedures for their study. Southern Coop. Series Bul. 61: 135-146.

22. Bouyoucos GJ (1962) Hydrometer method improved for making particle size analyses of soils. Agron J 54:464. doi: 10.2134/agronj1962.00021962005400050028x

23. Fox RL, Weaver JE, Lipps RC (1953) Influence of certain soil-profile characteristics upon the distribution of roots of grasses. Agron J 45:583. doi: 10.2134/agronj1953.00021962004500120001x

24. McCauley A, Jones C, Olson-Rutz K (2017) Soil pH and Organic Matter. Montana State University Extension, Bozeman, MT

25. Delta-T Devices (1996) Thetaprobe Soil Moisture User Manual.

26. R Core Team (2018) R: A language and environment for statistical computing. Foundation for Statistical Computing, Vienna, Austria

27. Wickham H (2009) ggplot2: Elegant Graphics for Data Analysis. Springer-Verlag, New York

28. Bates D, Mächler M, Bolker B, Walker S (2015) Fitting linear mixed-effects models using Ime4. J Stat Softw. doi: 10.18637/jss.v067.i01

29. Kuznetsova A, Brockhoff PB, Bojesen RH (2016) ImerTest. Tests in linear mixed effects models.

30. Halekoh U, Højsgaard S (2014) A Kenward-Roger approximation and parametric bootstrap methods for tests in linear mixed models - The R package pbkrtest. J Stat Softw 59:1-30. doi: 10.18637/jss.v059.i09

31. Natural Resources Conservation Service (2014) Soil Survey Field and Laboratory Methods Manual. United States Department of Agriculture

32. Jastrow JD (1987) Changes in soil aggregation associated with tallgrass prairie restoration. Am J Bot 74:1656-1664. doi: 10.1002/j.1537-2197.1987.tb08765.x 
33. Matamala R, Jastrow JD, Miller RM, Garten CT (2008) Temporal changes in C and N stocks of restored prairie: Implications for C sequestration strategies. Ecol Appl 18:1470-1488. doi: 10.1890/07-1609.1

34. McLauchlan KK, Hobbie SE, Post WM (2006) Conversion from agriculture to grassland builds soil organic matter on decadal timescales. Ecol Appl 16:143-153. doi: 10.1890/04-1650

35. Nelson JDJ, Schoenau JJ, Malhi SS (2008) Soil organic carbon changes and distribution in cultivated and restored grassland soils in Saskatchewan. Nutr Cycl Agroecosyst 82:137-148. doi: 10.1007/s10705-008-9175-1

36. Zilverberg CJ, Heimerl K, Schumacher TE, Malo DD, Schumacher JA, Johnson WC (2018) Landscape dependent changes in soil properties due to long-term cultivation and subsequent conversion to native grass agriculture. CATENA 160:282-297. doi: $10.1016 /$ j.catena.2017.09.020

37. Hutchinson GE (1959) Homage to Santa Rosalia or Why are there so many kinds of animals? Amer Nat 93:145-159.

38. Collins B, Wein G (1998) Soil heterogeneity effects on canopy structure and composition during early succession. Plant Ecol 138:217-230.

39. Baer SG, Blair JM, Collins SL, Knapp AK (2004) Plant community responses to resource availability and heterogeneity during restoration. Oecologia 139:617-629. doi: 10.1007/s00442-004-1541-3

40. Kucharik CJ (2007) Impact of prairie age and soil order on carbon and nitrogen sequestration. Soil Sci Soc Am J 71:430. doi: $10.2136 /$ sssaj2006.0074

41. Yost JL, Egerton-Warburton LM, Schreiner KM, Palmer CE, Hartemink AE (2016) Impact of restoration and management on aggregation and organic carbon accumulation in urban grasslands. Soil Sci Soc Am J 80:992. doi: 10.2136/sssaj2015.10.0383

42. Lamb JA, Fernandez FG, Kalser DE (2014) Understanding Nitrogen in Soils. University of Minnesota Extension

43. Miller JO (2016) Soil pH Affects Nutrient Availability. bttps:/ / extension.umd.edu/learn/soil-ph-affects-nutrient-availability.

44. Brye KR, Norman JM, Gower ST (2002) Assessing the progress of a tallgrass prairie restoration in southern Wisconsin. Am Midl Nat 148:218. doi: 10.1674/0003-0031(2002)148[0218:ATPOAT]2.0.CO;2

45. Laboski, CAM., Peters JB, Bundy, LG (2017) Nutrient application guidelines for field, vegetable, and fruit crops. Extension Publication A2809. University of Wisconsin - Madison.

46. Aciego Pietri JC, Brookes PC (2008) Relationships between soil pH and microbial properties in a UK arable soil. Soil Biol Biochem 40:1856-1861. doi: 10.1016/j.soilbio.2008.03.020

47. Jangid K, Williams MA, Franzluebbers AJ, Blair JM, Coleman DC, Whitman WB (2010) Development of soil microbial communities during tallgrass prairie restoration. Soil Biol Biochem 42:302-312. doi: 10.1016/j.soilbio.2009.11.008

48. Card SM, Quideau SA (2010) Microbial community structure in restored riparian soils of the Canadian prairie pothole region. Soil Biol Biochem 42:1463-1471. doi: 10.1016/j.soilbio.2010.05.010

49. Swab RM, Lorenz N, Byrd S, Dick R (2017) Native vegetation in reclamation: Improving habitat and ecosystem function through using prairie species in mine land reclamation. Ecol Eng 108:525-536. doi: 10.1016/j.ecoleng.2017.05.012

50. McKinley VL, Peacock AD, White DC (2005) Microbial community PLFA and PHB responses to ecosystem restoration in tallgrass prairie soils. Soil Biol Biochem 37:1946-1958. doi: 10.1016/j.soilbio.2005.02.033

51. David MB, McIsaac GF, Darmody RG, Omonode RA (2009) Long-term changes in Mollisol organic carbon and nitrogen. J Environ Qual 38:200. doi: 10.2134/jeq2008.0132

52. Rosenzweig ST, Carson MA, Baer SG, Blair JM (2016) Changes in soil properties, microbial biomass, and fluxes of C and N in soil following post-agricultural grassland restoration. Appl Soil Ecol 100:186-194. doi: 10.1016/j.apsoil.2016.01.001

53. Camill P, McKone MJ, Sturges ST, Severud WJ, Ellis E, Limmer J, Martin CB, Navratil RT, Purdie AJ, Sandel BS, Talukder $\mathrm{S}$, Trout A (2004) Community- and ecosystem-level changes in a species-rich tallgrass prairie restoration. Ecol Appl14:1680 1694. doi: 10.1890/03-5273

54. Adams WA (1973) The effect of organic matter on the bulk and true densities of some uncultivated podzolic soils. J Soil Sci 24:10-17. doi: 10.1111/j.1365-2389.1973.tb00737.x

55. Natural Resources Conservation Service Bulk Density/Moisture/Aeration. United States Department of Agriculture

56. Johnston MR, Balster NJ, Zhu J (2016) Impact of residential prairie gardens on the physical properties of urban soil in Madison, Wisconsin. J Environ Qual 45:45-52. doi: 10.2134/jeq2015.02.0093

57. Chesson P (2000) General theory of competitive coexistence in spatially-varying environments. Theor Popul Bio 58:211-237. doi: $10.1006 /$ tpbi.2000.1486

58. Williams BM, Houseman GR (2014) Experimental evidence that soil heterogeneity enhances plant diversity during community assembly. J Plant Ecol 7:461-469. doi: 10.1093/jpe/rtt056

59. Chandrasoma JM, Udawatta RP, Anderson SH, Thompson AL, Abney MA (2016) Soil hydraulic properties as influenced by prairie restoration. Geoderma 283:48-56. https://doi.org/10.1016/j.geoderma.2016.08.001 


\section{ABOUT THE STUDENT AUTHOR}

Krista Marshall performed this study during the summer of 2017 while working as an undergraduate research student in the Balster Lab and finishing her degree in Biological Systems Engineering and Environmental Studies at the University of Wisconsin - Madison. This study inspired Krista to pursue a graduate degree focused on soil science and food systems, her two primary areas of interest. She is currently enrolled in a Ph.D. program in horticulture and agronomy at the University of California Davis.

\section{PRESS SUMMARY}

Approaches for evaluating the progress of prairie restorations tend to focus on aboveground properties. As a result, how belowground properties impact the establishment and trajectory of restorations remains unclear. On this premise, we compared physiochemical soil properties of two adjacent parcels, one successful and one not, within a 13-year-old prairie restoration. We found that many soil properties differed (i.e., percent sand, percent silt, soil $\mathrm{pH}$, and total nitrogen) markedly between these two parcels. However, two soil properties that often correlate with restoration progress (increased soil organic matter and decreased bulk density) in similar studies did not do so at our site. Additionally, only total nitrogen was more spatially heterogeneous in unrestored parcel versus the other, which did not support the second hypothesis. These results emphasize the importance of including soil properties in evaluations of prairie restorations as well as their differential role in inhibiting or supporting restoration success. 


\title{
Selective Extraction of Red Phosphor $\left(\mathrm{Y}_{2} \mathrm{O}_{3}: \mathrm{Eu}^{3+}\right)$ Constituents from Waste Fluorescent Lamps Phosphor Using Acid Leaching
}

\author{
Parul Johar*a, Vishal Jangir*b, Yogita Choudhary', \& Sudhanshu Mallick ${ }^{c}$ \\ ${ }^{a}$ Department of Energy and Environment, TERI School of Advanced Studies, New Delhi, India \\ ${ }^{b}$ Centre for Converging Technologies, University of Rajasthan, Jaipur, India \\ 'Department of Metallurgical Engineering and Materials Science, IIT Bombay, Mumbai, India \\ Students:joharparul@gmail.com*,yogitta.choudhary@gmail.com,jvishalcct013.nano@gmail.com* \\ Mentor:mallick@iitb.ac.in
}

\begin{abstract}
Modern fluorescent lamp phosphor powder contains tricolor phosphor. This tricolor phosphor consists of three different types of rare earth phosphors: red (YOX), green (CMAT/LAP) and blue (BAM); mixed in varying proportions. The exact separation of these three rare earth phosphors is essential in order to precisely recover the contained rare earth elements from waste lamps phosphor. In this present work, we reported an efficient methodology for the separation of these three tricolor phosphors and the selective extraction of predominantly presented red phosphor (YOX) constituents using acid leaching. The waste phosphor powder was leached with different acids: both organic and inorganic type. The $3 \mathrm{M} \mathrm{H}_{2} \mathrm{SO}_{4}$ leaching was found to be most suitable for the selective extraction of red phosphor constituents, i.e. Y and Eu. The recovered phosphor powder was analyzed with SEM/EDS and XRD analysis. The obtained XRD pattern was refined using Rietveld refinement method for the quantification of phases present. Recovered red phosphor powder contained three main crystalline phases $\mathrm{Y}_{2} \mathrm{O}_{3}, \mathrm{Eu}_{2} \mathrm{O}_{3}$ and $\mathrm{Y}_{2} \mathrm{OS}_{2}$.
\end{abstract}

\section{KEYWORDS}

Waste Lamp Phosphor; Tricolor Phosphor; Rare Earth Elements; Acid Leaching

\section{INTRODUCTION}

The rare earth elements (REEs), which include 15 lanthanides, Y and Sc are essential for the development of various advanced technologies including efficient lighting, wind turbines, and hybrid electric vehicles. Moreover, their global demand is forecasted to continue with increasing rate of 3.7\%-8.6\% per year. ${ }^{1}$ The primary sources of REEs extraction are mining of various natural deposits, e.g. bastnaesite, xenotime, and monazite etc. and ion-adsorption ores, contain varying amount of different REEs. Although their mining production and separation are considered difficult because these elements share similar chemical properties and have associated environmental concerns with their extraction. ${ }^{2}$ To overcome both sustainable supply and environmental issues, an alternative approach as their efficient recovery from waste products i.e. urban mining is considered. Urban mining is emerging as an efficient source for REEs extraction and continuously receiving great attention towards their recovery from the end of life (EoL) products containing permanent magnets, phosphors, and NiMH rechargeable batteries.

Among all other EoL products, waste fluorescent lamps (FLs) are considered as the major source for REEs recovery since hundreds of millions of units of FLs are produced and discarded every year globally. As reported in the previous studies it is suggested that FLs phosphor often contributes to 2-3\% of the total mass of a FL, 3 and contains about 23\% of REEs., Modern FLs phosphors are typically composed of white calcium halophosphate and rare earth triphosphors, whose composition varies across manufacturers. These rare earth triphosphors are the mixture of red, green and blue rare earth phosphor with the varying composition and contain Y, La, Eu, Gd, Ce, and Tb as the key REEs (Table 1)..$^{7-9}$

Currently, various approaches are being employed for the recovery of REEs from lamp phosphors including hydrometallurgy ${ }^{4}, 10,11$ pyrometallurgy ${ }^{12}$, supercritical liquid extraction ${ }^{13}$, electrometallurgy ${ }^{14}$, and mechanical activation method. ${ }^{15}$ Among all these approaches, hydrometallurgy is most widely accepted for the selective recovery of REEs because of its large operational scale, low energy circulation and low investment cost with high extraction yield especially for Y and $\mathrm{Eu}^{16,17} \mathrm{Y}$ and Eu have special attention during the recovery of various REEs from waste lamp phosphors due to the high intrinsic value of $\mathrm{Y}_{2} \mathrm{O}_{3}: \mathrm{Eu}^{3+}$ as red rare earth phosphor present in them. ${ }^{17,18}$

Hydrometallurgy typically includes leaching process followed by precipitation and solvent extraction to dissolve, separate and recover pure REEs. Generally, different acids, e.g. $\mathrm{HCl}, \mathrm{H}_{2} \mathrm{SO}_{4}, \mathrm{HNO}_{3}$, and alkalis, e.g. $\mathrm{NaOH}$ and $\mathrm{NH}_{3}$ are employed as leaching agents. The leaching efficiencies for $\mathrm{Y}$ and Eu along with $\mathrm{Ca}$ are much higher than others like $\mathrm{Ce}$, $\mathrm{Tb}$, and $\mathrm{La}$, this is due to easy dissolution of calcium halophosphate and YOX in dilute acids. ${ }^{19}$ Under the conditions of pressure leaching of the waste phosphor blend, the leaching efficiencies for $\mathrm{Y}$ and Eu were achieved about $96.4 \%$ and $92.8 \%$, respectively. ${ }^{4}$ According to the previous studies, not much work has been done on the separation of red, green and blue rare earth phosphors, 
obtained from real waste fluorescent lamps. Otsuki ${ }^{20}$ used two liquid flotation process using N, N-dimethyl formamide (DMF) and heptane to separate $\mathrm{Y}_{2} \mathrm{O}_{3}: \mathrm{Eu}^{3+}, \mathrm{LaPO}_{4}: \mathrm{Ce}^{3+}, \mathrm{Tb}^{3+}$, and $(\mathrm{Sr}, \mathrm{Ca}, \mathrm{Be}, \mathrm{Mg})_{5}\left(\mathrm{PO}_{4}\right)_{3} \mathrm{Cl}_{\mathrm{E}} \mathrm{Eu}^{2+}$ three different lamp phosphors. Mei21 separated red $\left(\mathrm{Y}_{2} \mathrm{O}_{3}: \mathrm{Eu}^{3+}\right)$, blue $\left(\mathrm{BaMgAl}_{10} \mathrm{O}_{17}: \mathrm{Eu}^{2+}\right)$ and green $\left(\mathrm{CeMgAl}_{10} \mathrm{O}_{17}: \mathrm{Tb}^{3+}\right)$ rare earth phosphor from synthetic rare earth triphosphor mixture using liquid/liquid extraction, 2-thenoyltrifluoroacetone (TTA) and potassium sodium tartrate depressant (PST) used to extract blue and red phosphor, respectively while chloroform used to extract green phosphor. Schaeffer ${ }^{22}$ used a Brønsted acidic ionic liquid, i.e. 1-methylimidazolium hydrogen sulfate $\left([\mathrm{Hmim}]\left[\mathrm{HSO}_{4}\right]\right)$ at the place of $\mathrm{H}_{2} \mathrm{SO}_{4}$ for the recovery of $\mathrm{Y}_{2} \mathrm{O}_{3}: \mathrm{Eu}^{3+}$ (YOX) from waste fluorescent lamp phosphor.

\begin{tabular}{|c|c|c|}
\hline Type of phosphor & Potential compounds & $\begin{array}{c}\text { The approximate amount } \\
\text { in tricolor lamp phosphor }\end{array}$ \\
\hline Red & $\mathrm{Y}_{2} \mathrm{O}_{3}: \mathrm{Eu}^{3+}(\mathrm{YOX})$ & $55 \%$ \\
\hline Green & $\begin{array}{c}(\mathrm{Ce}, \mathrm{Tb}) \mathrm{MgAl}_{11} \mathrm{O}_{19}(\mathrm{CMAT}) \\
\mathrm{LaPO}_{4}: \mathrm{Ce}^{3+}, \mathrm{Tb}^{3+}(\mathrm{LAP})\end{array}$ & $35 \%$ \\
\hline Blue & $\mathrm{BaMgAl}_{10} \mathrm{O}_{17}: \mathrm{Eu}^{2+}(\mathrm{BAM})$ & $10-15 \%$ \\
\hline
\end{tabular}

Table 1. The appropriate chemical composition of tricolor rare earth phosphors used in modern FLs.

With respect to the above-mentioned issues, here we present an efficient methodology for the separation of red phosphor (YOX) from waste FLs phosphor mixture and its treatment to recover Y and Eu. The method used in this work incorporates the use of different leaching agents including various organic and inorganic acids for recovering REEs from the red phosphor. Further processes like precipitation and calcination were applied to separate the red phosphor constituents and to recover them. The challenges associated with recovery which include purities and concentrations of recovered REEs were also examined.

\section{MATERIALS AND METHODS}

Materials

The waste phosphor sample, collected from end-of-life FLs after removal of mercury, was provided by a leading Indian ewaste recycling company (Eco Recycling Ltd., Mumbai). As the leaching reagents; sulfuric acid (98\%), citric acid, and aqua regia ( $\mathrm{HCl}: \mathrm{HNO}_{3}$, volume ratio 3:1) were employed. The $3 \mathrm{M} \mathrm{H}_{2} \mathrm{SO}_{4}$ was prepared by diluting the sulfuric acid (98\%) with pure water. Sodium hydroxide and oxalic acid were used for the $\mathrm{pH}$ adjustment and precipitation of leaching residues to obtain REEs oxalates, respectively. All the chemicals used in this work were of analytical grade and used without any further purification.

\begin{tabular}{|c|c|c|c|c|c|}
\hline \multicolumn{3}{|c|}{ REEs } & \multicolumn{3}{c|}{ Other elements } \\
\hline Element & $\begin{array}{c}\text { Mass (wt. } \\
\text { \%) }\end{array}$ & Element & $\begin{array}{c}\text { Mass (wt. } \\
\text { \%) }\end{array}$ & Element & $\begin{array}{c}\text { Mass (wt. } \\
\text { \%) }\end{array}$ \\
\hline $\mathbf{Y}$ & 18.1 & $\mathbf{C a}$ & 11.0 & $\mathbf{A l}$ & 1.9 \\
\hline $\mathbf{E u}$ & 1.7 & $\mathbf{P}$ & 11.8 & $\mathbf{M n}$ & 0.6 \\
\hline $\mathbf{C e}$ & 1.6 & $\mathbf{O}$ & 10.2 & $\mathbf{Z n}$ & 1.4 \\
\hline $\mathbf{T b}$ & 2.2 & $\mathbf{B a}$ & 1.4 & $\mathbf{S i}$ & 0.3 \\
\hline $\mathbf{L a}$ & 1.6 & $\mathbf{M g}$ & 0.4 & $\mathbf{C l}$ & 0.5 \\
\hline $\mathbf{G d}$ & 2.9 & $\mathbf{S r}$ & 3.8 & $\mathbf{P t}$ & 28.5 \\
\hline
\end{tabular}

\begin{tabular}{|c|c|c|}
\hline Phase name & Chemical formula & Fraction (wt. \%) \\
\hline BAM & $\mathrm{Ba}_{0.9} \mathrm{Eu}_{0.1} \mathrm{Mg}_{2} \mathrm{Al}_{16} \mathrm{O}_{27}$ & 7.71 \\
\hline Fluorapatite & $\mathrm{Ca}_{5}\left(\mathrm{PO}_{4}\right)_{3} \mathrm{~F}_{0.94} \mathrm{Cl}_{0.1}$ & 7.95 \\
\hline CMAT & $\mathrm{Ce}_{0.67} \mathrm{~Tb}_{0.33}{ }_{\mathrm{MgAl}} \mathrm{Al}_{11} \mathrm{O}_{19}$ & 10.41 \\
\hline YOX & $\left(\mathrm{Y}_{0.95} \mathrm{Eu}_{0.05}\right)_{2} \mathrm{O}_{3}$ & 16.69 \\
\hline Hydroxylapatite & $\mathrm{Ca}_{9.42} \mathrm{Sr}_{0.18} \mathrm{H}_{0.4}\left(\mathrm{PO}_{4}\right)_{6}(\mathrm{OH})_{1.60}$ & 26.96 \\
\hline Coesite (Quartz) & $\mathrm{SiO}_{2}$ & 30.29 \\
\hline
\end{tabular}

Table 3. Weight fraction of each phase present in the raw waste phosphor sample; resultant from structure refinement of obtained XRD pattern using the Rietveld refinement method.

A report on the detailed characterization of this investigated waste phosphor sample has already been submitted elsewhere. Here, in the present paper, the results obtained we have also added the chemical composition results obtained from waste phosphor sample analysis. The preliminary elemental composition of waste phosphor sample was determined using EDS and ICP-AES analysis. The obtained EDS analysis results for various REEs and other elements are given in Table 2. XRD 
analysis was done to confirm the presence of various phases; this was followed by the structure refinement of obtained XRD pattern using Rietveld refinement method for the quantitative analysis of the phases and elements presented (Table 3).

\section{Experimental methodology}

a. Acid Leaching

Preliminary leaching tests were performed using various acids including both inorganic and organic acids as leaching reagent; in order to find out the appropriate leaching reagent to obtain the high recovery yield for REEs. These leaching reagents were sulfuric acid (3 $\mathrm{M}$ and $18 \mathrm{M})$, aqua regia $\left(\mathrm{HCl}: \mathrm{HNO}_{3}\right.$; volume ratio $\left.3: 1\right)$ and citric acid. Initially, $0.1 \mathrm{~g}$ of waste fluorescent lamp phosphor sample was dissolved into these different leaching reagents. The traditional aqua regia was employed since it is generally used to dissolve various metals. Two different molarities of sulfuric acid, $3 \mathrm{M}$ and $18 \mathrm{M}$ used to check its potential to dissolve all three rare earth phosphor present in waste phosphor sample. The citric acid was employed as an organic leaching agent, to recover REEs in an environmentally friendly manner. Some of the leaching parameters as the leaching temperature and solid to liquid (S/L) ratio (w/v) kept constant at $90{ }^{\circ} \mathrm{C}$ and $40 \%$, respectively for each leaching experiment performed, moreover according to the available literature, the optimized leaching time for sulfuric acid ${ }^{11}$ and aqua regia was kept constant at $4 \mathrm{~h}$. The leaching time for citric acid leaching experiment was varied from $1 \mathrm{~h}$ to $2 \mathrm{~h}$ to reveal its potential for employing it as the suitable organic leaching agent.

\section{b. Precipitation and calcination}

The change in $\mathrm{pH}$ of the leached solution of the phosphor was observed using $\mathrm{pH}$ meter and adjusted to 2.4 using sodium hydroxide solution for the further ease of separation of the constituent elements by precipitation. The precipitation of obtained filtrate was done using the oxalic acid to convert the rare earth elements present into their respective oxalates. The precipitate i.e. rare earth oxalates obtained from the leachate was filtered and dried. The dried precipitate was kept in the muffle furnace in an alumina crucible at $750{ }^{\circ} \mathrm{C}$ for $6 \mathrm{~h}$. This process was performed for the conversion of rare earth oxalate into their respective rare earth oxides. The possible chemical reactions that took place during the precipitation of the $\mathrm{Y}$ and Eu into their respective oxalates and the calcination of these oxalates in order to decompose them into their respective oxides are given below:

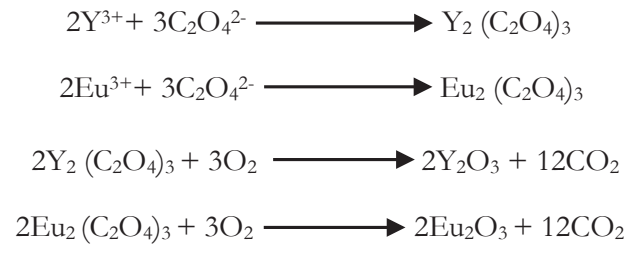

Equation 1.

Equation 2.

Equation 3.

Equation 4.

The complete experimental methodology used for the separation of tricolor phosphor and recovery of red phosphor is shown schematically in Figure 1.

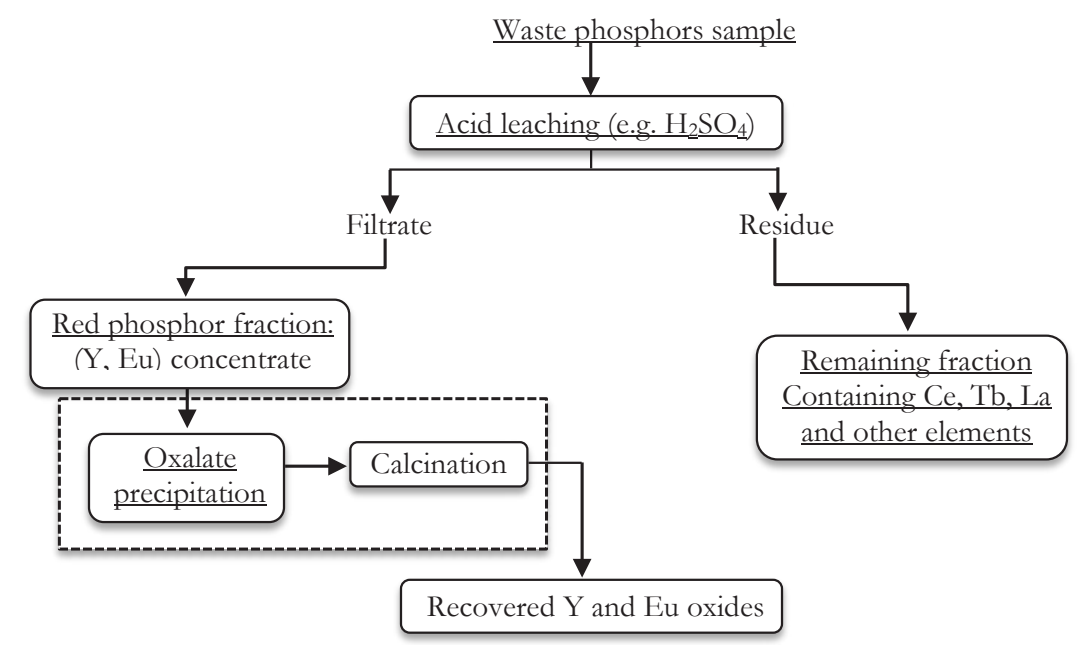

Figure 1. The experimental methodology used for the selective separation of red phosphor (YOX) and recovery of its constituents.

\section{c. Analytical techniques}

The chemical composition of the raw waste phosphor powder sample was analyzed using ICP-AES analysis. This technique was also used to determine the dissolution yield of the various elements in the leached liquor. The surface characteristics, morphology and elemental qualitative information of the resultant calcined powder of rare earth oxides were revealed using 
SEM (JEOL JSM-7600F) along with EDS. The main crystalline phases present in the recovered rare earth oxide powder were analyzed using XRD (EMPYREAN, PANalytical) analysis; operated at $45 \mathrm{kV}$ tube voltage and $40 \mathrm{~mA}$ tube current with the $\mathrm{Cu}-\mathrm{K} \alpha(\lambda=1.54 \AA \hat{\mathrm{A}})$ radiation and the scanning was performed between $0^{\circ}$ to $90^{\circ}$ using continuous scanning mode. Further, the structure refinement of obtained XRD data was done by using the Rietveld refinement method with FullProf software for quantitative phase analysis.

\section{RESULTS AND DISCUSSION}

Effect of different leaching agents on leaching rates of elements

Table 4 shows the extracted fractions of various elements as the function of different acids leaching of waste phosphor sample measured using ICP-AES (SECTRO ACROS). As seen from the results, it is possible to conclude that the solubility of the predominant calcium halophosphate and red phosphor constituents was much higher in the $3 \mathrm{M} \mathrm{H}_{2} \mathrm{SO}_{4}$ leaching since they both readily dissolve in the diluted acids. ${ }^{19}$

\begin{tabular}{|c|c|c|c|c|c|c|c|c|c|c|c|c|c|c|c|}
\hline & $\mathbf{Y}$ & $\mathbf{E u}$ & $\mathbf{C e}$ & $\mathbf{T b}$ & $\mathbf{G d}$ & $\mathbf{L a}$ & $\mathbf{C a}$ & $\mathbf{P}$ & $\mathbf{S r}$ & $\mathbf{A l}$ & $\mathbf{M g}$ & $\mathbf{B a}$ & $\mathbf{S i}$ & $\mathbf{S b}$ & $\mathbf{M n}$ \\
\hline $\begin{array}{c}\mathbf{S A ~ ( 3} \\
\mathbf{M} \mathbf{3}\end{array}$ & 18.55 & 1.75 & 0.07 & $<0.01$ & $<0.01$ & 0.06 & 19.55 & 9.21 & 0.09 & 1.34 & 0.03 & 0.02 & 0.31 & 0.36 & 0.28 \\
\hline $\begin{array}{c}\mathbf{S A} \\
\mathbf{1 8} \mathbf{M})\end{array}$ & 16.41 & 0.84 & 0.7 & $<0.01$ & $<0.01$ & 1.03 & 17.55 & 8.84 & 0.12 & 0.64 & 0.02 & 0.01 & 0.19 & 0.33 & 0.25 \\
\hline $\mathbf{C A} \mathbf{( 1 h})$ & 4.73 & 0.06 & 0.05 & 0.03 & $<0.01$ & $<0.01$ & 9.13 & n.d. & 0.03 & 0.67 & 0.08 & 0.19 & n.d. & n.d. & n.d. \\
\hline $\begin{array}{c}\mathbf{C A} \\
\mathbf{( 2 h}\end{array}$ & 3.37 & 0.16 & $<0.0$ & $<0.01$ & $<0.01$ & $<0.01$ & 3.95 & n.d. & 0.01 & 0.21 & 0.1 & 0.12 & n.d. & n.d. & n.d. \\
\hline $\mathbf{A q R}$ & 2.86 & 0.95 & 0.02 & n.d. & $<0.01$ & $<0.01$ & 17.61 & 8.86 & 0.09 & 2.67 & 0.06 & 0.08 & 0.57 & n.d. & n.d. \\
\hline
\end{tabular}

Table 4. Element extraction obtained using different acids as leaching agents (wt. \%) (SA= Sulfuric acid; $\mathrm{CA}=\mathrm{Citric}$ acid; AqR= Aqua Regia $*$ not determined).

The major advantage of using $\mathrm{H}_{2} \mathrm{SO}_{4}$ leaching is that it provides high rates of extraction for $\mathrm{Y}$ and Eu due to the low solubility of formed $\mathrm{CaSO}_{4}$ (gypsum), which is the major impurity to the leach liquor. ${ }^{11}$ The results suggest that the other REEs (e.g., Ce, Tb, La) contributed from the green and blue type phosphor were extracted in the much higher extent when waste powder was leached using concentrated $(18 \mathrm{M}) \mathrm{H}_{2} \mathrm{SO}_{4}$ since they have highly stable chemical structure of spinel type and requires alkali roasting before acid leaching to destroy their spinel chemical structure. ${ }^{23}$

Figure 2 reports the extracted fraction of four major elements including $\mathrm{Y}$ and $\mathrm{Eu}$ as a function of treatment with the different types of leaching agents. The highest contribution of $\mathrm{Y}$ and Eu to the leach liquor was found to be $18.55 \%$ and $1.75 \%$ respectively for the $3 \mathrm{M} \mathrm{H}_{2} \mathrm{SO}_{4}$ leaching. This trend was also observed with the calcium halophosphate constituents (e.g., Ca, P) as the Ca was also extracted in higher extent about $19.55 \%$ when treated with $3 \mathrm{M} \mathrm{H}_{2} \mathrm{SO}_{4}$ as compared to the 18 $\mathrm{M} \mathrm{H}_{2} \mathrm{SO}_{4}$ leaching. This is probably due to the formation of the low solubility of $\mathrm{CaSO}_{4}$.

The leaching experiments performed using citric acid did not provide satisfactory results as both the REEs and other elements were extracted in very limited extent which shows that it is not suitable as the leaching agent for the recovery of red phosphor constituents since the extraction of $\mathrm{Y}$ was found to be only about $4.73 \%$ which is too low with respect to the other acid leaching experiments. The similar behavior was seen using the aqua regia as leaching agent ( $\mathrm{Y}$ extraction was only $2.86 \%$ ). The maximum number of elements (about 15) were extracted using $\mathrm{H}_{2} \mathrm{SO}_{4}(3 \mathrm{M}$ as well as $18 \mathrm{M}$ ) leaching and other employed leaching agents were not able to extract more than 12 elements.

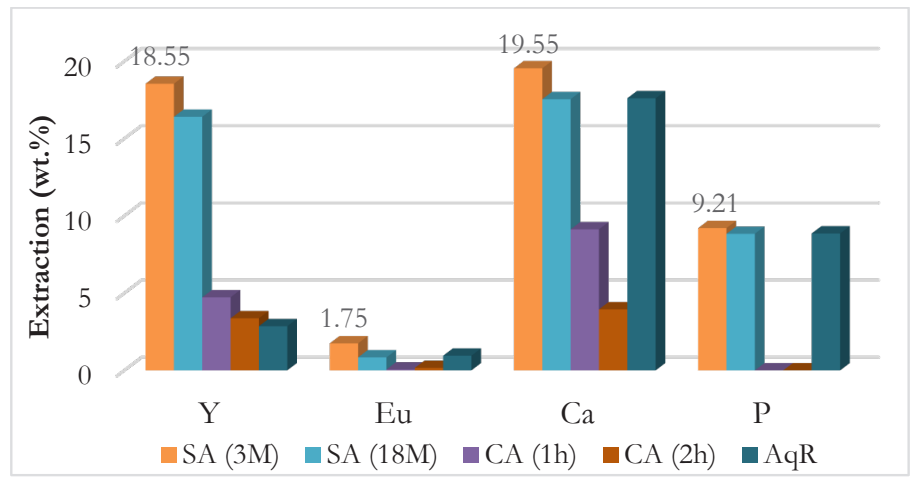

Figure 2. Extraction of major constituents of YOX and HALO phosphor obtained by various acid leaching of waste phosphor powder. 
Selective extraction of red $\left(\mathrm{Y}_{2} \mathrm{O}_{3}: \mathrm{Eu}^{3+}\right)$ phosphor constituents

As the $3 \mathrm{M} \mathrm{H}_{2} \mathrm{SO}_{4}$ leaching was found satisfactory for the leaching of $\mathrm{Y}$ and $\mathrm{Eu}$, the obtained filtrate was precipitated by the addition of oxalic acid. The obtained precipitate was filtered and dried overnight. Finally, this dried oxalate powder was calcined in order to produce the respective $\mathrm{Y}$ and Eu oxides.

\section{a. SEM/EDS results}

Figure 3(a) shows the characteristic micrograph of the obtained powder constituents as the densely packed flake-like morphology recovered using $3 \mathrm{M} \mathrm{H}_{2} \mathrm{SO}_{4}$ acid solution. All the elements were uniformly scattered as inferred from the EDS spectrum (Figure 3(b)). These obtained results clarify the existence of both $\mathrm{Y}$ and Eu as the major constituents in the recovered phosphor powder which are the major constituents of the red phosphor.

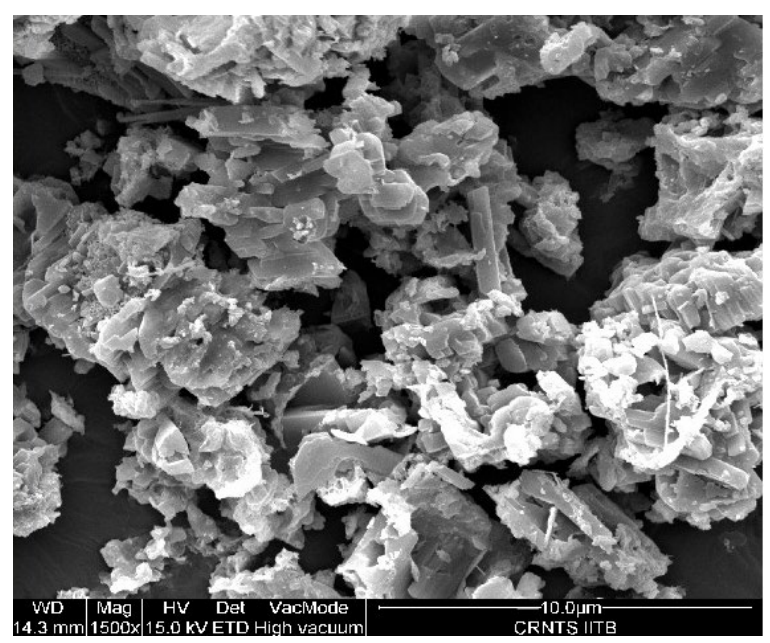

(a)

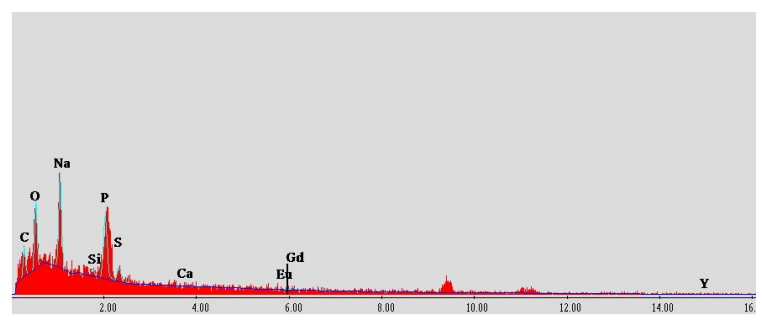

(吕)

Figure 3. (a). SEM micrograph \& (b). EDS spectrum of recovered red rare earth phosphor constituents.

As shown in Table 5, the yttrium and europium were found in the concentration of about $33.19 \%$ and $1.25 \%$ respectively. The appearance of Gadolinium in the obtained spectrum is significant to the presence of $\mathrm{Gd}_{2} \mathrm{O}_{3}$ phosphor in minor amount along with the YOX as the red rare earth phosphor ${ }^{24}$ in the waste phosphor sample and earlier this was also observed from the obtained ICP-AES results of waste phosphor sample (Table 4).

\begin{tabular}{|l|c|c|c|c|c|c|c|c|c|}
\hline Element & Y & Eu & Gd & P & S & Si & Na & O & C \\
\hline $\begin{array}{l}\text { Mass } \\
\text { (wt. \%) }\end{array}$ & 33.2 & 1.2 & 1.9 & 5.2 & 1.6 & 0.5 & 10.2 & 21.2 & 24.7 \\
\hline \multicolumn{8}{|c|}{ Table 5. EDS analysis of recovered red phosphor powder. }
\end{tabular}

The $\mathrm{Si}$ and $\mathrm{Na}$ appeared as minor impurity elements possibly due to leached quartz particles and added $\mathrm{NaOH}$ for the $\mathrm{pH}$ adjustment respectively. The impurities from other REE phosphors (e.g. BAM and CMAT) were not detected in recovered phosphor powder, these results suggest the successful separation of the red phosphor from other waste phosphor constituents.

\section{b. XRD and Rietveld refinement results}

Figure 4 shows the X-ray diffraction pattern of recovered phosphor powder by using dilute $(3 \mathrm{M}) \mathrm{H}_{2} \mathrm{SO}_{4}$ acid leaching along with the possible phases present. The major crystalline phases have been identified by their respective JCPDS cards Yttrium oxide ( $\mathrm{Y}_{2} \mathrm{O}_{3}$; JCPDS 00-041-1105), Europium oxide ( $\mathrm{Eu}_{2} \mathrm{O}_{3}$, JCPDS 00-034-0072) and Yttrium oxide sulphide $\left(\mathrm{Y}_{2} \mathrm{OS}_{2}\right.$, 
JCPDS 01-079-2251) along with the three minor impurity phases namely, quartz ( $\mathrm{SiO}_{2}$, JCPDS 00-012-0708), sodium oxalate ( $\mathrm{Na}_{2} \mathrm{C}_{2} \mathrm{O}_{4}$, JCPDS 00-049-1816) and calcium phosphate ( $\mathrm{Ca}_{3}\left(\mathrm{PO}_{4}\right)_{2}$, JCPDS 00-009-0169). The identified sodium oxalate phase is possibly present due to the remaining oxalate precipitate even after the calcination process, this clarifies that the calcination temperature should be higher than $750{ }^{\circ} \mathrm{C}$ for the complete decomposition of the generated oxalate precipitates. The presence of quartz phase is mainly due to the leached quartz impurities from the waste phosphor sample.

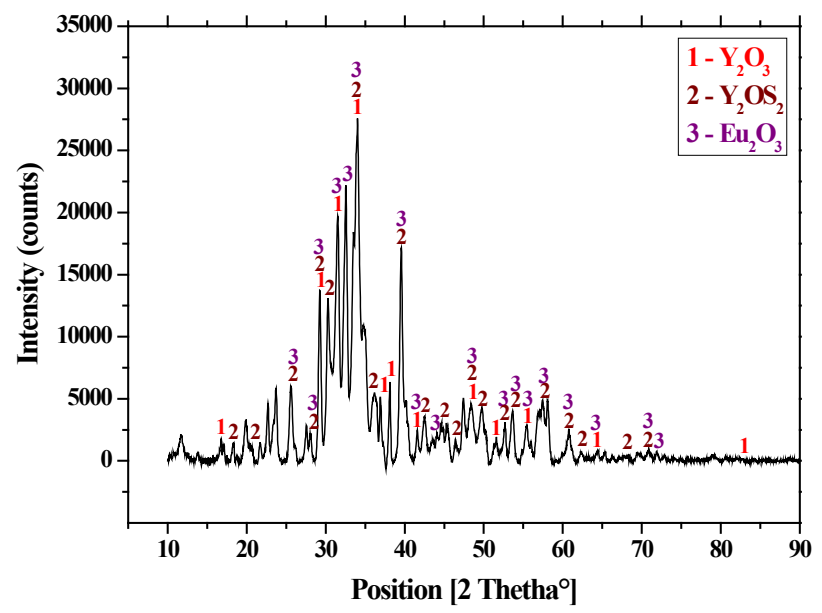

Figure 4. - X-ray diffraction pattern of the recovered red phosphor powder along with the three main crystalline phases present.

Figure 5 shows the refined X-ray diffraction patterns for the recovered phosphor powder as refined using the Rietveld refinement method. The diffraction pattern was refined, starting from the crystallographic parameters of $\mathrm{Y}_{2} \mathrm{O}_{3}{ }^{25}$ and then further refined by the crystallographic parameters of other phases: $\mathrm{Eu}_{2} \mathrm{O}_{3}{ }^{26}, \mathrm{Y}_{2} \mathrm{OS}_{2}{ }^{27}$. Finally, the minor impurities phases were refined in the sequence of $\mathrm{SiO}_{2}{ }^{28}, \mathrm{Na}_{2} \mathrm{C}_{2} \mathrm{O}_{4}{ }^{29}$ and $\mathrm{Ca}_{3}\left(\mathrm{PO}_{4}\right)_{2}{ }^{30}$, respectively.

$\mathrm{Y}_{2} \mathrm{OS}_{2}$ was identified as the major phase (41.71\%), this formation of yttrium oxide sulfide during the calcination process took place was likely due to a chemical reaction occurred between the yttrium sulfate which obtained from $3 \mathrm{M} \mathrm{H}_{2} \mathrm{SO}_{4}$ leaching (Equation 5) and the generated carbon monoxide due to the thermal decomposition of the remaining unreacted oxalic acid (Equation 6). ${ }^{31,32}$ During the $3 \mathrm{M} \mathrm{H}_{2} \mathrm{SO}_{4}$ leaching, the red phosphor $\left(\mathrm{Y}_{2} \mathrm{O}_{3}: \mathrm{Eu}^{3+}\right)$ was converted into yttrium sulfate and europium sulfate and further this yttrium sulfate was precipitated into yttrium oxalate by the use of oxalic acid in order to recover yttrium oxide. The precipitation step requires a stoichiometric amount of oxalic acid and an optimum $\mathrm{pH}$ in order to precipitate yttrium sulfate into its respective oxalate.

It is assumed that due to an imbalance in the $\mathrm{pH}$ of the obtained leached solution, some fraction of present yttrium sulfate was not precipitated into yttrium oxalate which led yttrium sulfate and oxalic acid to remain unreacted into leached solution. This remained unreacted oxalic acid was thermally decomposed into carbon monoxide during the calcination at $750{ }^{\circ} \mathrm{C}$ (Equation 6). ${ }^{31}$

The possible chemical reactions that took place in the formation of yttrium oxide sulfide during the calcination process are given below:

$$
\begin{aligned}
\left(\mathrm{Y}_{0.95} \mathrm{Eu}_{0.05}\right)_{2} \mathrm{O}_{3}+3 \mathrm{H}_{2} \mathrm{SO}_{4} & \longrightarrow \mathrm{Y}_{2}\left(\mathrm{SO}_{4}\right)_{3}+\mathrm{Eu}_{2}\left(\mathrm{SO}_{4}\right)_{3}+3 \mathrm{H}_{2} \mathrm{O} \\
\mathrm{H}_{2} \mathrm{C}_{2} \mathrm{O}_{4} \cdot 2 \mathrm{H}_{2} \mathrm{O} & \longrightarrow \mathrm{CO}+\mathrm{CO}_{2}+3 \mathrm{H}_{2} \mathrm{O} \\
\mathrm{Y}_{2}\left(\mathrm{SO}_{4}\right)_{3}+11 \mathrm{CO} & \longrightarrow \mathrm{Y}_{2} \mathrm{OS}_{2}+11 \mathrm{CO}_{2}+\mathrm{S}
\end{aligned}
$$




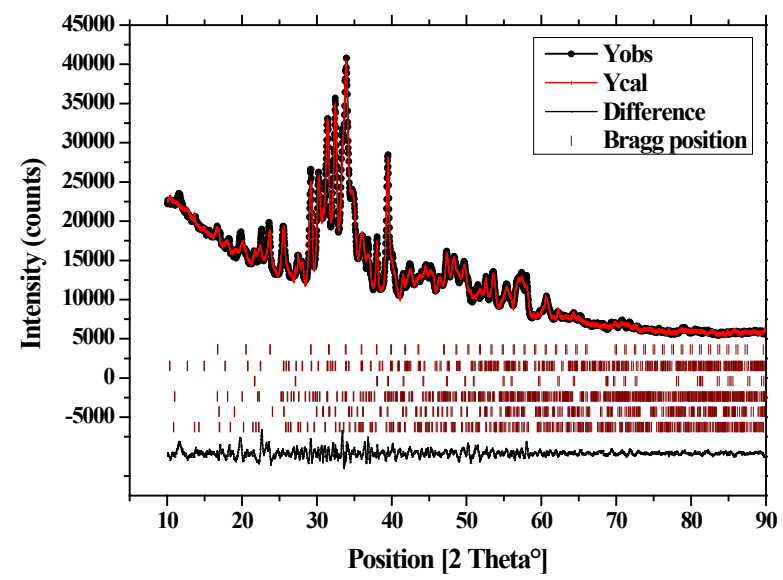

Figure 5. Observed (Yobs), Calculated (Ycal) and difference X-ray diffraction profiles for phosphor powders mixture. The vertical bars indicate the position of Bragg reflections for the various phase present. ( ${ }^{*}$ for $\mathrm{Y}_{2} \mathrm{O}_{3}, \mathrm{Eu}_{2} \mathrm{O}_{3}, \mathrm{SiO}_{2}, \mathrm{Y}_{2} \mathrm{OS}_{2}, \mathrm{Na}_{2} \mathrm{C}_{2} \mathrm{O}_{4}$ and $\mathrm{Ca}_{3}$ ( $\left.\mathrm{PO}_{4}\right)_{2}$ from upper to lower, respectively).

The quantified amount of the various phases present in the recovered phosphor powder as resultant from the Rietveld refinement of the observed diffraction pattern is shown in Table 6. These results confirm that the major fraction of recovered phosphor powder obtained from the treatment of raw phosphor powder by using dilute $\left(3 \mathrm{M} \mathrm{H}_{2} \mathrm{SO}_{4}\right.$ acid contains red phosphor constituents, i.e. $\mathrm{Y}$ and Eu. Two major compounds were found for $\mathrm{Y}-\mathrm{Y}_{2} \mathrm{O}_{3}$ and $\mathrm{Y}_{2} \mathrm{OS}_{2}$ accounting for about approx. $60 \%$ of the total fraction. Another important phase present was $\mathrm{Eu}_{2} \mathrm{O}_{3}$ which accounted for about $24.68 \%$ as the second major rare earth oxide recovered. This high amount is possible due to the presence of Eu in both YOX and BAM rare earth phosphor. The remaining undecomposed fraction of sodium oxalate was found to be $13.40 \%$. $\mathrm{Ca}_{3}\left(\mathrm{PO}_{4}\right)_{2}$ was found in very low amount due to the formation of calcium sulfate which has low solubility and it was filtered out with the remaining green and blue phosphor filtrate which shows that most of the calcium halophosphate had been filtered which as an advantage of using dilute $(3 \mathrm{M}) \mathrm{H}_{2} \mathrm{SO}_{4}$ leaching over leaching by other acids. The minor impurities fraction of $\mathrm{SiO}_{2}$ was also found. The recovery percent of yttrium and europium were calculated ca. $73 \%$ and ca. $71 \%$, respectively.

\begin{tabular}{|c|c|}
\hline Phase name & Fraction (wt. \%) \\
\hline $\mathbf{Y}_{2} \mathbf{O S}_{2}$ & 41.71 \\
\hline $\mathbf{Y}_{2} \mathbf{O}_{3}$ & 18.14 \\
\hline $\mathbf{E u}_{2} \mathbf{O}_{3}$ & 24.68 \\
\hline $\mathbf{N a}_{2} \mathbf{C}_{2} \mathbf{O}_{4}$ & 13.41 \\
\hline $\mathbf{C a}_{3}\left(\mathbf{P O}_{4}\right)_{2}$ & 2.04 \\
\hline
\end{tabular}

Table 6. Weight fraction of phases present in recovered red phosphor powder resultant from structure refinement using the Rietveld method (excluding the $\mathrm{SiO}_{2}$ impurity phase, i.e. assuming 100 wt. \% of remaining five red phosphor crystalline phases).

\section{CONCLUSIONS}

The waste phosphor powder mostly contains many valuable REEs in the mixture of their respective oxides as in the form of the tricolor phosphor. The work represented in this research was mainly focused on the recovery of red phosphor constituents and the separation of tricolor phosphors as the treatment of waste phosphor powder sample with the various type of inorganic and organic acids. After the detailed characterization of waste phosphor sample (submitted for publication elsewhere, the red phosphor was separated from the green and blue phosphor by the treatment of waste phosphor with $3 \mathrm{M}$ $\mathrm{H}_{2} \mathrm{SO}_{4}$. The $3 \mathrm{M} \mathrm{H}_{2} \mathrm{SO}_{4}$ leaching was found suitable in order to recover the $\mathrm{Y}$ and $\mathrm{Eu}$ to a higher extent in comparison to the other leaching acids employed. The recovered phosphor powder mainly contained three crystalline phases - $\mathrm{Y}_{2} \mathrm{O}_{3}, \mathrm{Eu}_{2} \mathrm{O}_{3}$, and $\mathrm{Y}_{2} \mathrm{OS}_{2}$ as identified from the obtained diffraction pattern. The refinement of the diffraction pattern provided the quantified amount of phases identified, these three major phases accounted for about $60 \%$ of the total amount of recovered red phosphor powder.

\section{ACKNOWLEDGMENTS}

The authors acknowledge the Eco Recycling Ltd. (Ecoreco, India) for providing the samples. The analytical facilities provided by SAIF at IIT Bombay are sincerely acknowledged. Authors are greatly thankful to IRCC, IIT Bombay, TERI School of Advanced Studies and CCT, University of Rajasthan for providing the opportunity to work on this project. 


\section{REFERENCES}

1. Alonso, E., M Sherman, A., J Wallington, T., Everson, M., Field, F., Roth, R., Kirchain, R. (2012) Evaluating Rare earth Element Availability: A Case With Revolutionary Demand from Clean Technologies, Environ. Sci. Technol. 46, 3406-3414; doi: 10.1021/es203518d.

2. Krishnamurthy, N., Gupta, C.K. (2004) Extractive Metallurgy of Rare Earths. CRC Press.

3. Raposo, C., Windmöller, C.C., Júnior, W.A.D. (2003) Mercury speciation in fluorescent lamps by thermal release analysis, Waste Manag. 23, 879-886; doi: 10.1016/S0956-053X(03)00089-8.

4. Rabah, M.A. (2008) Recyclables recovery of europium and yttrium metals and some salts from spent fluorescent Lamps, Waste Manag. 28, 318-325; doi: 10.1016/j.wasman.2007.02.006.

5. Yang, F., Kubota, F., Baba, Y., Kamiya, N., Goto, M. (2013) Selective extraction and recovery of rare earth metals from phosphor powders in waste fluorescent lamps using an ionic liquid system, J. Hazard. Mater. 254-255, 7988; doi: 10.1016/j.jhazmat.2013.03.026.

6. Zhang, S.-G., Yang, M., Liu, H., Pan, D.-A., Tian, J.-J. (2013) Recovery of waste rare earth fluorescent powders by two steps acid leaching, Rare Met. 32, 609-615; doi: 10.1007/s12598-013-0170-6.

7. Jüstel, T., Nikol, H., Ronda, C. (1998) New Developments in the Field of Luminescent Materials for Lighting and Displays, Angew. Chemie Int. Ed. 37, 3084-3103.

8. Adachi, G., Imanaka, N., Kang, Z.C. (2006) Binary Rare Earth Oxides. Springer Netherlands.

9. Song, X., Chang, M.-H., Pecht, M. (2013) Rare-Earth Elements in Lighting and Optical Applications and Their Recycling, JOM 65, 1276-1282; doi: 10.1007/s11837-013-0737-6.

10. Innocenzi, V., Michelis, I. De, Ferella, F., Vegliò, F. (2013) Recovery of yttrium from cathode ray tubes and lamps ' fluorescent powders : experimental results and economic simulation, Waste Manag. 33, 2390-2396; doi: 10.1016/j.wasman.2013.06.002.

11. Michelis, I. De, Ferella, F., Varelli, E.F., Vegliò, F. (2011) Treatment of exhaust fluorescent lamps to recover yttrium: Experimental and process analyses, Waste Manag. 31, 2559-2568; doi: 10.1016/j.wasman.2011.07.004.

12. Wu, Y., Wang, B., Zhang, Q., Li, R., Yu, J. (2014) A novel process for high efficiency recovery of rare earth metals from waste phosphors using a sodium peroxide system, RSC Adv. 4, 7927-7932; doi: 10.1039/C3RA46381H.

13. Shimizu, R., Sawada, K., Enokida, Y., Yamamoto, I. (2005) Supercritical fluid extraction of rare earth elements from luminescent material in waste fluorescent lamps, Journal of Supercritical Fluids 33, 235-241; doi: 10.1016/j.supflu.2004.08.004.

14. Srivastava, A.M., Kumar, P., Ramachandran, C., Comanzo, H.A. (2012) Rare earth recovery from phosphor material and associated method, U.S. Patent No.US2012152062-A1.

15. Tan, Q., Deng, C., Li, J. (2016) Innovative Application of Mechanical Activation for Rare Earth Elements Recovering: Process Optimization and Mechanism Exploration, Sci. Rep. 6, 19961; doi: 10.1038/srep19961.

16. Tanaka, M., Oki, T., Koyama, K., Narita, H., Oishi, T. (2013) Recycling of Rare Earths from Scrap, Handb. Phys. Chem. Rare Earths 43, 159-211; doi: 10.1016/B978-0-444-59536-2.00002-7.

17. Innocenzi, V., Michelis, I., Kopacek, B., Veglio, F. (2014) Yttrium recovery from primary and secondary sources: A review of main hydrometallurgical processes, Waste Manag. 34, 1237-1250; doi: 10.1016/j.wasman.2014.02.010.

18. Binnemans, K., Tom, P., Blanpain, B., Gerven, T. Van, Yang, Y., Walton, A., Buchert, M. (2013) Recycling of rare earths : a critical review, J. Clean. Prod. 51, 1-22; doi: 10.1016/j.jclepro.2012.12.037.

19. Tunsu, C., Ekberg, C., Retegan, T. (2014) Hydrometallurgy Characterization and leaching of real fluorescent lamp waste for the recovery of rare earth metals and mercury, Hydrometallurgy 144-145, 91-98; doi: 10.1016/j.hydromet.2014.01.019.

20. Otsuki, A., Dodbiba, G., Shibayama, A., Sadaki, J., Mei, G., Fujita, T. (2008) Separation of Rare Earth Fluorescent Powders by Two-Liquid Flotation using Organic Solvents. Jpn. J. Appl. Phys. 47, 5093; doi: 10.1143/JJAP.47.5093.

21. Mei, G., Rao, P., Matsuda, M., Fujita, T. (2009) Separation of red $\left(\mathrm{Y}_{2} \mathrm{O}_{3}: \mathrm{Eu}^{3+}\right)$, blue $\left(\mathrm{BaMgAl}_{10} \mathrm{O}_{17}: \mathrm{Eu}^{2+}\right)$ and green $\left(\mathrm{CeMgAl}_{10} \mathrm{O}_{17}: \mathrm{Tb}^{3+}\right)$ rare earth phosphors by liquid/liquid extraction, J. Wuban Univ. Technol. Sci. Ed. 24, 603-607; doi: 10.1007/s11595-009-4603-x.

22. Schaeffer, N., Feng, X., Grimes, S., Cheeseman, C.R. (2017) Recovery of an yttrium europium oxide phosphor from waste fluorescent tubes using a Brønsted acidic ionic liquid, 1-methylimidazolium hydrogen sulfate, $J$. Chem. Technol. Biotechnol. 92, 2731-2738; doi: 10.1002/jctb.5297.

23. Jha, M.K., Kumari, A., Panda, R., Kumar, J.R., Yoo, K., Lee, J.Y. (2016) Review on hydrometallurgical recovery of rare earth metals, Hydrometallurgy 165, 2-26: doi: 10.1016/j.hydromet.2016.01.035.

24. Tamrakar, R.K., Bisen, D.P., Brahme, N. (2014) Characterization and luminescence properties of $\mathrm{Gd}_{2} \mathrm{O}_{3}$ phosphor, Res. Chem. Intermed. 40, 1771-1779; doi: 10.1007/s11164-013-1080-9.

25. Ferreira, F.F., Granado, E., Carvalho Jr, W., Kycia, S.W., Bruno, D., Droppa Jr, R. (2006) X-ray powder diffraction beamline at D10B of LNLS: application to the $\mathrm{Ba}_{2} \mathrm{FeReO}_{6}$ double perovskite, J. Synchrotron Radiat. 13, 46-53; doi: 10.1107/S0909049505039208.

26. Yakel, H.L. (1979) A refinement of the crystal structure of monoclinic europium sesquioxide, Acta Crystallogr. 
Sect. B 35, 564-5691; doi: 10.1107/S0567740879004167.

27. Schleid, T. (2010) ChemInform Abstract: Crystal Structures of $\mathrm{D}-\mathrm{Y}_{2} \mathrm{~S}_{3}$ and $\mathrm{Y}_{2} \mathrm{OS}_{2}$, ChemInform 24; doi: 10.1002/chin.199308007.

28. Kihara, K. (1990) An X-ray study of the temperature dependence of the quartz structure, Eur. J. Mineral. 2, 63-78; doi: 10.1127/ ejm/2/1/0063.

29. Boldyreva, E., Ahsbahs, H., Chernyshev, V., Ivashevskaya, S., Oganov, A. (2006) Effect of hydrostatic pressure on the crystal structure of sodium oxalate: X-ray diffraction study andab initiosimulations, Zeitschrift fur Krist. 221, 186-197; doi: 10.1524/zkri.2006.221.3.186.

30. Yashima, M., Sakai, A., Kamiyama, T., Hoshikawa, A. (2003) Crystal structure analysis of $\beta$-tricalcium phosphate $\mathrm{Ca}_{3}\left(\mathrm{PO}_{4}\right)_{2}$ by neutron powder diffraction, J. Solid State Chem. 175, 272-277; doi: 10.1016/S0022-4596(03)00279-2.

31. Suponitskii, Y. L., Kuz'micheva, G. M., Eliseev, A. A. (1988) Lanthanide Oxide Sulphides, Russian Chem. Reviews 57:3, 209-220; doi: 10.1070/RC1988v057n03ABEH003345.

32. Higgins, J., Zhou, X., Liu, R., Huang, T.S. (1997) Theoretical study of thermal decomposition mechanism of Oxalic acid, J. Phys. Chem. A 101, 14, 2702-2708; doi: 10.1021/jp9638191.

\section{ABOUT STUDENT AUTHORS}

Parul Johar graduated from The Energy and Resources Institute (TERI) School of Advanced Studies in June of 2017 with a major in Enviromental studies and resource management. She is currently pursuing her Ph.D. in chemistry at University of York, England. Yogita Choudhary graduated from the Indian Institute of Technology Bombay in June of 2018 with major in Metallurgical Engineering and Materials Science and specilization in Ceramics and Composites. She is currently working for Cairn, India. Vishal Jangir is currently pursuing his Masters of Technology with major in Nanotechnology at Center for Converging Technologies, University of Rajasthan. Vishal plans on pursuing Ph.D. This project was carried out by students authors while pursuing their undergraduate studies.

\section{PRESS SUMMARY}

The tricolor phosphor present in the waste fluorescent lamp phosphors consists of three different type of rare earth phosphors: red (YOX), green (CMAT/LAP) and blue (BAM) which are mixed in varying proportions. These three rare earth phosphors should be separated individually in order to precisely recover the contained rare earth elements into them. This current study reports an efficient methodology for the separation of these three tricolor phosphors and the selective extraction of predominantly presented red phosphor (YOX) constituents using acid leaching. The waste phosphor powder was leached with different acids: both organic and inorganic type. The recovered phosphor powder mainly contains the $\mathrm{Y}$ and Eu compounds which confirmed the successful extraction of red phosphor from waste fluorescent lamp phosphor. 
Print Edition ISSN 1536-4585

Online Edition ISSN 2375-8732 